Portland State University

PDXScholar

Fall 12-10-2014

\title{
The Objective vs. the Perceived Environment: What Matters for Active Travel
}

Liang Ma

Portland State University

Follow this and additional works at: https://pdxscholar.library.pdx.edu/open_access_etds

Part of the Transportation Commons, and the Urban Studies Commons Let us know how access to this document benefits you.

\section{Recommended Citation}

Ma, Liang, "The Objective vs. the Perceived Environment: What Matters for Active Travel" (2014). Dissertations and Theses. Paper 2090.

https://doi.org/10.15760/etd.2088

This Dissertation is brought to you for free and open access. It has been accepted for inclusion in Dissertations and Theses by an authorized administrator of PDXScholar. Please contact us if we can make this document more accessible: pdxscholar@pdx.edu. 
The Objective vs. the Perceived Environment: What Matters for Active Travel

by

Liang Ma

A dissertation submitted in partial fulfillment of the requirements for the degree of

\author{
Doctor of Philosophy \\ in \\ Urban Studies
}
Dissertation Committee:
Jennifer Dill, Chair
James Strathman
Kelly Clifton
Cynthia Mohr

Portland State University

2014 
(C) 2014 Liang Ma 


\begin{abstract}
This study aims to explore the relationship between the objective (actual) environment and people's perceptions of the environment, and their relative effects on active travel behavior, particularly bicycling behavior. This is an important research gap in the current literature linking the built environment and active travel. Better understanding this relationship will help to explore the mechanism underlying the built environmentbehavior relationship and identify potential interventions to promote active travel.

Relying on the data from Portland, OR, this study investigated the following four research questions: (1) How does the objectively measured environment correspond to the perceived environment? And what factors contribute to the mismatch between the objective and perceived environment? (2) What are the different effects of the perceived and objective environment on active travel behavior? (3) Do perceptions mediate the effects of the objective environment on active travel behavior? (4) Do changes in the built environment change perceptions, and in turn change travel behavior?
\end{abstract}

Through various statistical methods, this study found that there was a mismatch between perceptions and objectively measured environment, and such factors as sociodemographics, attitudes, social environment, and behavior could contribute to this mismatch. This study also found the perceived environment and objective environment had independent effects on bicycling. Further, this study found the objectively measured bicycling environment had only an indirect effect on bicycling behavior through influencing one's perceptions of the environment. Finally, this study found changes in the 
actual built environment may change the perceptions of the walking environment, but not the perceptions of the bicycling environment, at least in the short term. 


\section{Acknowledgements}

This work would not have been possible without the advice and support of many people. First and foremost, I would like to express my deepest gratitude to my academic advisor Dr. Jennifer Dill. During the past five years, she spent much time on guiding me from a fresh student to an experienced researcher, offered me various opportunities to conduct cutting-edge research, and gave me much freedom in my own research work. I owe my gratitude to Dr. James Strathman. He was always patient in discussing my research work. He also helped me to position my research work in a big context, and link my research work to my long-term career goal. I would like to express my great appreciation to Dr. Kelly Clifton. From her class I developed the initial idea for this dissertation work, and she gave me constructive comments and suggestions to conduct this research. I would also like to sincerely thank Dr. Cynthia Mohr for reviewing and improving the methods used in this study. She helped me publish my dissertation work.

I would like to thank OTREC for the research funding support, Center for Urban Studies for providing me with a great work environment, and the Nohad A. Toulan School of Urban Studies \& Planning for giving me the opportunity to study in the Ph.D. program. I would like to thank my classmates, especially the Ph.D. students in the PHT group. They provided constructive suggestions and comments on improving this research work.

I would also like to thank my parents, my parents-in-law, my brothers, and my friends for their support and encouragement. Finally, I would like to thank my wife, Runing Ye, who gave me spiritual support and always stands by me. 


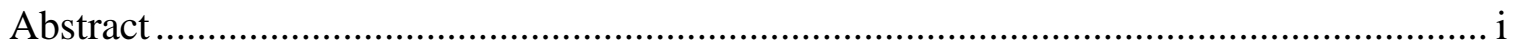

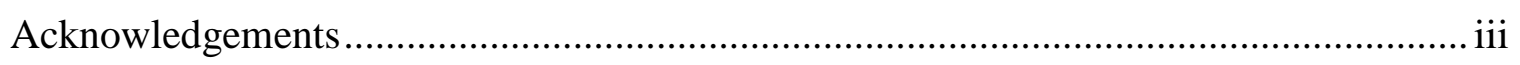

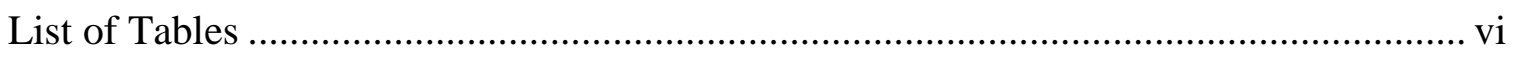

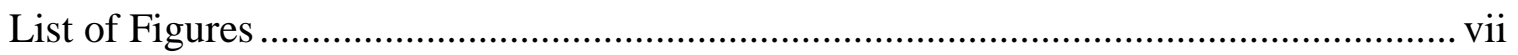

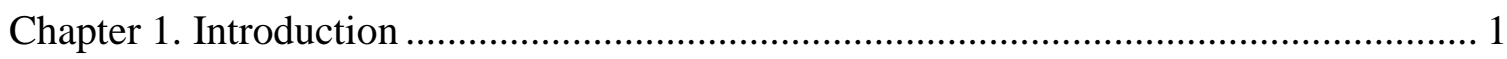

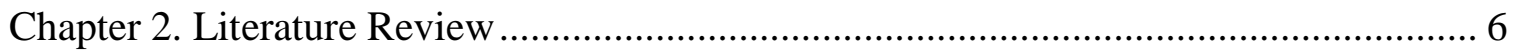

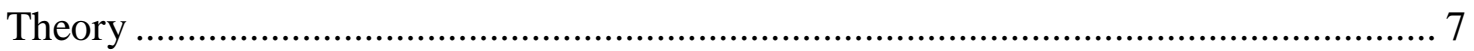

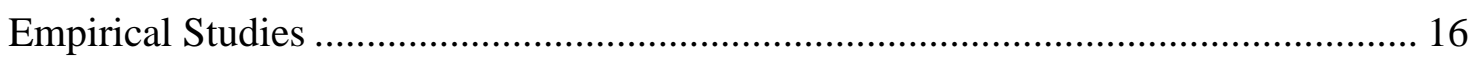

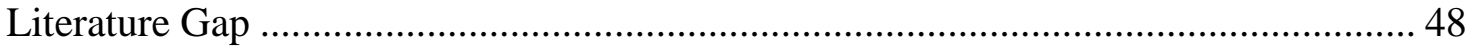

Chapter 3. Research Questions and Hypothesis ....................................................... 51

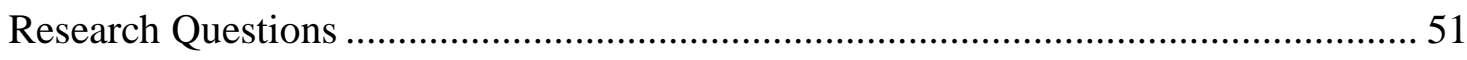

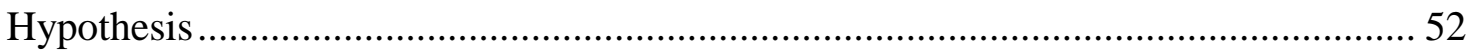

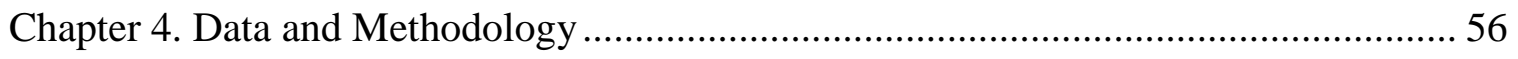

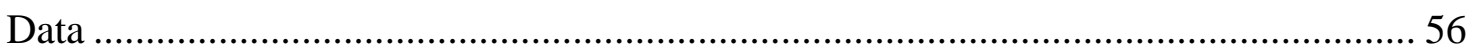

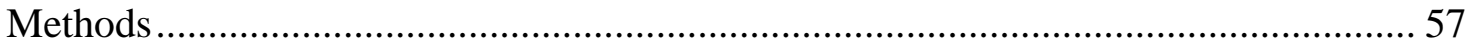

Chapter 5. Paper 1: Effects of the Objective and Perceived Built Environment on

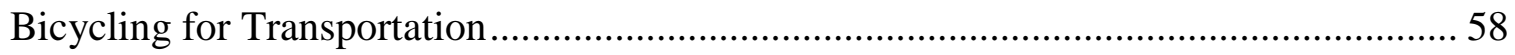

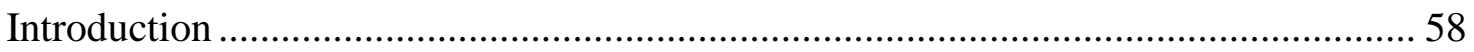

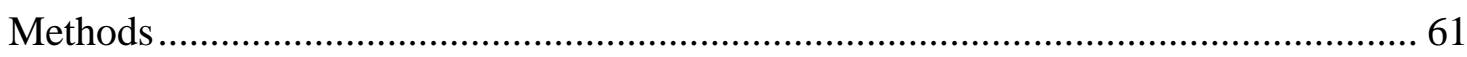

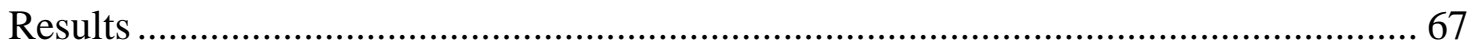

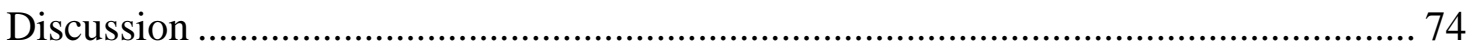

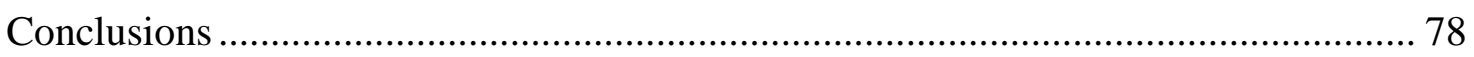

Chapter 6. Paper 2: The Objective vs. the Perceived Environment: What Matters for

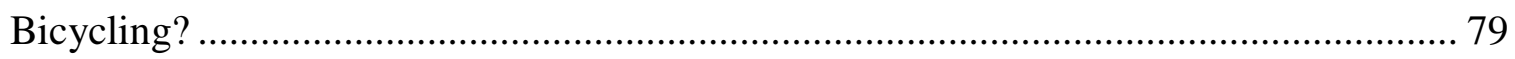

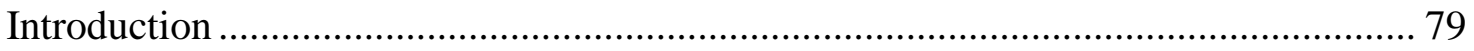

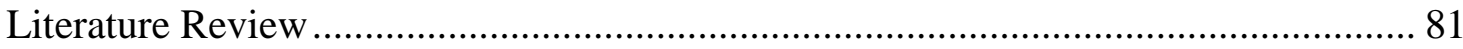

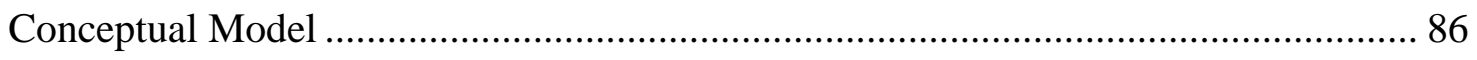

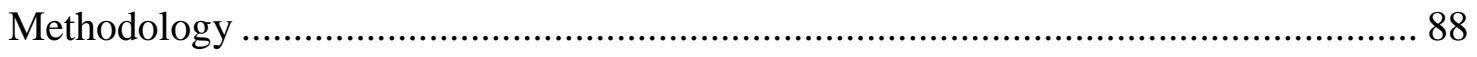

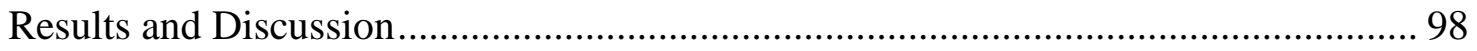


Conclusions and Policy Implications 102

Chapter 7. Paper 3: Mismatch between Objective and Perceived Bicycling Environment

Introduction


Table 1: Measurement of Built Environment in Active Travel Behavior Study (Selected Research) - Density....

Table 2: Measurement of Built Environment in Active Travel Behavior Study (Selected

Research) - Diversity 24

Table 3: Measurement of Built Environment in Active Travel Behavior Study (Selected

Research) - Design ................................................................................................. 26

Table 4: Measurement of Built Environment in Active Travel Behavior Study (Selected

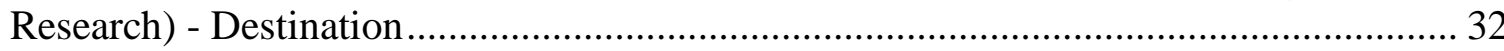

Table 5: Measurement of Built Environment in Active Travel Behavior Study (Selected

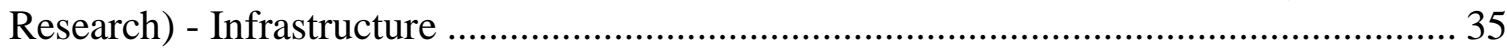

Table 6: Measurement of Perceived Built Environment in Physical Activity Study

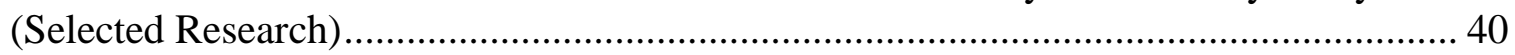

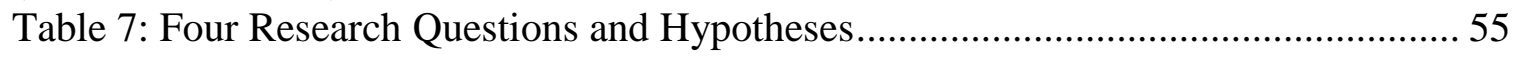

Table 8: Paired Perceived and Objective Measures of Bike Environment ....................... 64

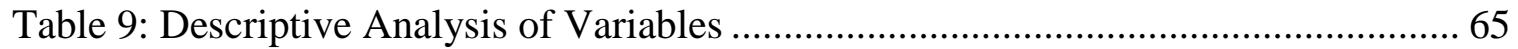

Table 10: Binary Logit Models for the Odds of Bicycling for Transportation ................. 70

Table 11: Multivariate Linear Models for Bicycling Frequency .................................. 73

Table 12: Variable Descriptions ........................................................................ 91

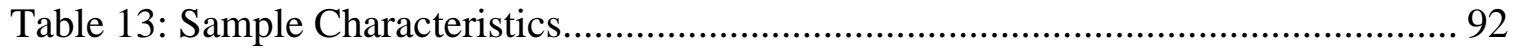

Table 14: Factor Analysis for Perceived Bikeability ................................................ 111

Table 15: Factor Analysis for Objective Bikeability ............................................... 111

Table 16: Different Perceptions between Group 1 and Group 2 ................................ 113

Table 17: Different Built-environment Attributes among Group 1, Group 2 and Group 3

Table 18: Comparison of Perceptions among the Three Groups of Objective Bikeability

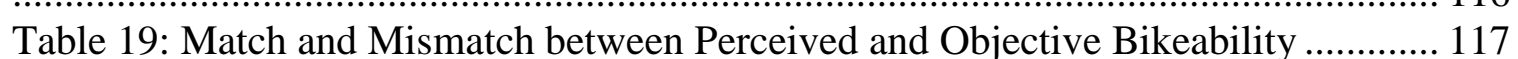

Table 20: Comparisons of Bicycling Frequency among Different Groups ..................... 119

Table 21: Socio-demographics of Participants in Matched and Mismatched Groups.... 121

Table 22: Binary Logistic Models for HOLP, MOLP, and LOHP .............................. 125

Table 23: Sampling Characteristics at Time of Recruitment....................................... 136

Table 24: Descriptions of Perception Measures .......................................................... 138

Table 25: Descriptive Analysis of Perception Measures ............................................. 139

Table 26: Results of Tobit Models with Difference-in-differences Specification.......... 142

Table 27: Summary of the Main Findings of This Study ......................................... 150 


\section{List of Figures}

Figure 1: Theory of Planned Behavior (adapted from Ajzen, 1991) 12 Figure 2 Stimulus-Organism-Response Model of Decision Making(Adapted from Mehrabian and Russell, 1974) 15

Figure 3: A Cognitive Model for Active Travel Behavior ............................................... 53

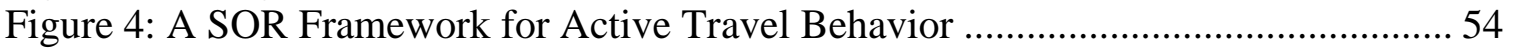

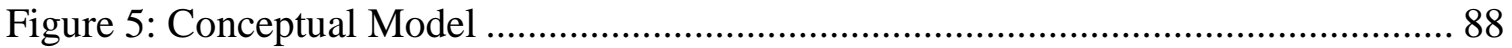

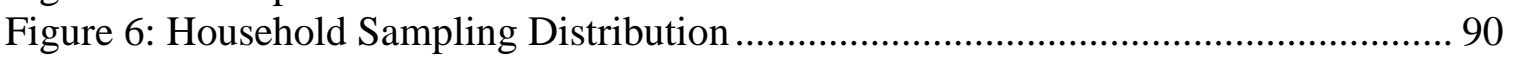

Figure 7: Mediation Effect....................................................................................... 93

Figure 8: Latent Constructs for Objective and Perceived Bicycling Environment .......... 97

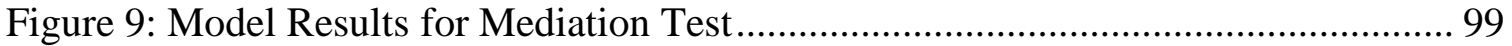

Figure 10: Results of the Full Conceptual Model ........................................................ 101 Figure 11: Predicted Values of Perceptions for Treatment and Control Groups at Pre and

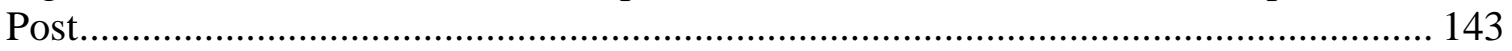




\section{Chapter 1. Introduction}

The relationship between the built environment and individual travel behavior is an important field in transportation planning. Over the past 30 years, there are more than 200 empirical studies linking the built environment and travel behavior (Ewing \& Cervero, 2010). Even though most of these studies consistently found significant associations between the built environment and individual travel behavior, the relationships are weak or non-significant while controlling for socio-demographics and other subjective factors like attitudes and perceptions. For example, recent empirical studies addressing selfselection have found that the effects of the built environment on travel behavior are much attenuated or even negligible after accounting for attitudes towards behavior (Bagley \& Mokhtarian, 2002; Handy, Cao, \& Mokhtarian, 2005, 2006). Results from these studies imply that the effects of the built environment on travel behavior vary among persons with different socio-demographic characteristics, and among persons with different attitudes and perceptions towards travel behavior. Better understanding of these complex relationships will help to explore the mechanism underlying the built environmentbehavior relationship and identify potential interventions to promote sustainable and healthy travel.

Several studies have pointed out the importance to explore the structural relationships among the built environment, intrapersonal characteristics and travel behavior. For example, socio-ecological theory (Sallis, Owen, \& Fisher, 2002) deems that many factors - including intrapersonal, interpersonal and external physical environment factors - play a 
role in people's travel behavior, and all these factors interact with each other. Previous studies have investigated the links between each of these factors with travel behavior. However, the structural relationships among these factors, which requires a deeper analysis of direct and indirect relationships, interactions, mediations, and hypothesized paths of causality, are largely absent from current literature (McMillan, 2005).

This study aims to explore one spectrum of these complex relationships - the relationship between the objective and perceived environment, which is an important part of the puzzle for understanding travel behavior (Handy, et al., 2006). Early theory on "image" (Boulding, 1956; Lynch, 1960) has emphasized the role of environmental image on man's behavior and argued that man's behavior is based on the perception of what reality is, not on reality itself. In other words, the image or the perceived reality was the mediator between the environment and man, and the image was the key to understanding the relationship between the environment and observed behavior. Perceptions of the environment reflect an individual's interaction with the environment, involving an awareness and perception of the outside world through primary receptive senses such as sight, smell, hearing, taste and touch. All of these sensory inputs are then integrated to form our cognitive representation of the environment (Sherrington, 1961). A mix of individual and societal factors, such as gender, social class, personal values, place attachment, local culture, social norms, past experiences, physical capacity, and individual personal characteristics, may influence the understanding of these cognitive representations, and perceptions of the environment therefore may not correspond to objective reality. 
As the "image" theory suggested, perceptions of the environment may not correspond to the objective environment. This means our planning strategies on promoting sustainable and healthy travel behavior by changing the built environment might not yield expected results if the residents living in our planner-called walkable or bikeable neighborhoods could not perceive the advantages of these design features because individual travel behavior is immediately determined by subjective perceptions of what the environment is, not on the environment itself.

This study helps to better understand the mechanism underlying the built environmentbehavior relationship by systematically exploring the relationships between the objective (actual) environment and people's perceptions of the environment, and their relative effects on active travel behavior. In specific, this study aims to address the following research questions:

(1) Do perceived- and objective-environment attributes have different effects on active travel behavior?

(2) Do perceptions mediate the effects of the objective environment on active travel behavior?

(3) How does the objectively measured built environment correspond to the perceived built environment? And what factors may contribute to the mismatch between the objective and perceived built environment?

(4) Do changes in the built environment change perceptions, and in turn change travel behavior? 
Each of these research questions is addressed in a chapter separately, and each chapter is a stand-alone paper. To explore these research questions, this study relies on the data from three research projects: Types of Cyclists, SmartTrips, and Family Activity Study. These research projects provide individual-level data that enable this study to quantitatively explore the four research questions at the disaggregate level. All of the socio-demographic variables, attitudinal variables, perception variables, and travelbehavior variables used in this study are derived from the surveys of these research projects. In addition to the survey data, this study also relies on the data from the Regional Land Information System (RLIS) from Portland Metro, the region's transportation and land-use planning agency; Longitudinal Employer-Household Dynamics (LEHD) data from the U.S. Census Bureau; and ReferenceUSA to develop the built-environment variables. A Geographic Information System (GIS) was employed to measure the built-environment attributes and conduct the spatial analysis.

Relying on various statistical analysis, this study found that the perceived environment and objective environment had independent effects on bicycling. The objective bicycling environment had only an indirect effect on bicycling behavior through influencing one's perceptions of the environment. Further, this study found that there was a mismatch between perceptions and the objectively measured environment, and such factors as socio-demographics, attitudes, social environment, and behavior could contribute to this mismatch. Finally, this study found that changes in the actual built environment may change perceptions of the walking environment, but not perceptions of the bicycling environment, at least in the short term. 
In the following chapters, I will first review the theories and previous studies that link the built environment and active travel behavior and identify the research gaps (Chapter 2), and then I will propose the hypothesis for my research questions (Chapter 3). A brief overview of the data and methods used in this study will follow (Chapter 4). Chapters 5-8 are four stand-alone papers that aim to answer the four research questions. Finally, I will summarize the key findings and important policy implications (Chapter 9). 


\section{Chapter 2. Literature Review}

Physical inactivity is likely to be a major cause of obesity as well as other related chronic diseases (Wareham, van Sluijs, \& Ekelund, 2005). Yet studies show that less than half of U.S. children and adolescents meet the recommended guidelines of at least 60 minutes of daily moderate-to-vigorous physical activity, and indicate that less than 10 percent of

adults in the U.S. get the recommended 30 minutes of moderate-to-vigorous physical activity per day (Centers for Disease Control and Prevention, 2005; Haskell, et al., 2007; Troiano, et al., 2008). It is well known that walking and bicycling for daily transportation, such as to work and school, are two of the easiest way to reach the recommended daily amount of physical activity. However, the National Household Travel Survey (NHTS, 2009) indicates that walking and bicycling only account for about 12 percent of all trips in the United States. There may be a variety of reasons leading to the low percentage of walking and bicycling trips, and a spread out built environment and lack of infrastructure for walking and bicycling definitely would be important factors. In recent years, there has been growing interest in linking the built environment with active travel behavior among researchers from both the planning and public health fields. Almost all of the empirical studies in both fields have concluded that the built environment has a significant association with active travel behavior, even though the causal link is not well established.

Both the transportation planning and public health disciplines have many empirical studies linking the built environment and active travel behavior, but the two disciplines have distinct measurement methods on the built environment due to the unique 
preference of researchers in each discipline. Scholars in the transportation planning field generally prefer to measure the built environment using objective indicators, which are

primarily calculated based on GIS or an audit. Scholars in the public health field rely more on self-reported data to measure the built environment, focusing on the responder's perception of environment. Though they use different measurements, research from both fields finds a relatively consistent result, which is that the built environment has a significant role in promoting active travel behavior and physical activity. These studies, however, ignore the mismatch between the objective and perceived environment, and equate objective environment with perceived environment or vice versa. Until recently, researchers in both fields incorporated both objectively measured and perceivedenvironment variables into the models after realizing both the real environment and perceptions of the environment may have different roles on active travel behavior.

The present literature review summarizes the studies linking the built environment with active travel behavior in both fields, with a focus on related theory linking built environment and active travel and measurement methods of the objective and perceived built environment.

\section{Theory}

\section{Utility theory}

The transportation planning field's theoretic framework to understand the relationship between the built environment and travel behavior is based on the utility theory. Land use impacts travel behavior by affecting the generalized cost of travel to various destinations 
(Boarnet \& Sarmiento, 1998). New urbanism and related designs, such as higher densities, mixed land use, and pedestrian-friendly design, can alter the time cost of traveling from one location to various other locations by concentrating trip origins closer to destinations and by influencing travel speed. Based on this theory, a travel-demand model integrating land-use factors was constructed. Travel demand was determined by three factors: generalized travel cost, income, and social-demographic characteristics of the traveler (Crane, 1996). Generalized cost can be influenced by densities, street connectivity, and land-use diversity, and thus land use is added as a vector in the travel-demand model. The rationale for this model depends on the conventional theory of consumer demand, assuming that households choose the number of trips by each mode to maximize the wellbehaved utility function, subject to their time and money budget. Most of the empirical studies accounting for travel demand for a typical travel mode are conducted under this theoretical framework.

This theory assumes that human is rational and his or her behavior is totally influenced by objective factors external to himself or herself, of which he or she had total knowledge. All constraints were completely known and all were considered. In reality, however, these assumptions are hardly met, as people rarely have adequate information, motivation or time to make such a perfect decision and often act upon less rational influences such as social relationships and values. Moreover, individuals are often described as seeking satisfactory rather than optimum choices (Simon, 1997). For example, Ratner and Kahn et al. (1999) found that some consumers are "willing to sacrifice real-time enjoyment for the sake of variety." In addition, travel is traditionally considered as a derived demand, 
and travel per se is judged as wasted time and only yields negative utility. However, a number of studies have recognized that an individual can also gain positive value during travel (Mokhtarian \& Salomon, 2001; Mokhtarian, Salomon, \& Redmond, 2001; Steg, 2005). People may enjoy traveling for a number of reasons including the sensation of speed, the feeling of freedom, exposure to the environment and movement through the environment, the ability to control movement, the enjoyment of scenic beauty or the attractions of a route. For example, the enjoyment of walking per se (fresh air, physical exercise, scenery along the path, social interaction) could largely offset an increase in the time cost from choosing to walk (Handy, 2005). These possibilities call for an expansion of the utility-maximum model to include more subjective or psychological factors.

Recently, a number of studies include attitudes and preferences in modeling travel behavior (Bagley \& Mokhtarian, 2002; Handy, et al., 2005, 2006; Kitamura, Mokhtarian, \& Daidet, 1997). Even though the initial purpose of these studies is to address the selfselection problems by controlling for attitude and preference towards travel and location choice, these studies consistently found that attitudes and preferences play a much more significant role in explaining the variation of travel behavior. These findings imply that a comprehensive travel-behavior model should consider linking and combining theories based on microeconomics and those from socio-psychology (Van Acker, Van Wee, \& Witlox, 2010).

\section{Socio-ecological theory}

The socio-ecological model was adapted from Urie Bronfenbrenner's Ecological Systems Theory (Bronfenbrenner, 1977, 1979), which divides factors into four levels: macro-, 
exo-, meso- and micro-. These describe influences as intercultural, community, organizational, and interpersonal or individual.

The socio-ecological model recognizes the interwoven relationship that exists between the individual and their environment. While individuals are responsible for instituting and maintaining the lifestyle changes necessary to reduce risk and improve health, individual behavior is determined to a large extent by social environment (e.g., community norms and values, regulations, and policies). The most effective approach to intervene in an individual's travel behaviors is a combination of the efforts at all levels - individual, interpersonal, organizational, community, and public policy.

According to the socio-ecological theory, Sallis and Owen (2002) developed a theoretical framework for travel-behavior study. This theory holds that individual's travel behavior is affected by three groups of key factors: the individual level, the social environment, and the physical environment. Generally, the individual level refers to one's ability to act, make decisions, and take part in an activity (which could include traveling to or from the location where an activity takes place). The social environment primarily refers to the relationships with other people that individuals have within their surroundings or within some proximity. The physical environment refers to the characteristics of the surrounding community, including the built environment, accessibility to facilities, and the availability of services (Hough, Cao, \& Handy, 2008). 


\section{Theory of planned behavior}

Health behavior studies have heavily drawn on the socio-ecological theory and theories from the field of psychology. One such theory is the theory of planned behavior (TPB) developed by Icek Ajzen (Ajzen, 1991). The theory (see Figure 1) holds that behavior is guided by (1) a person's attitude toward the behavior, including the likely consequences of the behavior; (2) subjective norms, including the expectations of others; and (3) the person's perceived control over the behavior. Attitudes are people's favorable or unfavorable evaluative reactions to the behavior of interest. Subjective norms concern the perception of whether important others think the person should or should not perform the behavior of interest. Finally, perceived behavioral control is the extent to which people believe they have the skills and ability to enact the behavior. These factors determine the person's intention to behave in a certain way which, in turn, influences actual behavior, as long as the behavior is under the person's control. The theory has been applied to a wide range of behaviors, including playing video games, voting, shoplifting, and gift giving. Garling et al. (1998) described how the theory could be useful in travel-behavior research, and there is a growing body of research linking TPB to travel-mode choice. However, much of the TPB travel-behavior research has not included variables related to the built environment (Van Acker, et al., 2010). 


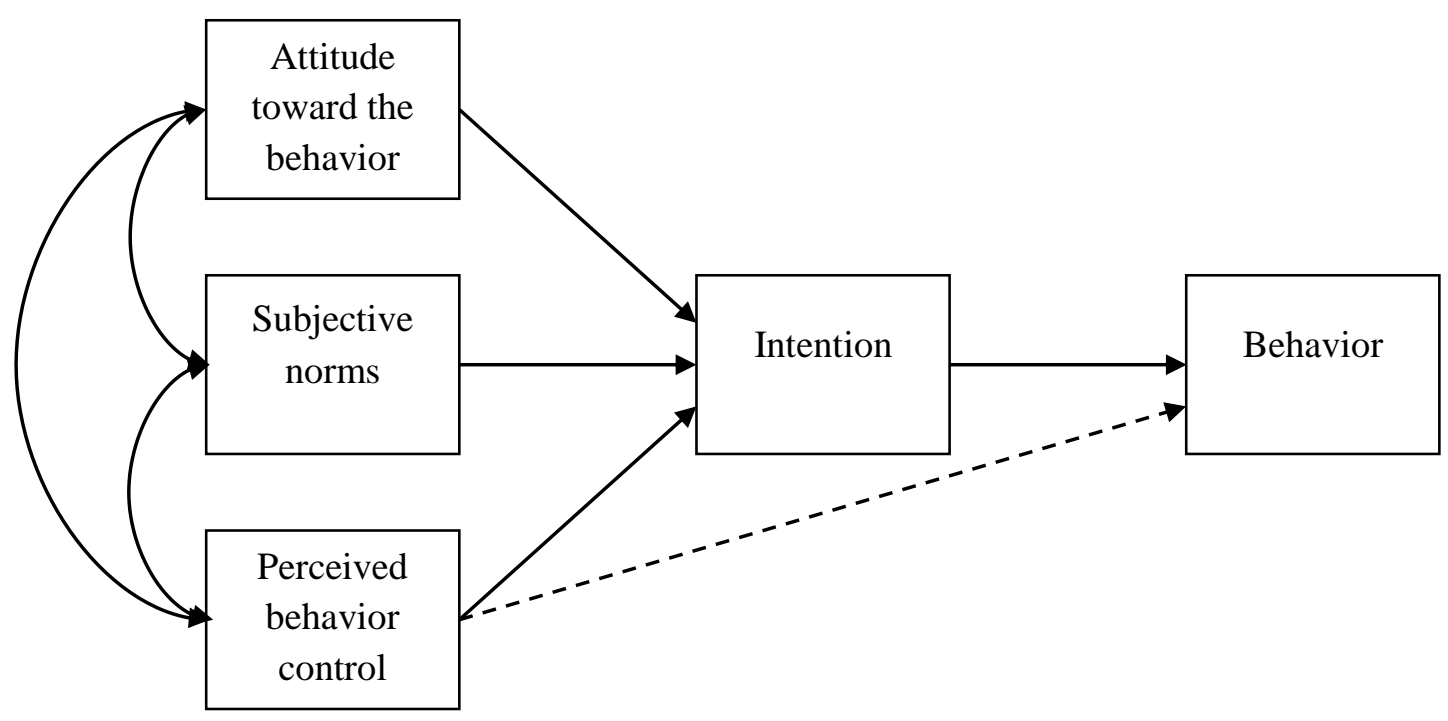

Figure 1: Theory of Planned Behavior (adapted from Ajzen, 1991)

\section{Theories concerning perception and reality}

\section{Cognitive behaviorism}

The theoretical premise of cognitive behaviorism is that a person reacts to his milieu as he perceives and interprets it in light of his previous experience and knowledge (Sprout \& Sprout, 1956). In the early 1960s, two significant streams emerged in human geography. One was a rise in emphasis on man-environment relations as expressed through man's perception of the environment. Two was a growing interest in exploring the effects of motivation, aspirations and goals in the decision-making process (Golledge, Brown, \& Williamson, 1972). Empirical studies investigating the elements of the perceived environment and their relation to the objective environment have since boomed in human geography and make a significant contribution to the cognitive study of human behavior. However, the earliest idea about perception and the theoretical framework of cognitive behavior was not proposed in geography. 
The term "image" was first emphasized in studying human behavior by the economist Boulding (1956) in his book “The Image.”. He provided an initial theoretical basis, arguing that the image or the perceived reality was the mediator between environment and man, and the image was the key to understanding the relationship between the environment and observed behavior. Lynch (1960) was the first significant attempt to examine environmental images empirically. By measuring images of three large cities in America - Boston, Jersey City and Los Angeles - and by asking interviewed residents to sketch a map their city, Lynch found broad areas of agreement as well as individual nuances. Based on his data, Lynch categorized the mental images of environment into five elements: paths, edges, districts, nodes, and landmarks.

Different from previous behavioral framework based on economic theories, which assumes people make rational behavioral choices to optimize individual utility subject to spatial environment, cognitive theory emphasizes the individual's environmental experience in influencing one's behavior.

\section{Stimulus-Organism-Response model}

The Stimulus-Organism-Response (SOR) model, as proposed by Mehrabian and Russell (1974), established the link between physical environment and an individual's behavior. The SOR framework introduces a mechanism for how environmental characteristics influence individual internal states and, in turn, their approach-avoidance behavior (see Figure 2). In this model, individual emotional responses serve as mediating variables in determining a variety of behaviors. Therefore, an environmental stimulus that produces a 
certain behavioral response in one individual or group of people at a given point in time may produce an entirely different behavioral response in another individual or group.

The SOR model has been widely applied in understanding the relationship between retail environments and consumer behavior (Turley \& Milliman, 2000). In these studies, the atmospheric characteristics of the store are the stimuli $(\mathrm{S})$; the consumer's evaluations of the store environment are organism $(\mathrm{O})$; and sales, time in the store, and approachavoidance behavior often serve as the behavioral response (R). These studies argue that retail atmosphere can create one's mood, activate intentions, and affect a customer's reactions.

As Schellinck (1983) defined, a stimulus cue is "a characteristic, event, quality, or object, external to a person that can be encoded and used to categorize a stimulus object." Bitner (1992) classifies environmental components into three dimensions, which are (1) ambient conditions, (2) spatial layout and functionality, and (3) signs, symbols and artifacts. Similarly, Baker (1987) categorizes the environmental characteristics into ambient, design and social factors. Ambient conditions refer to the non-visual elements of a space that impact the consumer's subconscious (e.g., temperature, music and lighting). Design factors represent the visual elements of a space that exist more at the forefront of a consumer's awareness (e.g., color, layout and architectural elements). Social factors involve the presence of employees and customers in the environment.

Moreover, physical environment can induce two types of internal states for an individual: affective and cognitive (Mehrabian \& Russell, 1974). Affective evaluation is a judgment 
of something as pleasant, attractive, valuable, likable or preferable. Cognitive evaluation refers to one's perception, which is deemed as a high level of psychological activity concerned with the process whereby sensory stimulation is converted into meaningful information (Bettman, 1979). Past empirical studies have well established that environmental cues influence one's affective and cognitive evaluations.

In sum, either the cognitive theory or SOR model emphasizes the role of the perceived environment or image in explaining human behavior, and argues that the perceived environment is the mediator between environmental stimulus and behavioral response. These theories have been widely employed in studying shopping behavior and other spatial behaviors, but linking these theories with travel-behavior study is rare.

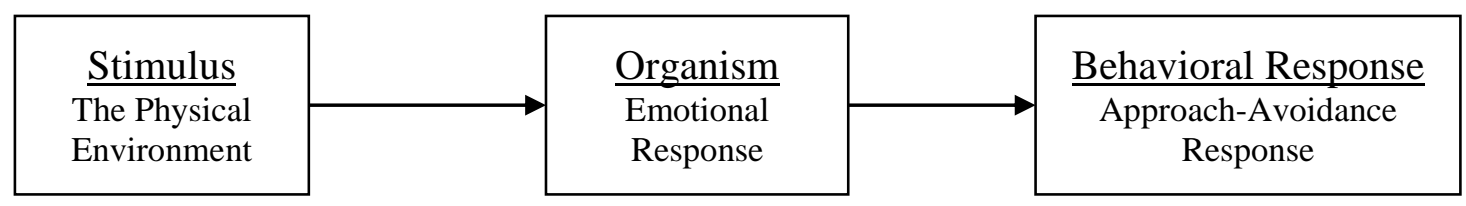

Figure 2 Stimulus-Organism-Response Model of Decision Making (Adapted from Mehrabian and Russell, 1974) 


\section{Empirical Studies}

\section{Studies linking the objective environment with active travel behavior}

The research on the relationship between the built environment and travel behavior could be traced to the 1970s (Boarnet \& Crane, 2001; Ewing \& Cervero, 2001), and a recent meta-analysis found that there are over 200 studies, most of which were completed since 2001 (Ewing and Cervero, 2010). As Handy (2005) stated, however, the majority of travel-behavior research is used to focus on automobile travel rather than active travel

(e.g., walking and bicycling). The role of the built environment in promoting walking and bicycling has received increasing attention in both the transportation and public health disciplines over the last decade (Ewing \& Cervero, 2010; Saelens \& Handy, 2008; Saelens, Sallis, \& Frank, 2003). Many previous studies have focused on walking behavior or combined walking and bicycling behavior, while empirical evidence specifically on bicycling is more limited. Several studies have pointed to the need to consider bicycling and walking separately (Krizek, Handy, \& Forsyth, 2009). While both modes are nonmotorized "alternatives" to driving, the factors that influence the behaviors may vary in a number of important ways.

Variables measuring the built environment can be classified into five dimensions: density, diversity, design, destinations and infrastructure. In addition to the GIS tool which is commonly employed to calculate the built-environmental variables in planning and transportation studies, there are self-reported factors derived from the survey to represent individuals' perceptions of the built environment. Both objective and perceived builtenvironment variables have significant effects on travel behavior, and this will be 
discussed in a following section. Even though there are mixed measurements of the built environment, most of these studies have found that high density (Kitamura, et al., 1997); mixed land uses (Frank \& Engelke, 2005); well-connected streets (Handy, Boarnet, Ewing, \& Killingsworth, 2002); sidewalks (Forsyth, Hearst, Oakes, \& Schmitz, 2008); and bike infrastructure (Jennifer Dill, 2009; Pucher, Dill, \& Handy, 2010) are associated with more active travels. A summary table below provides the details of the builtenvironment measurements in literature.

\section{Density}

Several aspects of density are commonly used, including population density, employment density, housing density, and retail-employment density. Even though the ways measuring density are similar between studies, the spatial units for the measurement can be very different from block level to neighborhood level and to city level. Density is generally assumed to have positive associations with walking and bicycling behavior, but results of empirical studies are not consistent. For example, Boarnet et al. (2008) found that population density and retail-employment density were significantly associated with longer walking distance based on travel-diary data from Portland, OR, while other studies (Cervero \& Duncan, 2003; Chatman, 2009) concluded non-significant relationships between density and walking trips. However, density itself may be a composite indicator representing many other environmental characteristics, such as street connectivity, landuse mix and block size, which are all supposed to influence walking and bicycling. Therefore, density was not found to be significant in many studies while controlling for other environmental characteristics. Moreover, Ewing and Cervero (Ewing \& Cervero, 
2010) found that, comparing with other built-environmental variables, density has the weakest association with travel choice.

The association between density and bicycling is less explored and the findings are mixed. Cervero and Duncan (2003) found that the objectively measured number of jobs within five miles of a trip origin was negatively associated with odds of the trip made by bicycle, but the association was not statistically significant. Similarly, Forsyth and Oakes (2013) found that the total miles of bicycling was negatively related with objectively measured population density and employment density based on bivariate correlation analysis. Parkin et al. (2008), however, concluded that an increase in population density had the effect on increasing the likelihood of bicycling to work. Also, relying on longitudinal data, Beenackers et al. (2012) found that greater residential density was positively associated with an increase in transportation-related bicycling after home relocation. 
Table 1: Measurement of Built Environment in Active Travel Behavior Study (Selected Research) - Density

\begin{tabular}{|c|c|c|c|c|c|}
\hline $\begin{array}{c}\text { Built Environment } \\
\text { Variables }\end{array}$ & $\begin{array}{l}\text { Spatial Unit of } \\
\text { Measurement }\end{array}$ & Measurement & Behavior Variables & Findings & Sources \\
\hline \multirow{3}{*}{ Population density } & Block group & Persons per square mile & Two-day walking distance & + & Boarnet et al., 2008 \\
\hline & One-mile buffer & $\begin{array}{l}\text { Residents per road mile, 1-mile } \\
\text { radius }\end{array}$ & $\begin{array}{l}\text { Number of nonwork trips by } \\
\text { walk/bike }\end{array}$ & n.s. & Chatman, 2009 \\
\hline & One mile buffer & Persons per hectare & $\begin{array}{l}\text { Home-based non-work trip choose } \\
\text { walk }\end{array}$ & + & Reilly, 2002 \\
\hline \multirow{3}{*}{ Employment density } & TAZ & Jobs per square mile & Two-day walking distance & n.s. & Boarnet et al., 2008 \\
\hline & Five-mile buffer & Jobs within five miles of origin & $\begin{array}{l}\text { Probability that a trip will be made } \\
\text { by bike }\end{array}$ & n.s. & Cervero \& Duncan, 2003 \\
\hline & One-mile buffer & Jobs within one mile of origin & $\begin{array}{l}\text { Probability that a trip will be made } \\
\text { by walk }\end{array}$ & n.s. & Cervero \& Duncan, 2003 \\
\hline \multirow{2}{*}{ Housing density } & Neighborhood & Residential units per acre & $\begin{array}{l}\text { Number of walking trips per person } \\
\text { per day }\end{array}$ & n.s. & Boarnet et al., 2010 \\
\hline & One-km & & $\begin{array}{l}\text { Walked at least once over two } \\
\text { days/walked over } 0.5 \text { mile per day }\end{array}$ & + & Frank et al., 2007 \\
\hline
\end{tabular}




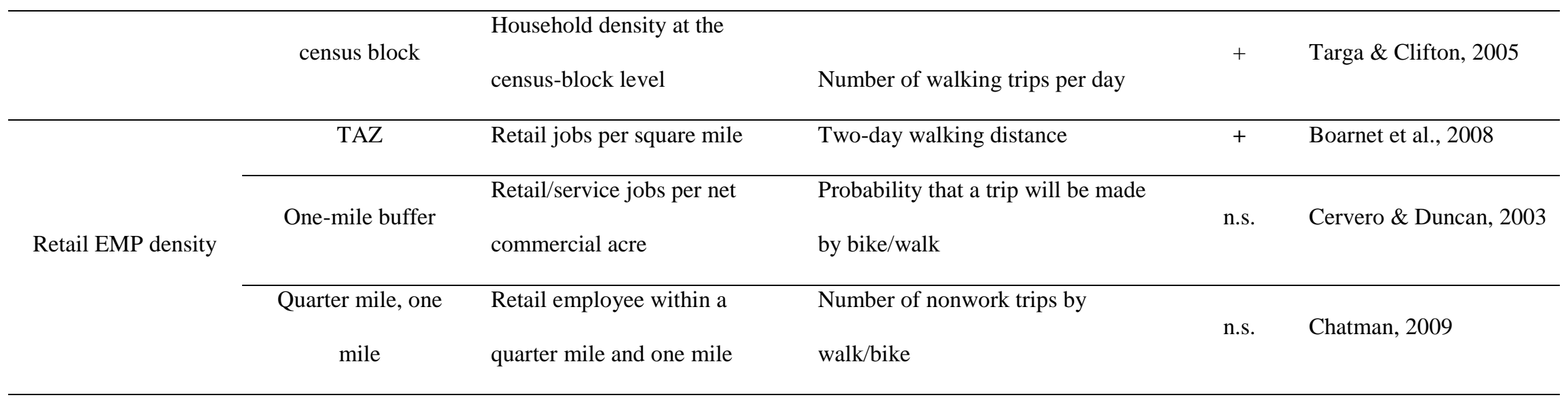




\section{Diversity}

Diversity refers to the mix of different types of land uses within a given area. The simple way of measuring diversity is the proportion of each type of land use in a given area; a complicated index for land-use mix is also created. Entropy, for example, is the most common method to measure land-use mix. Such an index, however, may not be measuring land-use types at the right scale or level. Entropy measures are typically calculated at an aggregate level (e.g., residential, commercial, industrial, etc.). There are a wide variety of uses within each of those categories that likely have different effects on walking and bicycling. Consider, for example, the difference between a big-box home improvement store and an office building, both of which fall into the commercial landuse category. Jobs-housing balance is also used as an indicator for diversity in walking/bicycling studies (Cervero \& Duncan, 2003), and meta-analysis from Ewing and Cervero found this indicator is a stronger predictor of walk-mode choice than land-use mix measures. Targa and Clifton (2005) measured land-use mix as "Proportion of household units within 1/4 mile of commercial uses," only considering the balance of households on commercial land use. Results of empirical studies indicate that land-use mix, jobs-housing balance, and a higher proportion of commercial and recreational land use are associated with more walking trips and higher odds to walk.

The relationship between land-use diversity and bicycling is also not clear. Using the Entropy index, Winters et al. (2010) found that greater land-use mix was associated with higher odds a trip was made by bicycle versus by car. Similarly, Cervero and Duncan (2003) found that mixed land use (Entropy index) might support bicycling, but this 
relationship was not statistically significant in their study. Forsyth and Oakes (2013), however, found that non-cyclists were more likely to live in areas with the most dissimilar land uses, but the magnitude of the association was small.

\section{Design}

The design of a place can influence one's walking and bicycling experience in very significant ways. Due to lack of data, current studies measure urban design in a very coarse way which cannot capture design details and quality. Street connectivity is the most frequent variable used to measure street design in these studies, and usually measured as number of (four-way) intersections or proportion of four-way intersections in a given area. Empirical studies found that street connectivity is significantly associated with walking, and may have the strongest effect on walking among all the builtenvironment factors (Ewing \& Cervero, 2010).

Block size was also used to capture neighborhood design features. It corresponds closely to street density - the greater the intersection density, the smaller the blocks. Hess (1999) found that large block size was associated with lower volumes of pedestrians walking into the neighborhood center.

The design elements considered in current bicycling studies are primarily limited to street connectivity. Based on the evidence from Bogota, Cervero et al. (2009) found that objectively measured street density was positively associated with odds of bicycling for utilitarian purposes. By analyzing the changes in bicycling behavior of people moving to new homes in Perth, Western Australia, Beenackers et al. (2012) found that an objective 
measure of street connectivity was the strongest predictor of odds of taking up bicycling for recreation after home relocation. Forsyth and Oakes (2013), however, found that noncyclists lived in areas with smaller blocks and higher intersection density. 
Table 2: Measurement of Built Environment in Active Travel Behavior Study (Selected Research) - Diversity

\begin{tabular}{|c|c|c|c|c|c|}
\hline $\begin{array}{l}\text { Built Environment } \\
\text { Variables }\end{array}$ & $\begin{array}{l}\text { Spatial Unit of } \\
\text { Measurement }\end{array}$ & Measurement & Behavior Variables & Findings & Sources \\
\hline \multirow{5}{*}{ Land-use mix } & One mile & $\begin{array}{l}\text { Factor analysis of land-use } \\
\text { mix, jobs-housing balance at } \\
\text { origin }\end{array}$ & $\begin{array}{l}\text { Probability that a trip will be } \\
\text { made by walk }\end{array}$ & + & Cervero \& Duncan, 2003 \\
\hline & One mile & $\begin{array}{l}\text { Factor analysis of land-use } \\
\text { mix, jobs-housing balance at } \\
\text { destination }\end{array}$ & $\begin{array}{l}\text { Probability that a trip will be } \\
\text { made by walk }\end{array}$ & n.s. & Cervero \& Duncan, 2003 \\
\hline & One-km network & $\begin{array}{l}\text { Having commercial } \\
\text { destinations within walking } \\
\text { distance }\end{array}$ & $\begin{array}{l}\text { Walked at least once over two } \\
\text { days/walked over } 0.5 \text { mile per } \\
\text { day }\end{array}$ & + & Frank, Kerr, Chapman \& Sallis, 2007 \\
\hline & Census block & $\begin{array}{l}\text { Proportion of household units } \\
\text { within a quarter mile of } \\
\text { commercial uses }\end{array}$ & $\begin{array}{l}\text { Number of walking trips per } \\
\text { day }\end{array}$ & n.s. & Targa \& Clifton, 2010 \\
\hline & Quarter mile & Urban dissimilarity index & $\begin{array}{l}\text { Home-based shopping, } \\
\text { multipurpose and }\end{array}$ & + & Reilly, 2005 \\
\hline
\end{tabular}




\begin{tabular}{|c|c|c|c|c|c|}
\hline & & & $\begin{array}{l}\text { entertainment trips choose } \\
\text { walk }\end{array}$ & & \\
\hline $\begin{array}{l}\text { Single-family land } \\
\text { use }\end{array}$ & Quarter mile & $\begin{array}{l}\text { Proportion of detached home } \\
\text { within buffer area }\end{array}$ & $\begin{array}{l}\text { Home-based entertainment } \\
\text { and transit-access trips choose } \\
\text { walk }\end{array}$ & - & Reilly, 2011 \\
\hline $\begin{array}{l}\text { Commercial land } \\
\text { use }\end{array}$ & $\begin{array}{l}\text { One-km network } \\
\text { buffer }\end{array}$ & Dummy variable & $\begin{array}{l}\text { Walked at least once over two } \\
\text { days/walked over } 0.5 \text { mile per } \\
\text { day }\end{array}$ & + & Frank, Kerr, Chapman \& Sallis, 2007 \\
\hline $\begin{array}{l}\text { Recreation and } \\
\text { open-space land use }\end{array}$ & $\begin{array}{l}\text { One-km network } \\
\text { buffer }\end{array}$ & Dummy variable & $\begin{array}{l}\text { Walked at least once over two } \\
\text { days/walked over } 0.5 \text { mile per } \\
\text { day }\end{array}$ & + & Frank, Kerr, Chapman \& Sallis, 2007 \\
\hline
\end{tabular}


Table 3: Measurement of Built Environment in Active Travel Behavior Study (Selected Research) - Design

\begin{tabular}{|c|c|c|c|c|c|}
\hline $\begin{array}{c}\text { Built } \\
\text { Environment } \\
\text { Variables }\end{array}$ & $\begin{array}{l}\text { Spatial Unit of } \\
\text { Measurement }\end{array}$ & Measurement & Behavior Variables & Findings & Sources \\
\hline \multirow{6}{*}{ Street connectivity } & Neighborhood & $\begin{array}{l}\text { Percentage of intersections } \\
\text { that are four-way }\end{array}$ & $\begin{array}{l}\text { Number of walking trips per } \\
\text { person per day }\end{array}$ & n.s. & Boarnet et al., 2010 \\
\hline & Quarter mile & $\begin{array}{l}\text { Number of four-way } \\
\text { intersections }\end{array}$ & $\begin{array}{l}\text { Number of non-work trips by } \\
\text { walk/bike }\end{array}$ & + & Chatman, 2009 \\
\hline & TAZ & $\begin{array}{l}\text { Number of intersections in } \\
\text { TAZ }\end{array}$ & Two-day walking distance & + & Boarnet et al., 2008 \\
\hline & Census block & $\begin{array}{l}\text { Census block's perimeter in } \\
\text { miles }\end{array}$ & $\begin{array}{l}\text { Number of walking trips per } \\
\text { day }\end{array}$ & + & Targa \& Clifton, 2006 \\
\hline & $\begin{array}{c}\text { One-km network } \\
\text { buffer }\end{array}$ & $\begin{array}{l}\text { Number of intersections } \\
\text { divided into three categories } \\
\text { based on tertile value }\end{array}$ & $\begin{array}{l}\text { Walked at least once over two } \\
\text { days/walked over } 0.5 \text { mile per } \\
\text { day }\end{array}$ & + & Frank, Kerr, Chapman \& Sallis, 2007 \\
\hline & Quarter mile & & $\begin{array}{l}\text { Home-based entertainment } \\
\text { trips choose walk }\end{array}$ & + & Reilly, 2007 \\
\hline
\end{tabular}




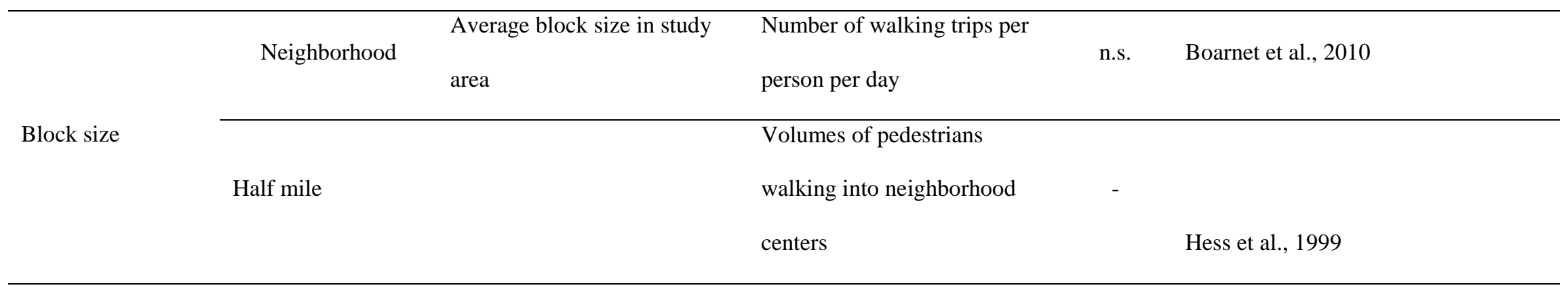




\section{Destination}

Almost all of the active travel studies have included one or more variables accounting for walking or bicycling destinations, which can generally classify into four aspects: business destination, downtown destination, transit destination, and park or recreational destinations. Measuring destination accessibility is straightforward, either by calculating the total number of destinations within a given area or the distance to the nearest destination.

First, business accessibility is proven by much more empirical evidence that has a significant association with walking frequency. For example, Boarnet et al. (2010) found that the total number of business establishments within a neighborhood is positively associated with the number of walking trips of residents who lived in that neighborhood. Cao et al. (2009) found that a home's distance to institutional businesses (i.e., library, theater, post office) were negatively associated with walking/bicycling frequency. In order to reflect the diversity of businesses, Cao et al. (2009) also calculated the number of business types within a buffer area, and found accessibility to diverse businesses was also associated with higher walking/bicycling frequency.

Second, access to public transit also proved to promote walking and bicycling trips. For example, Chatman (2009) found that having a light-rail station within a half mile of a home was associated with more walking/bicycling non-work trips. Targa and Clifton (2005) found a home's distance to the nearest bus stop is negatively associated with walking trips per day. 
Third, the effects of downtown accessibility and park/recreation accessibility on active travel behavior are not clear. Chatman (2009) found that residents who lived close to downtown tended to have more walking trips, while Boarnet et al. (2008) found residents away from downtown were more likely to walk longer distances. Moreover, accessibility to a park may not have a significant association with walking/bicycling trips (Lund, 2003; Targa \& Clifton, 2005).

The findings from studies exploring the associations between bicycling and proximity to common bicycle destinations are relatively consistent. For example, both objective distance to work (Parkin, et al., 2008) and perceived distance to work (Handy \& Xing, 2011) have been found to be negatively associated with the odds of choosing to bicycle to work. In addition, Emond and Handy (2012) found that both the objective and perceived distance to school were negatively associated with the probability of a student usually bicycling to and/or from school. Furthermore, Emond et al.(2009) found that if people perceived accessibility to many destinations, including a grocery store, post office, elementary school, restaurant, bike shop, and transit stops, they were more likely to bicycle in the last week. Using the same dataset with Emond et al., Xing, Handy, and Mokhtarian (2010) further found that perceived accessibility to destinations was positively associated with total miles of bicycling in the last week. In addition, Beenackers et al. (2012) found that if people perceived higher accessibility to mixed services (shops, many places, public transit stops) after home relocation, they would be more likely to take up bicycling after the relocation. However, their objective measure of destination accessibility was not significant in predicting the odds of taking up bicycling. 


\section{Infrastructure}

Transportation infrastructure serves to facilitate walking and bicycling by providing a safe and comfortable environment for pedestrians and bicyclists. Sidewalks are the typical infrastructure for walking, and empirical evidence has found that the presence of sidewalks or a higher ratio of sidewalks in a street network is positively associated with walking (Chatman, 2009; Hess, 1999). The associations between the bicycle infrastructure and bicycling are the primary interests of the early work linking the built environment with bicycling. Most previous work has focused on evaluating the effect or value of a striped bicycle lane and/or separated path, which are the common bicycle facilities in North America and Europe. Pucher et al. (2010) provided a comprehensive review of the effects of different types of bicycle facilities on bicycling behavior. Findings regarding the association between striped bicycle lanes and levels of bicycling are mixed; aggregate studies often find a positive correlation, but individual-level studies sometimes do not. For example, using objective measures at least two studies found a positive association between bicycle lanes and bicycling (Jennifer Dill \& Carr, 2003; Krizek \& Johnson, 2006). However, other studies found no effect (Jennifer Dill \& Voros, 2007; Vernez-Moudon, et al., 2005). Interestingly, Dill and Voros (2007) found their objective measures of proximity to off-street trails and bike lanes were not associated with a higher level of bicycling, while positive perceptions of the availability of bike lanes was associated with more bicycling. 
Some studies have found a stronger relationship between cycling levels and off-street bike paths. For example, Parkin (2008) and Akar et al. (2013) found proximity to an offstreet trail, objectively measured, was a significant variable in predicting odds of bicycling. In addition, Handy et al. (2010) found that if the respondent perceived that the city had off-street bike paths he or she would be more likely to be a regular bicyclist. Vernez-Moudon et al. (2005) found that both an objective measure (distance to nearest trail) and perceived measure (perceived presence of combined trails and bicycle lanes in the neighborhood) were associated with the likelihood of bicycling. However, there are two studies (Jennifer Dill \& Voros, 2007; Krizek \& Johnson, 2006) which found that proximity to an off-street trail had no effect on bicycling, and both studies used objective measures. Some studies have suggested that bicyclists may prefer to use low-traffic or quiet streets. One GPS-revealed preference study confirmed that bicyclists went out of their way to use bicycle boulevards (Broach, Dill, \& Gliebe, 2012). Emond et al. (2009) found that survey respondents were most comfortable bicycling on a quiet street. Winters et al. (2010) found that the presence of traffic calming, and road marking and signage (common elements of a bicycle boulevard), objectively measured, were positively associated with the odds of a trip made by bicycle. 
Table 4: Measurement of Built Environment in Active Travel Behavior Study (Selected Research) - Destination

\begin{tabular}{|c|c|c|c|c|c|}
\hline $\begin{array}{c}\text { Built } \\
\text { Environment } \\
\text { Variables }\end{array}$ & $\begin{array}{l}\text { Spatial Unit of } \\
\text { Measurement }\end{array}$ & Measurement & Behavior Variables & Findings & Sources \\
\hline \multirow{5}{*}{$\begin{array}{l}\text { Business } \\
\text { accessibility }\end{array}$} & Neighborhood & $\begin{array}{l}\text { Total businesses per acre; neighborhood businesses per } \\
\text { acre }\end{array}$ & $\begin{array}{l}\text { Number of walking trips } \\
\text { per person per day }\end{array}$ & + & Boarnet et al., 2010 \\
\hline & 400 meters & Number of business types within 400 meters & $\begin{array}{l}\text { Walking/biking } \\
\text { frequency }\end{array}$ & + & Cao et al., 2009 \\
\hline & 800 meters & Number of business types within 800 meters & $\begin{array}{l}\text { Walking/biking } \\
\text { frequency }\end{array}$ & n.s. & Cao et al., 2009 \\
\hline & 800 meters & Number of institutional businesses & $\begin{array}{l}\text { Walking/biking } \\
\text { frequency }\end{array}$ & n.s. & Cao et al., 2009 \\
\hline & $\begin{array}{c}400,800,1,600 \\
\text { meters }\end{array}$ & $\begin{array}{l}\text { Number of institutional establishments (church, library, } \\
\text { post office, bank; household maintenance; grocery } \\
\text { store, convenience store, pharmacy; eating out: bakery, } \\
\text { pizza, ice cream, take-out; leisure: health club, } \\
\text { bookstore, bar, theater, video rental) }\end{array}$ & $\begin{array}{l}\text { Walking to the store } \\
\text { frequency }\end{array}$ & n.s. & Handy et al., 2006 \\
\hline
\end{tabular}




\begin{tabular}{|c|c|c|c|c|c|}
\hline & $\begin{array}{l}400,800,1,600 \\
\text { meters }\end{array}$ & $\begin{array}{l}\text { Number of types of businesses within } 400,800 \text { and } \\
1,600 \text { meters }\end{array}$ & $\begin{array}{l}\text { Walking to the store } \\
\text { frequency }\end{array}$ & + & Handy et al., 2006 \\
\hline & Distance & Distance to library & $\begin{array}{l}\text { Walking/biking } \\
\text { frequency }\end{array}$ & - & Cao et al., 2009 \\
\hline & Distance & Distance to theater & $\begin{array}{l}\text { Walking/biking } \\
\text { frequency }\end{array}$ & - & Cao et al., 2009 \\
\hline & Distance & Distance to post office & $\begin{array}{l}\text { Walking/biking } \\
\text { frequency }\end{array}$ & - & Cao et al., 2009 \\
\hline & Distance & $\begin{array}{l}\text { Institutional: church, library, post office, bank; } \\
\text { household maintenance: grocery store, convenience } \\
\text { store, pharmacy; eating out: bakery, pizza, ice cream, } \\
\text { take-out; leisure: health club, bookstore, bar, theater, } \\
\text { video rental }\end{array}$ & $\begin{array}{l}\text { Walking to the store } \\
\text { frequency }\end{array}$ & - & Handy et al., 2006 \\
\hline & Distance & Distance to commercial & $\begin{array}{l}\text { Home-based non-work } \\
\text { trip choose walk }\end{array}$ & - & Reilly, 2004 \\
\hline Downtown & Distance & Distance to city hall & $\begin{array}{l}\text { Two-day walking } \\
\text { distance }\end{array}$ & - & Boarnet et al., 2008 \\
\hline & Distance & Distance to downtown & Number of non-work & + & Chatman, 2009 \\
\hline
\end{tabular}

$\stackrel{w}{\omega}$ 


\begin{tabular}{|c|c|c|c|c|c|}
\hline & & & trips by walk/bike & & \\
\hline \multirow{5}{*}{$\begin{array}{l}\text { Transit } \\
\text { accessibility }\end{array}$} & Distance & Distance to LRT & $\begin{array}{l}\text { Two-day walking } \\
\text { distance }\end{array}$ & n.s. & Boarnet et al., 2008 \\
\hline & Half mile & Heavy-rail station within a half mile & $\begin{array}{l}\text { Number of non-work } \\
\text { trips by walk/bike }\end{array}$ & n.s. & Chatman, 2009 \\
\hline & Quarter mile & GTAI score & $\begin{array}{l}\text { Home-based shopping, } \\
\text { multipurpose and transit- } \\
\text { access trips choose walk }\end{array}$ & + & Reilly, 2006 \\
\hline & Half mile & Light-rail station within a half mile & $\begin{array}{l}\text { Number of non-work } \\
\text { trips by walk/bike }\end{array}$ & + & Chatman, 2009 \\
\hline & Distance & Distance in miles to the nearest bus stop & $\begin{array}{l}\text { Number of walking trips } \\
\text { per day }\end{array}$ & - & Targa \& Clifton, 2008 \\
\hline \multirow[b]{2}{*}{ accessibility } & Neighborhood & Local access to park (dummy variable) & $\begin{array}{l}\text { Number of walking-to- } \\
\text { destination trips }\end{array}$ & n.s. & Lund, 2003 \\
\hline & Census block & Proportion of census block's area designated to parks & $\begin{array}{l}\text { Number of walking trips } \\
\text { per day }\end{array}$ & n.s. & Targa \& Clifton, 2009 \\
\hline
\end{tabular}


Table 5: Measurement of Built Environment in Active Travel Behavior Study (Selected Research) - Infrastructure

\begin{tabular}{|c|c|c|c|c|c|}
\hline $\begin{array}{c}\text { Built Environment } \\
\text { Variables }\end{array}$ & $\begin{array}{l}\text { Spatial Unit of } \\
\text { Measurement }\end{array}$ & Measurement & Behavior Variables & Findings & Sources \\
\hline \multirow[b]{2}{*}{ Sidewalk } & Half mile & $\begin{array}{l}\text { Whether sidewalk is on both sides of } \\
\text { street (dummy) }\end{array}$ & $\begin{array}{l}\text { Number of non-work trips by } \\
\text { walk/bike }\end{array}$ & + & Chatman, 2009 \\
\hline & Half mile & $\begin{array}{l}\text { A ratio of the length of the sidewalk } \\
\text { system to the length of all public } \\
\text { street frontage }\end{array}$ & $\begin{array}{l}\text { Volumes of pedestrians } \\
\text { walking into neighborhood } \\
\text { centers }\end{array}$ & + & Hess et al., 1999 \\
\hline \multirow{2}{*}{ Bicycle lane } & 1.86 miles & $\begin{array}{l}\text { Percentage of streets lined with } \\
\text { bicycle lanes }\end{array}$ & Odds of cycling & n.s. & Moudon et al., 2005 \\
\hline & City & Bike lanes per square mile & $\begin{array}{l}\text { Percentage commuting by } \\
\text { bicycle }\end{array}$ & + & Dill and Carr, 2003 \\
\hline
\end{tabular}




\begin{tabular}{|c|c|c|c|c|c|}
\hline & Quarter mile & $\begin{array}{l}\text { Proximity to a regional trail } \\
\text { within/beyond a quarter mile }\end{array}$ & Number of bicycling trips & n.s. & Dill and Voros, 2007 \\
\hline & 1.86 miles & $\begin{array}{l}\text { Category: }<1 / 2 \text { mile; } 1 / 2-1 \text { mile; } 1 \text { - } \\
1.75 \text { mile; } 1.75+\text { mile }\end{array}$ & Odds of cycling & + & Moudon et al., 2005 \\
\hline \multirow[t]{2}{*}{ Off-street trail } & Distance & $\begin{array}{l}\text { Distance to the nearest on-street } \\
\text { bicycle path: dummy category: } 400 \text {, } \\
800,1,600 \text { and } 1600+\text { meters }\end{array}$ & $\begin{array}{l}\text { Complete at least one bicycle } \\
\text { trip from home during the } 24- \\
\text { hour period }\end{array}$ & n.s. & Krizek and Johnson, 2006 \\
\hline & Route & $\begin{array}{l}\text { Proportion of route on off-street, } \\
\text { regional bike path }\end{array}$ & Bicycling route choice & + & Broach et al., 2012 \\
\hline
\end{tabular}




\section{Studies linking perceived environment with active travel behavior}

The built environment as an intervention on people's active travel behavior and physical activity acquired little attention until recently in the public health field, where scholars traditionally focus on interventions addressing individual and social environment. Research on the built-environment correlate of walking has proliferated in recent years, while the research on the correlate of bicycling is relatively sparse. Different from the motivation of the transportation planning field, where the study of walking and bicycling aims to provide alternative travel options and reduce car-dependent travel, research in the public health field treats walking and bicycling as important forms of physical activity. Moreover, different from the objective built-environment variables used widely in the transportation planning field, scholars in the public health field traditionally relied more on self-reported perceptions of the built environment (Alton, Adab, Roberts, \& Barrett, 2007; Carver, et al., 2005; Evenson, et al., 2006; Mota, et al., 2007). However, there is a trend to use both objective and perceived measurements recently in both fields. The review here focuses on measurement methods of the perceived built environment and empirical findings on the relationship between the perceived built environment and active travel behavior. A list of recent empirical studies linking walking/bicycling and the perceived built environment is provided in Table 6 .

Similar to measurement of the objective built environment, measurement of the perceived built environment can also be classified into five dimensions, including perceived density (De Bourdeaudhuij, Teixeira, Cardon, \& Deforche, 2005); perceived diversity (i.e., landuse mix) (De Bourdeaudhuij, et al., 2005; Spence, et al., 2006); perceived design (i.e., 
street connectivity, street light, aesthetics) (Burton, Turrell, Oldenburg, \& Sallis, 2005; Duncan \& Mummery, 2005; Hooker, Wilson, Griffin, \& Ainsworth, 2005); perceived destination (i.e., park, transit, shops, open space) (Bopp, et al., 2006; De Bourdeaudhuij, et al., 2005; van Lenthe, Brug, \& Mackenbach, 2005); and perceived infrastructure (i.e., sidewalk, bike lane, physical activity facilities, footpath condition) (Bopp, et al., 2006; Burton, et al., 2005; De Bourdeaudhuij, et al., 2005; Duncan \& Mummery, 2005). Moreover, perceived traffic and neighborhood safety (Burton, et al., 2005; Hoehner, Brennan Ramirez, Elliott, Handy, \& Brownson, 2005a; Hooker, et al., 2005) is another important measure which is not usually captured in research using objective measures. Likert scale is the most frequent method for participants to assess the extent they agree or disagree with each statement of environmental features.

Similar with studies using objective measures, most studies using perceived measurements also found that higher walking activity/sufficient walking/regular walking is associated with higher mixed land use (De Bourdeaudhuij, et al., 2005; Hoehner, et al., 2005a); more street intersections (Fuzhong, Fisher, Brownson, \& Bosworth, 2005); more proximity to shops (van Lenthe, et al., 2005); more green and open space (Fuzhong, et al., 2005); presence of sidewalks (De Bourdeaudhuij, et al., 2005); greater perceived neighborhood safety (Hooker, et al., 2005); and higher perceived aesthetics (Suminski, Poston, Petosa, Stevens, \& Katzenmoyer, 2005).

Moreover, results of these studies indicate that different built-environment elements may be associated with walking for transportation and walking for recreation, and future 
research on walking and bicycling should differentiate these two purposes. Meanwhile, research on bicycling and the perceived built environment is rather sparse. 
Table 6: Measurement of Perceived Built Environment in Physical Activity Study (Selected Research)

\begin{tabular}{|c|c|c|c|c|}
\hline Built Environment Variables & Measurement & $\begin{array}{c}\text { Travel Behaivor } \\
\text { Variables }\end{array}$ & Findings & Sources \\
\hline Perceived neighborhood environment & $\begin{array}{l}\text { Composite score of } \\
\text { dichotomous } \\
\text { coded perceptions of } \\
\text { neighborhood: } \\
\text { - walkable } \\
\text { - crime present } \\
\text { - sidewalks } \\
\text { - street lighting } \\
\text { - public parks }\end{array}$ & $\begin{array}{l}\text { Met or did not meet } \\
\text { recommendation of } \\
\text { walking } \geq 30 \\
\text { mins } \geq 5 \text { days/week }\end{array}$ & n.s. & Bopp et al., 2006 \\
\hline Perceived physical features & $\begin{array}{l}\text { Footpaths, public } \\
\text { transport, services, } \\
\text { streetlights; 5-point Likert } \\
\text { scale response format } \\
\text { Perceived safety, } \\
\text { ambience, cleanliness, } \\
\text { friendliness; 5-point } \\
\text { Likert scale response } \\
\text { format }\end{array}$ & \multirow{3}{*}{$\begin{array}{l}\text { Likelihood of none } \\
\text { or some walking } \\
\text { activity }\end{array}$} & \multirow{3}{*}{$\begin{array}{l}\text { Environment accounted for } 0.6 \% \\
\text { of the } \\
\text { unique variance in walking } \\
\text { activity }\end{array}$} & \multirow[t]{3}{*}{ Burton et al., 2006} \\
\hline Perceived traffic & $\begin{array}{l}\text { Busyness of streets and } \\
\text { extent of traffic flow; } 5- \\
\text { point Likert scale } \\
\text { response format }\end{array}$ & & & \\
\hline Perceived facilities & $\begin{array}{l}\text { Facilities for activity } \\
\text { participation, e.g., gyms, } \\
\text { pools, paths; 5-point } \\
\text { Likert scale }\end{array}$ & & & \\
\hline $\begin{array}{l}\text { Perceived residential density } \\
\text { Perceived land use mix } \\
\text { Perceived transit access }\end{array}$ & Four-point scale & $\begin{array}{l}\text { Long IPAQ usual } \\
\text { week time spent } \\
1 \text { walking/cycling } \\
\text { for } \\
\text { transport }\end{array}$ & $\begin{array}{l}\text { 1. Walking/cycling for transport } \\
\text { related to higher land use mix } \\
2 \text { Walking for leisure related to } \\
\text { higher availability of sidewalks } \\
\text { (Portuguese sample only) and }\end{array}$ & $\begin{array}{l}\text { De Bourdeaudhuij et al., } \\
2005\end{array}$ \\
\hline
\end{tabular}

o 
Perceived sidewalks

Perceived bike lanes

Perceived neighborhood aesthetics

Perceived activity equipment

Perceived proximity to shops/services and open space

Perceived aesthetics

Perceived footpaths condition

Five-point Likert scale

Perceived traffic volume

Perceived lighting

Perceived land use mix, proximity of recreational facilities,

active transport infrastructure (e.g., sidewalks present),

Likert scale

transit access, traffic safety, aesthetics, crime safety

\section{Perceived traffic \\ Perceived street light}

Perceived unattended dogs

Perceived crime safety

Likert-type scale

Walking (regular higher land use mix (Belgian sample only) Associations

between walking and

environmental variables attenuated

fter accounting for psychosocial

factors (e.g., selfefficacy)
Perceived public recreation facility safety

Any versus no active
transport in past 7
days
Met/did not meet
$150+$ minutes of
activity through
active transport only
recommendation

walking) or not

walking at least 150

minutes per

week

Any recreational

walking in past week

Higher likelihood of recreational walking related to having poorer perceptions of footpath condition

Active transport likelihood

increased with greater perceived

and objective land use mix,

objective transit access, and

objective pedestrian comfort

amenities (e.g., tree, benches);

decreased likelihood with greater

objective sidewalk quality and

objective neighborhood

cleanliness

Regular walking likelihood was

associated with greater perceived

neighborhood safety;

regular walking likelihood was

lower in

moderate traffic versus heavy

Hooker et al., 2005

neighborhoods (both findings only

present among White, not AfricanAmerican, samples)

Any transportation

and/or recreation

walk trips (walker

More likely to be both a

transportation and recreation

walker if

perceive neighborhood as mixed

2005

Hoehner et al., 2005
Duncan and Mummery,

Perceived aesthetics 
walker) in a usual

week

No, moderate (1-4

times), or frequent (5

or more times)

Perceived traffic

walking per week

Perceived proximity to local recreational facilities

Five-point Likert scale

Perceived walking and traffic safety

Perceived number of nearby recreational facilities

\begin{tabular}{|c|c|c|c|c|}
\hline Perceived number of nearby recreational facilities & & & $\begin{array}{l}\text { walking safety; higher walking } \\
\text { activity among residents reporting } \\
\text { more traffic safety in } \\
\text { neighborhoods }\end{array}$ & \\
\hline Perceived sidewalk presence & yes/no/don't know & $\begin{array}{l}\text { Regular }(\geq 150 \\
\text { mins), irregular (1- } \\
149 \text { mins), or no } \\
\text { walking per week }\end{array}$ & $\begin{array}{l}\text { Irregular walkers more likely to } \\
\text { report presence of sidewalks than } \\
\text { non-walkers; finding not } \\
\text { significant in separate models } \\
\text { based on race }\end{array}$ & Reed et al., 2006 \\
\hline Perceived land use mix & & & & \\
\hline $\begin{array}{l}\text { Perceived crime safety } \\
\text { Perceived sidewalk presence } \\
\text { Perceived recreation availability } \\
\text { Perceived aesthetics }\end{array}$ & Four-point scale & $\begin{array}{l}\text { Sufficient walking in } \\
\text { the past week ( } 5 \text { or } \\
\text { more days of at least } \\
30 \text { minutes of } \\
\text { walking per day) }\end{array}$ & $\begin{array}{l}\text { Sufficient walking more likely } \\
\text { among individuals reporting } \\
\text { greater neighborhood aesthetics } \\
\text { and land use mix, especially } \\
\text { among women }\end{array}$ & Spence et al., 2006 \\
\hline Perceived street connectivity & & & & \\
\hline Perceived route functionality (sidewalk condition) & 10-point scale & $\begin{array}{l}\text { In the past } 7 \text { days, } 1 \\
\text { transportation }\end{array}$ & $\begin{array}{l}\text { Transportation walking more } \\
\text { likely among women reporting }\end{array}$ & Suminski et al., 2006 \\
\hline
\end{tabular}

Li et al., 2005

recreational facilities and better

walking safety; higher walking

activity among residents reporting

more traffic safety in

neighborhoods

\section{Irregular walkers more likely to}

eport presence of sidewalks than

non-walkers; finding not
1 Higher walking activity at

neighborhood level related to

higher employment place and

residential household density,

more street intersections, and more

green and open space; 2 Higher

Likert rating of

frequency of

walking activity in

neighborhood

wating at resident level

D 
Perceived aesthetics

Perceived destiantions

Perceived attractiveness

Perceived traffic noise

Perceived proximity to food shops

Perceived green space quality

Perceived crime safety walking

2 exercise walking

3 walking a dog

moderate versus low walk

destinations; transportation

walking less likely among men

reporting moderate route

functionality and aesthetics

compared to low levels of these

factors. Exercise and dog walking

more likely among women

reporting moderate versus low

neighborhood safety

Greater walking likelihood

associated with less traffic noise

(for adults $\leq 49$ years old) and

$<$ ('almost never

walking') or $>15$

mins per day

walking or cycling

to shops or work

greater proximity to food shop
(for adults $>49$ years old and

particularly in lower

Van Lenthe et al., 2006

socioeconomic neighborhoods) 


\section{Studies comparing the objective and perceived built environment}

About a dozen recent studies were identified that examine the concordance between the perceived and objectively measured built environment, and compare their different roles on physical activity. Almost all of these studies are published in health journals. Though the initial purpose of these studies is often to investigate the validity of their survey instruments, the researchers appeared to realize that the difference between self-reported perceptions and objective measures of the environment can be substantive, and this difference is due to many other factors besides the survey design or methods. In these studies, the perceived environment is usually derived from self-reported surveys, and GIS databases and audit tools are used to measure the objective environment. Most of these studies use cross-sectional data with only one exception (Gebel, Bauman, Sugiyama, \& Owen, 2011). Kappa statistics are commonly used to quantify the level of agreement between perceptions and objective measures, and are thought to be more appropriate than simple percent agreement calculations because they take into account the agreement occurring by chance. Multivariate regression is then often employed to measure the effect of both the perceived and objective environment on physical activity or travel behavior.

\section{Agreement between the objective and perceived built environment}

Most of these studies find that agreement or concordance between the objective and perceived (also referred to as "subjective") built environment is poor to moderate, based on kappa statistics. Kirtland et al. (2003) conducted a telephone survey to investigate walking environments in Sumter County, SC. Using kappa statistics, they found fair to low agreement between subjective and objective measures. McCormack et al. (2007) 
compared the perceived and objectively measured distance to several destinations and found that distances to most destinations close to home were overestimated, whereas distances to those farther away were underestimated. They also concluded that concordance between subjective and objective measures was low to moderate. McGinn et al. (2007) used a telephone survey $(n=1,270)$ in Forsyth County, NC, and Jackson, MS, and also found poor agreement between perceived and objective measures. Ball et al. (2008) investigated the concordance between self-reported and objective (audit) measures of physical activity facilities based on self-reported surveys of 1,540 women from 45 neighborhoods in Melbourne, Australia, and they found relatively poor agreement. Lackey and Kaczynski (2009) examined how the individual, neighborhood, and parkrelated variables influenced the agreement between self-reported and objectively measured distance to parks, and they also found that agreement was poor but higher in certain subgroups. Prins et al. (2009) explored the degree of agreement between objective and perceived availability of physical activity facilities in neighborhoods as well as the relative effect of the perceived and objective environment on adolescent engagement in sports activities and walking and cycling in leisure time. They found that agreement was low to moderate, based on the kappa values.

\section{Factors contributing to the mismatch}

Several studies further explored the factors contributing to the mismatch between the perceived and objective environment, and most of these studies concluded that level of physical activity, socio-demographic characteristics of respondents, and number and quality of built-environment attributes can influence agreement. Kirtland et al. (2003) 
found that those engaging in physical activity tended to have higher agreement than inactive individuals. McCormack et al. (2007) explored the moderation effect of age, gender, and walking behavior on the agreement between objective and perceived distance and found the following: men tended to overestimate distance to the nearest supermarket than women; those who walked for utilitarian purposes for more than 25 minutes per week overestimated distance to the nearest supermarket compared with those walking less than 25 minutes per week; and those who walked for recreation for less than 130 minutes per week overestimated distance to the closest shop to a larger extent than those walking more than 130 minutes per week. Ball et al. (2008) found that the mismatch between the perceived and objectively measured environments was more frequent among women who were relatively younger, older, lower income, less active, used fewer facilities, and lived in the neighborhood for less than two years. Lackey and Kaczynski (2009) found that respondents with the following characteristics were more likely to achieve a match: they reported participating in at least some park-based physical activity; they had access to a greater number of parks nearby; their closest park had more features; and their closest park contained a playground or wooded area. Gebel et al. (2009) identified that adults with lower educational attainment and lower income, and those who were less physically active or overweight, were more likely to perceive their high walkable neighborhood as low walkable. McGinn et al. (2007) also investigated whether the agreement varied between active and inactive people, but found no significant difference.

\section{Independent role of perceived and objective role on physical activity}


Most of these studies find that both the objective environment and perceived environment may have different effects on physical activity and active travel behavior, while perceptions may play a much larger role than the objective environment. In their study of a low-walkable city (St. Louis, MO) and high-walkable city (Savannah, GA), Hoehner et al. (2005a) found that levels of physical activity for transportation and recreation are associated with different perceived and objective environmental measures after controlling for age, gender and education. The objectively measured environment had much weaker effects on exercising compared with individual and social determinants. The authors concluded that the objective environment was necessary but not sufficient for physical activity participation. Scott et al. (2007) found that both perceptions of facilities and total number of facilities were associated with increased physical activity, while the objectively measured number of facilities was not significantly related with physical activity. Prins et al. (2009) found only perceived availability of sports facilities and parks was significantly associated with sports activities, and with walking and cycling in leisure time. McGinn et al. (2007) found independent effects of perceptions and objective measures on physical activity, and they recommended that evaluating both objective and perceived measures of the built environment was necessary when examining the relationship between the built environment and physical activity. Lackey and Kaczynski (2009) concluded that park-based physical activity was not related to either perceived or objective proximity to parks unless there was a match between perceived and objective proximity. Gebel et al. (2009) concluded that perceptions may be more strongly associated with behavior than are objective measures. In their follow-up study (Gebel, et al., 2011), they used longitudinal survey data from the city of Adelaide, Australia, and 
found that persons who perceived their high-walkable neighborhood as low-walkable decreased their walking and increased their body mass index (BMI) significantly more than those with matched perceptions.

In summary, previous empirical studies have shown that the agreement between the objective and perceived environment is low to moderate, and such factors as sociodemographic characteristics, level of physical activity, and quality of the built environment can contribute to the match or mismatch. Moreover, both the objective and perceived built environment has independent effects on physical activity, and the effect of the objective environment is often weak or non-significant when the perceived environment is also included in the modeling. One common omission of these studies, however, is a test of the link from objective environment to perceived environment. This link helps us understand the indirect effect of the objective environment on active travel behavior or physical activity by influencing the perceived environment. The standard OLS regression models used in several previous studies preclude exploring these complex relationships because each variable is treated as exogenously affecting the dependent variable. Structural equation modeling overcomes this limitation.

\section{Literature Gap}

Several literature gaps can be identified from previous studies, and some of these have been mentioned in previous literature reviews (Burbidge \& Goulias, 2008; Krizek, et al., 2009; McMillan, 2005; Sallis, et al., 2006).

1. Empirical studies linking the built environment and bicycling are limited. Many previous studies on active travel behavior often group walking and bicycling 
behavior together. However, walking and bicycling may fulfill different daily purposes of individuals and require different design and planning support (Krizek, et al., 2009). Studies comparing different built-environment elements related to walking and bicycling are needed.

2. Conventional active-travel behavior models are largely built based on utility theory, which simplifies the travel decision as a process to minimize travel cost and ignores the complexity of decision making on travel choice. The cognitive and ecological models capturing multiple dimensions of factors and reflecting the mechanism of behavioral decision making are therefore needed to construct a comprehensive framework for active travel behavior.

3. Cognitive and ecological models are often involved with structural relationships between variables, which require a deeper examination of direct and indirect effects, interactions, mediations, and recursive effects. Addressing these relationships requires appropriate modeling methods, such as structural equation model (SEM) and multilevel model (MLM), which have been widely applied in other disciplines. Application of these estimation models in active travel behavior is needed.

4. We are clear about the relationship between the external built environment and active travel, but we are less clear what intrapersonal factors may intervene in this relationship. Perception, for example, may be an important mediator between the objective built environment and active travel. Exploring such intervening factors is very important to make effective interventions to promote active travel. 
5. We are not confident about the causality between the built environment and active travel because little empirical research employs panel design. This limits the ability of current studies to make policy implications. 


\section{Chapter 3. Research Questions and Hypothesis}

This study aims to partially fill these research gaps by systematically exploring the relationships between the objective (actual) environment and people's perceptions of the environment, and their relative effects on travel behavior, particularly bicycling behavior. The analysis starts from exploring the different effects of the perceived and objective environment on travel behavior, and then further looks at the possible relationships between the perceived and objective environment based on cognitive theories. This is followed by investigating the factors contributing to the mismatch between the perceived and objective environment and the reasons why people living in presumably highbikeable environments perceive it as a low-bikeable environment. Finally, this study explores the causal relationship between the objective and perceived environment using a longitudinal design.

\section{Research Questions}

Specifically, this study aims to address the following research questions:

(1) Do perceived and objective environment attributes have different effects on active travel behavior?

(2) Do perceptions mediate the effects of the objective environment on active travel behavior?

(3) How does the objectively measured built environment correspond to the perceived built environment? And what factors may contribute to the mismatch between the objective and perceived built environment? 
(4) Do changes in the built environment change perceptions, and in turn change travel behavior?

\section{Hypothesis}

H1: There is a mismatch between the objective and perceived environment. This is to say people may not perceive a walk- or bike-friendly environment defined using objective measures as walkable or bikeable. And people's socio-demographic attributes, their attitude about travel behavior, their walking and cycling behavior, their general health condition, the number of years they have lived in a neighborhood, their social norms and neighborhood safety may contribute to the mismatch. Therefore, the perceived and objective environment may have independent effects on active travel behavior.

H2: People's active travel behavior is directly influenced by their image of the built environment rather than the built environment itself. This means the objective built environment may only have an indirect effect on active travel by influencing people's perceptions. In other words, perception is a mediator between the objective environment and active travel behavior. This also means that the perceived built environment may have a much stronger effect on active travel behavior than the objective built environment when both are presented in the same model. Based on $\mathrm{H} 1$ and $\mathrm{H} 2$, a conceptual model based on cognitive theory for active travel behavior is developed (Figure 3).

H3: The objective environment may not only affect people's perception of the built environment, but also their perception of safety, social environment, and perceived self- 
efficacy towards behavior, all of which may have a direct effect on active travel behavior. Meanwhile, the active travel behavior may have a feedback effect on people's perception. This hypothesis can be analyzed using a Stimulus-Organism-Response (SOR) framework (Figure 4).

H4: Improvements in the built environment may increase the level of perceptions of the environment, and in turn promote active travel behavior.

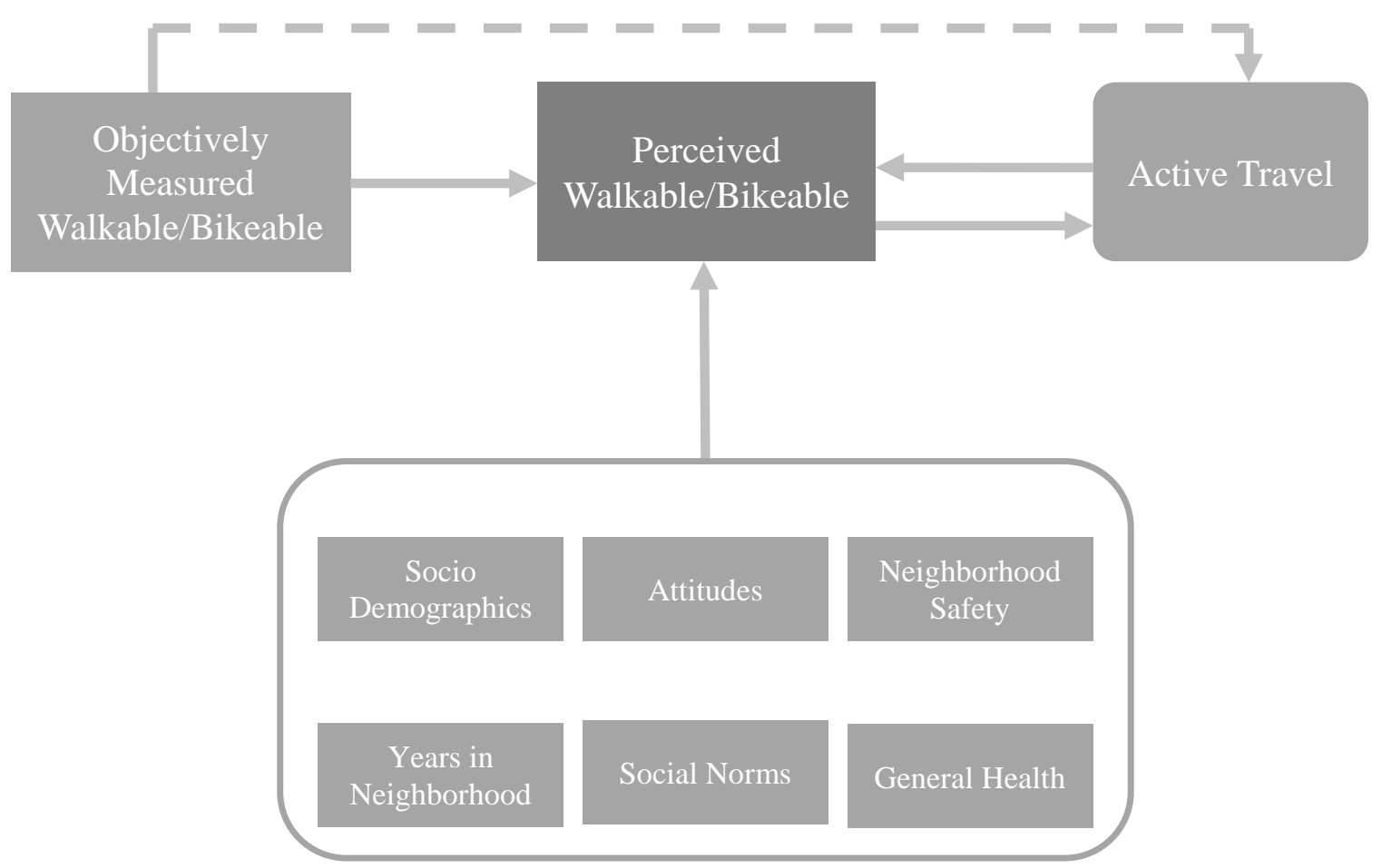

Figure 3: A Cognitive Model for Active Travel Behavior 
Stimulus

\begin{tabular}{|ll|}
\hline Objective \\
Environment \\
. & Density \\
: & Diversity \\
D & Design \\
$\cdot$ & Infrastion \\
& \\
\\
\end{tabular}

Organism

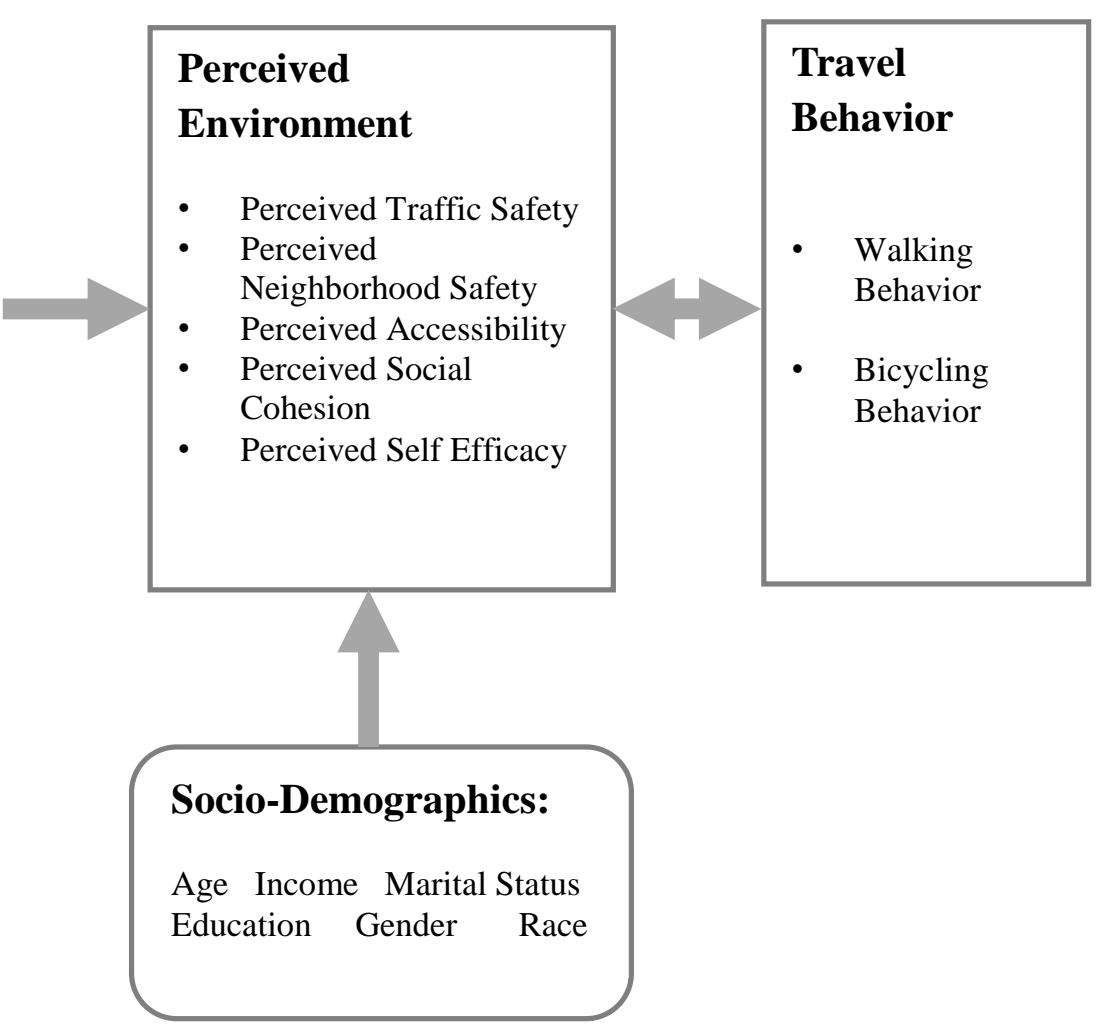

Figure 4: A SOR Framework for Active Travel Behavior 
In the following chapters, Chapter 4 will briefly introduce the data and methods used in this study, and Chapters 5-8 are four stand-alone papers that aim to test each of the four hypotheses (see Table 7).

Table 7: Four Research Questions and Hypotheses

\begin{tabular}{cll}
\hline Chapters & Research questions & Hypotheses \\
\hline Chapter 5 & $\begin{array}{l}\text { Do perceived and objective environment attributes have } \\
\text { different effects on active travel behavior? }\end{array}$ & $\begin{array}{l}\text { Independent } \\
\text { effects }\end{array}$ \\
Chapter 6 & $\begin{array}{l}\text { Do perceptions mediate the effects of the objective } \\
\text { environment on active travel behavior? }\end{array}$ & Yes \\
Chapter 7 & $\begin{array}{l}\text { How does the objectively measured built environment } \\
\text { correspond to the perceived built environment? }\end{array}$ & $\begin{array}{l}\text { There is a } \\
\text { mismatch }\end{array}$ \\
Chapter 8 & $\begin{array}{l}\text { Do changes in the built environment change perceptions, and } \\
\text { in turn change travel behavior? }\end{array}$ & Yes \\
\hline
\end{tabular}




\section{Chapter 4. Data and Methodology}

\section{Data}

The analysis of this study primarily relied on the data from three research projects: Types of Cyclists (Jennifer Dill \& McNeil, 2013a), SmartTrips (Jennifer Dill \& Mohr, 2010), and Family Activity Study (http://www.pdx.edu/ibpi/family-activity-study). The data of Types of Cyclists were obtained through a random phone survey of adults in the Portland, OR, region. The sample included both land-line and mobile phone numbers and was conducted July 19-Aug. 10, 2011. A total of 902 interviews were completed. The data of SmartTrips were collected from a 2008 phone survey of adult residents in three neighborhoods in Portland. The survey targeted three neighborhoods located in the Southwest (SW), Northeast (NE) and Southeast (SE) quadrants of the city, all of which have distinct built-environment characteristics. The Family Activity Study is a longitudinal study of the effects of traffic calming infrastructure (bicycle boulevards) on behavior. The data were collected at three points in time: Pre, Post, and Interim through a household survey. The Pre ( $\mathrm{n}=491$ adults) and Post ( $\mathrm{n}=385)$ surveys are approximately two years apart, with bicycle boulevard construction occurring in between. The sociodemographic characteristics, psychological measures (e.g. attitudes, perceptions), and measures of travel behavior were derived from these surveys. The details of the data are described in the following chapters.

In addition, the objective built-environment data are primarily from the Regional Land Information System (RLIS) from Portland Metro, the region's transportation and land-use 
planning agency. RLIS includes detailed GIS data required for this study, such as street network, land-use information, and locations of transit stops and public institutions.

\section{Methods}

This study primarily employed quantitative analysis. Various statistical methods were used to answer different research questions, and they include:

- ANOVA test

- Cluster analysis

- Factor analysis

- Mediation analysis

- Multivariate linear regression

- Binary logit regression

- Structural equation modeling

- Tobit model

- Difference-in-differences estimation

The details of the research methods are introduced in the following chapters. 


\section{Chapter 5. Paper 1: Effects of the Objective and Perceived Built Environment on Bicycling for Transportation}

\section{Introduction}

The health benefits of bicycling have been recognized (Garrard, Rissel, \& Bauman, 2012; Sallis, Frank, Saelens, \& Kraft, 2004). Bicycling can be a moderate to vigorous intensity activity that helps people achieve the goal of physical activity at a relatively low monetary and time cost. Bicycling is also an environmental friendly travel mode for displacing vehicle-related pollution (Haines, et al., 2009; Maizlish, et al., 2013; Woodcock, et al., 2009). Despite a growing commitment to implementing policies, plans, and projects that promote more bicycling in light of its promising benefits to public health and the environment, bicycling is an under-used mode for transportation in the United States. According to the 2009 National Household Travel Survey, for the trips with a distance equal or less than five miles (equivalent to a 30-minute bicycle trip assuming an average speed of 10 miles/hour), bicycling only represents $1.7 \%$ of these trips for all purposes, $2.6 \%$ of these trips for commuting, and $2.9 \%$ of these trips for shopping, social and recreational purposes (United States Department of Transportation, 2011).

Even though there has been growing interest in linking the built environment to bicycling in both the transportation and health disciplines, the empirical evidence is still limited (Heinen, van Wee, \& Maat, 2010; Pucher, et al., 2010; Yang, Sahlqvist, McMinn, Griffin, \& Ogilvie, 2010). Further, the inconsistent measurements of the built environment lead to mixed findings from the current studies, and one of these inconsistencies is the difference 
in using objective measures and subjective measures (Ma, Dill, \& Mohr, 2014). Objective measures are typically obtained from systematic observations, audit, or calculated based on existing spatial data (e.g. street network and land use data) using GIS, and subjective measures are generally derived from self-reported data, which reflects the subjective perceptions of the respondents of the environment (Brownson, Hoehner, Day, Forsyth, \& Sallis, 2009). Subjective measures have often been considered a substitute for objective measures when objective data are unavailable. However, recent studies argue that both objective and subjective measures should be included when possible, because different associations were found between the objective measures and perceived measures of the same environmental attribute with walking behavior (Ewing, Handy, Brownson, Clemente, \& Winston, 2006; Gebel, et al., 2011; Hoehner, Brennan Ramirez, Elliott, Handy, \& Brownson, 2005b; Lin \& Moudon, 2010; McGinn, et al., 2007; Prins, et al., 2009; Rodriguez, Evenson, Diez Roux, \& Brines, 2009; Scott, et al., 2007; Van Acker, Derudder, \& Witlox, 2013; Van Dyck, Veitch, De Bourdeaudhuij, Thornton, \& Ball, 2013). In other words, the objective environment may not be equivalent to the perceived environment.

Social cognitive models of behavior, including both socio-cognitive theory (Bandura 1986) and theory of planned behavior (Ajzen 1991), inherently recognize the important distinction between the built environment as it is objectively measured and the built environment as perceived by individuals. According to these models, the built environment may influence behavior but it will probably do so by influencing the perceptions of individuals. Perceptions of the environment reflect an individual's 
interaction with the actual environment, involving an awareness and perception of the outside world through their primary receptive senses. All these sensory inputs are then integrated to form a spatial cognitive representation of the environment, which has been called a mental map of the environment by geographers (Sherrington 1961; Golledge and Stimson 1997). Further, a mix of individual and societal factors, such as gender, social class, personal values, place attachment, local culture, social norms, past experiences, physical capacity, and individual personal characteristics may influence the individual's perception of the built environment. Therefore, different people might form different mental maps of the same built environment and consequently behave differently (Ewing and Handy 2009).

Despite the recognized difference, little research has explored the relationship between the objective environment and perceived environment, and their relative associations with bicycling behavior. Improved understanding of different effects of objective and perceived environment on bicycling behavior could be important for understanding the mechanism underlying the built environment-bicycling relationship and for identifying potential interventions (Emond \& Handy, 2012; Forsyth \& Oakes, 2013; Handy, et al., 2006).

To help fill this research gap, we tested the relative effects of the perceived and objective environment on bicycling behavior through multivariate models using data from a random survey of adults in the Portland, Oregon, metropolitan region. The aim was to present a solid analysis of the choice to bicycle and bicycling frequency, focusing on the roles of perceived versus objective measures of the bicycling environment. 


\section{Methods}

\section{Data and Measures}

The data were obtained through a random phone survey of adults in the Portland, Oregon region. The sample included both land-line and mobile phone numbers and was conducted from July 19 through August 10, 2011. A total of 902 interviews were completed. Of those, 130 (14 percent) were completed on mobile phones. The mobile phone sample was used to help reduce sampling bias, particularly among younger adults. The overall response rate was $20 \%$. More details about the survey are available in Jennifer Dill and McNeil (2013a). This analysis uses the 616 observations with complete data.

The dependent variable was derived from the following survey questions: (1) "Over the past month, about how many days did you ride a bike?", (2) “Of those days, about how many days did you ride a bike to work or school?", and (3) "Of those days, about how many days did you ride a bike to shop, dine out, run errands, visit people, go to a movie, or similar activities?" Considering that different associations may exist between the built environment and transportation bicycling versus recreational bicycling, we only included transportation bicycling to create the dependent variable by using number of bicycling days for commuting and daily errands (shop, dine out, etc.).

Variables for socio-demographic characteristics and perceptions of the built environment were derived from survey questions. Socio-demographic variables include age, gender, income, and whether there is at least one child in the household. Perceived environment 
variables were derived from the respondent's level of agreement with the following statements: (1) "There are off-street bike trails or paved paths in or near my neighborhood that are easy to get to"; (2) "There are bike lanes that are easy to get to"; (3) "There are quiet streets, without bike lanes, that are easy to get to on a bike"; and (4) "Many of the places I need to get to regularly are within bicycling distance of my home." A four-point Likert scale was used to measure respondent's agreement to these statements.

Different objective measures of the built environment were created to correspond with the perceived measures (Table 8). For example, several objective measures, including miles of off-street bike path within 1/8-, 1/4- 1/2- and 1-mile circular and network buffers around each participant's household and distance from the household to the nearest offstreet bike path, were created to match with perceptions of off-street paths. Similar objective measures were created to match with the perception of bike lanes and quiet streets. For the perceived measure of "Many of the places... within bicycling distance of my home," we used the number of retail jobs within different buffer widths as the corresponding objective measure. All the candidate objective measures were initially tested in the models, and the following four objective measures were used for the final estimations because they have the best associations with the perception measures: miles of off-street bike path within 1/2-mile circular buffer, miles of bike lanes within 1/2-mile circular buffer, miles of minor streets within 1/2-mile circular buffer, and number of retail jobs within 1/2-mile circular buffer. Objective environmental data, such as street network and land use information, are from the Regional Land Information System 
(RLIS) from Portland Metro, the region's transportation and land use planning agency. Information on retail jobs was acquired from Longitudinal Employer-Household Dynamics (LEHD) data from the U.S. Census Bureau.

In addition to the socio-demographics and built environment variables, we included variables which might influence bicycling behavior, such as hilliness, respondents' health condition, respondents' attitudes towards their daily travel, and their social environment for bicycling. Health condition was subjectively assessed by the respondents using a 5point scale from poor (1) to excellent (5). Eight attitudinal variables were derived from a factor analysis based on 26 survey questions (see appendix A) that assess the respondents' attitudes regarding their daily travel using a 4-point scale from strongly disagree (1) to strongly agree (4). The social environment variable was the mean score for five survey questions: (1) "Most people who are important to me, for example my family and friends, think I should bike more"; (2) "Most people who are important to me, for example my family and friends, would support me in using a bike more"; (3) "People I live with ride a bike to get to places, such as errands, shopping, and work"; (4) "Many of my friends ride a bike to get to places, such as errands, shopping, and work"; (5) "Many of my coworkers ride a bike to get to work." All of these survey questions had a 5-point scale from strongly disagree (1) to strongly agree (5). Variable descriptions are listed in Table 9Error! Reference source not found. 
Table 8: Paired Perceived and Objective Measures of Bike Environment

Perceived Measures (Survey)

\section{Candidate Objective Measures (GIS)}

There are off-street bike trails or paved paths in or near my neighborhood that are easy to get to. (Likert Scale: 1-4)

There are bike lanes that are easy to get to. (Likert Scale: 1-4)

There are quiet streets, without bike lanes, that are easy to get to on a bike. (Likert Scale: 1-4)

Many of the places I need to get to regularly are within bicycling distance of my home. (Likert Scale: $1-5)$
Miles of off-street bike path within 1/8-, 1/41/2- and 1-mile circular and network buffers

Distance to the nearest off-street bike path

Miles of bike lane within 1/8-, 1/4- 1/2- and 1mile circular and network buffers

Distance to the nearest bike lane

Miles of minor streets within 1/8-, 1/4- 1/2and 1-mile circular and network buffers

Distance to the nearest minor street

\# retail jobs within 1/8-, 1/4- 1/2- and 1-mile circular and network buffers 
Table 9: Descriptive Analysis of Variables

\begin{tabular}{|c|c|c|c|c|c|}
\hline Variable & Obs & Mean & Std. Dev. & Min & Max \\
\hline \multicolumn{6}{|l|}{ Dependent Variables } \\
\hline Whether the respondent bicycled for utilitarian purpose in the past month & 616 & 0.32 & 0.47 & 0 & 1 \\
\hline \# days of utilitarian bicycling in the past month & 214 & 8.99 & 8.88 & 1 & 31 \\
\hline \multicolumn{6}{|l|}{ Socio-Demographics } \\
\hline Age & 616 & 51.28 & 14.75 & 18 & 88 \\
\hline Children in household & 616 & 0.35 & 0.48 & 0 & 1 \\
\hline Female & 616 & 0.58 & 0.49 & 0 & 1 \\
\hline Total household income per year ${ }^{a}$ & 616 & 4.23 & 1.88 & 0 & 7 \\
\hline \multicolumn{6}{|l|}{ Health Condition } \\
\hline General health condition & 616 & 3.65 & 0.93 & 1 & 5 \\
\hline \multicolumn{6}{|l|}{ Built Environment } \\
\hline Perception of off-street bike paths & 616 & 2.69 & 1.23 & 1 & 4 \\
\hline Perception of bike lanes & 616 & 2.74 & 1.18 & 1 & 4 \\
\hline Perception of quiet streets easy for bike & 616 & 3.43 & 0.85 & 1 & 4 \\
\hline Perception of many bike destinations nearby & 616 & 3.11 & 1.62 & 1 & 5 \\
\hline Miles of off-street bike path within 1/2-mile buffer & 616 & 0.22 & 0.41 & 0.00 & 2.39 \\
\hline Miles of bike lane within 1/2-mile buffer & 616 & 1.15 & 0.93 & 0.00 & 5.46 \\
\hline Miles of minor street within 1/2-mile buffer & 616 & 12.43 & 4.01 & 0.32 & 22.50 \\
\hline \# retail jobs $(000)$ within 1/2-mile buffer & 616 & 0.21 & 0.42 & 0 & 4.442 \\
\hline \multicolumn{6}{|l|}{ Attitudes (factor scores) } \\
\hline Pro-bike & 527 & -0.07 & 0.98 & -2.45 & 1.88 \\
\hline Pro-transit & 527 & -0.02 & 0.99 & -2.26 & 2.45 \\
\hline Car is safer than other modes & 527 & 0.03 & 0.95 & -2.47 & 2.80 \\
\hline Focus on fuel efficiency and the environment & 527 & 0.02 & 0.94 & -3.76 & 2.11 \\
\hline Pro-walk & 527 & 0.15 & 0.97 & -3.85 & 2.72 \\
\hline Pro-environment & 527 & 0.16 & 1.00 & -3.49 & 2.77 \\
\hline Anti-car & 527 & -0.07 & 1.00 & -2.39 & 3.41 \\
\hline Travel is negative & 527 & -0.05 & 0.94 & -4.08 & 1.96 \\
\hline \multicolumn{6}{|l|}{ Social Environment } \\
\hline Supportive social environment for bicycling & 616 & 2.69 & 0.98 & 1 & 5 \\
\hline \multicolumn{6}{|l|}{ Terrain } \\
\hline$\%$ area with a slope greater than 25 percent & 616 & 0.19 & 0.21 & 0.00 & 0.93 \\
\hline
\end{tabular}

${ }^{\mathrm{a}} 0=$ Less than $\$ 15,000 ; 1=\$ 15,000$ to less than $\$ 25,000 ; 2=\$ 25,000$ to less than $\$ 35,000 ; 3=\$ 35,000$ to less than $\$ 50,000 ; 4=\$ 50,000$ to less than $\$ 75,000 ; 5=\$ 75,000$ to less than $\$ 100,000 ; 6=\$ 100,000$ to less than $\$ 150,000 ; 7=\$ 150,000$ or more

\section{Statistical Analysis}

The dependent variable is the number of days that the respondents bicycled for transportation purposes.

Considering the abundance of zeros and skewed distribution of non-zero count, two-part models are typically employed to address the data with these issues (Ridout, Demétrio, \& Hinde, 1998). Also, we believe that there is a huge gap between those who biked and 
those not, and it is more appropriate to predict whether biked or not versus frequency of bike separately. Previous studies have found that the factors influencing whether the respondents bicycle (bicycling propensity) and how often they bicycle (bicycling frequency) can differ (Noland, Deka, \& Walia, 2011), we employed a similar two-step modeling strategy as Sallis, et al. (2013). First, a binary logistic model was employed to estimate whether the respondent had bicycled for transportation in the past month or not. Second, for those that had bicycled for transportation in the past month, a multivariate linear model was used to predict the frequency of transportation bicycling over the past month. The model structure is specified as:

- $\operatorname{Pr}(\mathrm{Y}=0)=1-\pi, 0 \leq \pi \leq 1$

- $\quad Y=B_{1} X+e ; y=1,2,3, \ldots$

Where $\pi=\operatorname{Pr}(\mathrm{Y}>0)$ is the probability of the respondent biked over the past month.

We also explored other model specifications, including a Hurdle model (Mullahy, 1986), which combined the two steps and predicted the propensity and frequency simultaneously. However, there were no meaningful differences in coefficients compared with the results from two separate models.

To compare the different associations of perceived and objective measures of the built environment with bicycling behavior, we estimated four models for each of the two dependent variables. The first model used perceived measures only, the second model used objective measures only, the third model included both, and the fourth model further controlled for the attitudes and social environment. All the models also controlled for 
socio-demographics, respondents' health condition, and terrain. In addition, because participants came from 26 cities within Portland Metro we used clustered standard errors in all models. The Variances Inflation Factor (VIF) is also derived in order to detect multicollinearity, and the VIFs in all models are less than 2.5 , indicating no collinearity in the model according to Allison (1999).

\section{Results}

Table 10 presents the results of the binary logistic models, which predict the propensity that the respondent bicycled for commuting and/or daily errands in the past month. First of all, the model fit indices (pseudo R-squared) indicate that Model 3 with both types of measures has the best model fit among the first three models, and Model 1 with only perceived measures is about the same as Model 2 with only objective measures. This may indicate that including both objective and perceived measures in bicycling model helps to improve the model fit. However, even Model 3 is only able to explain about $16 \%$ of the variation in the dependent variable, while Model 4 which includes attitudes and social environment improved the model fit significantly. This may imply that bicycling propensity is determined more by attitudes and the social environment than the built environment.

Secondly, different perceived and objective measures of the built environment were found significant in predicting odds of bicycling. For example, Model 1 indicates that if the respondent perceived that there are many bikeable destinations near the home, she or he would have been more likely to bicycle for transportation in the past month; however, the corresponding objective measure, number of retail jobs around respondent's home, 
was not significant in Model 2. Conversely, the objective measure, miles of minor streets, was found significant in Model 2, but its corresponding perceived measure, perception of quiet streets in the neighborhood, was not significant in Model 1. These two measures remain significant in Model 3 where both perceived and objective measures are controlled for, indicating that the perceived and objective built environment have independent effects on the odds of bicycling.

Further, it is interesting to note that controlling for attitudes and social environment has an impact on the coefficients of the built environment variables (Model 4). For example, the perceived measure of bike destinations becomes insignificant in Model 4, while the other three insignificant objective measures in Model 3, including miles of off-street bike paths, miles of bike lanes and number of retail jobs, become significant in Model 4, and the absolute magnitudes of coefficients for these variables increase significantly. Results of Model 4 suggest that investment on bicycling infrastructure, such as bicycle lanes, offstreet bicycle paths, and low traffic streets, encourages transportation bicycling. Unexpectedly, the objective measure of accessibility to retail was negatively associated with odds of transportation bicycling. It is possible that people living very close to retail (1/2-mile) prefer walking to these destinations rather than bicycling.

The socio-demographic variables are relatively consistent among the models in terms of the magnitude and significance level of the coefficients, indicating that using either objective or perceived measures of the built-environment does not influence the effect of these variables on odds of bicycling. Also these socio-demographic variables had expected associations with odds of bicycling and these associations are consistent with 
previous literature (Jennifer Dill \& Voros, 2007; Vernez-Moudon, et al., 2005; Winters, et al., 2010). For example, those who are male, relatively young, and in good health are more likely to bicycle. In addition, most attitudinal variables and the social environment are significant and usually with the expected signs. The large increase in the pseudo-R2 value indicates that these attitudinal variables play important roles in explaining the propensity to bicycle, suggesting interventions aimed at changing personal attitudes and social culture could be effective in encouraging transportation bicycling. 
Table 10: Binary Logit Models for the Odds of Bicycling for Transportation

\begin{tabular}{|c|c|c|c|c|c|}
\hline & $\begin{array}{l}\text { Model 1 } \\
\text { SD+PE }\end{array}$ & $\begin{array}{l}\text { Model } 2 \\
\text { SD+OE }\end{array}$ & $\begin{array}{c}\text { Model 3 } \\
\text { SD+PE+OE }\end{array}$ & $\begin{array}{r}\text { Mode } \\
\mathrm{SD}+\mathrm{PE}+\mathrm{O}\end{array}$ & 4 \\
\hline Variables & Coef. & Coef. & Coef. & Coef. & \\
\hline Age & -0.037 & -0.037 & -0.038 & -0.022 & $* * *$ \\
\hline Whether child in household & -0.010 & -0.010 & -0.033 & -0.006 & \\
\hline Female & -0.834 & -0.875 & -0.840 & -0.791 & $* *$ \\
\hline Total household income per year & 0.041 & 0.028 & 0.035 & 0.023 & \\
\hline General health condition & $0.310 \quad * * *$ & $0.290 \quad * * *$ & 0.306 & 0.277 & $* *$ \\
\hline Perceived there are off-street bike paths & 0.003 & & 0.091 & 0.118 & \\
\hline Perceived there are bike lanes & 0.081 & & 0.023 & -0.144 & \\
\hline Perceived there are quiet streets easy for bikng & 0.085 & & 0.013 & -0.070 & \\
\hline Perceived there are many bikeable destinations & 0.302 & & 0.264 & -0.004 & \\
\hline Miles of off-street bike path (GIS) & & 0.115 & 0.047 & 0.352 & $* * *$ \\
\hline Miles of bike lane (GIS) & & -0.028 & -0.052 & 0.313 & $* * *$ \\
\hline Miles of minor street (GIS) & & $0.118 \quad * * *$ & $0.101 \quad * * *$ & 0.156 & $* * *$ \\
\hline Number of retail jobs (GIS) & & -0.027 & -0.087 & -0.757 & $* * *$ \\
\hline Pro-bike & & & & 1.329 & $* * *$ \\
\hline Pro-transit & & & & 0.194 & $*$ \\
\hline Car is safer than other modes & & & & -0.144 & $*$ \\
\hline Focus on fuel efficiency and the environment & & & & 0.194 & $*$ \\
\hline Pro-walk & & & & -0.079 & \\
\hline Pro-environment & & & & -0.263 & ** \\
\hline Anti-car & & & & 0.223 & $* *$ \\
\hline Limits driving & & & & 0.163 & ** \\
\hline Supportive social environment for bicycling & & & & 0.671 & $* * *$ \\
\hline$\%$ area with a slope $>25 \%$ & $-1.432 \quad * * *$ & $-1.347 \quad * * *$ & -1.033 & -0.534 & \\
\hline Constant & -1.000 & -0.870 & $-1.921 \quad * * *$ & -4.197 & $* * *$ \\
\hline \multicolumn{6}{|l|}{ Model Statistics } \\
\hline Number of observations & 616 & 616 & 616 & 527 & \\
\hline Log-likelihood at 0 & -386.81 & -386.81 & -386.81 & -335.67 & \\
\hline Log-likelihood at convergence & -334.93 & -337.33 & -326.97 & -211.39 & \\
\hline Pseudo R2 & 0.134 & 0.128 & 0.155 & 0.370 & \\
\hline
\end{tabular}

Note: $* \mathrm{p}<.1, * * \mathrm{p}<.05, * * * \mathrm{p}<.01$

SD: Socio-demographics; PE: Perceived environment; OE: Objective environment; AT: Attitudes

Table 11 presents the results of multivariate linear models for bicycling frequency in the

past month. Consistent with findings from the binary logistic models, the model (Model 3) including both objective and perceived measures had the best model fit among the first 
three models; about $18 \%$ of the variation in bicycling frequency is accounted for by this model. The model with only perceived measures (Model 1) had stronger power than the model with only objective measures (Model 2).

In contrast to the models predicting bicycling propensity, more of the built environment variables, measured objectively or subjectively, are significant in predicting bicycling frequency. For example, both the perception of quiet streets and objectively measured miles of minor streets are positively associated with bicycling frequency, indicating that low-traffic streets can encourage more transportation bicycling. Similarly, both perceived and objective measures of destinations within bicycling distance are significant in predicting bicycling frequency, suggesting that proximity to many destinations promotes more frequent bicycling. Interestingly, the objective and perceived measures of off-street bike paths have converse associations with bicycling frequency; people who perceive that there are off-street bike paths in their neighborhood bicycle less frequently for transportation, while those who actually live close to off-street bike paths bicycle more frequently. It is possible that frequent bicyclists have higher expectations for the amount of bicycle infrastructure within their neighborhood. It is also possible that occasional bicyclists overestimate the presence of the off-street bike paths in their neighborhood. When both types of measures of the built environment are included simultaneously in Model 3, three pairs are significant, suggesting independent effects of the perceived and actual built environment on bicycling frequency. Consistent with some of the literature (Jennifer Dill \& Voros, 2007; Vernez-Moudon, et al., 2005), neither measure of striped 
bicycle lanes is associated with more bicycling frequency, though they were associated with the propensity to bicycle when measured objectively and controlling for attitudes.

After controlling for attitudes and social environment, all the significant built environment variables in Model 3 remain significant except the objective measure of minor streets. Further, most of the socio-demographic variables are relatively consistent among models. Those who are male, relatively young, have good health condition and those without children bicycle for transportation more frequently. It is interesting to note that having a child is not significantly associated with odds of bicycling but negatively correlated with frequency of bicycling.

Finally, most of the attitudinal variables are significant in predicting the bicycling frequency for transportation purposes, and the adjusted R2 increased from 18\% to $29 \%$ by including these variables in the model, suggesting that attitudes towards travel play a great role in how often people choose to bicycle to work and for daily errands. By contrast, the social environment was not significantly associated with bicycling frequency. This may be due to the relative lack of variation of this variable in the sample of people who did bicycle for transportation. 
Table 11: Multivariate Linear Models for Bicycling Frequency

\begin{tabular}{|c|c|c|c|c|c|c|c|c|}
\hline \multirow[b]{2}{*}{ Variables } & \multicolumn{2}{|c|}{$\begin{array}{c}\text { Model 1 } \\
\text { SD+PE }\end{array}$} & \multicolumn{2}{|c|}{$\begin{array}{l}\text { Model } 2 \\
\text { SD+OE }\end{array}$} & \multicolumn{2}{|c|}{$\begin{array}{c}\text { Model 3 } \\
\text { SD+PE+OE }\end{array}$} & \multicolumn{2}{|c|}{$\begin{array}{c}\text { Model } 4 \\
\text { SD+PE+OE } \\
+\mathrm{AT} \\
\end{array}$} \\
\hline & Coef. & & Coef. & & Coef. & & Coef. & \\
\hline Age & -0.076 & $* *$ & -0.079 & & -0.087 & $* *$ & -0.057 & $* *$ \\
\hline Whether child in household & -2.443 & $* *$ & -1.816 & $*$ & -2.186 & $* *$ & -1.444 & $*$ \\
\hline Female & -2.646 & $* * *$ & -3.564 & $* * *$ & -3.072 & $* * *$ & -2.623 & $\begin{array}{l}* * \\
*\end{array}$ \\
\hline Total household income per year & 0.257 & & 0.261 & & 0.326 & & 0.374 & \\
\hline General health condition & 0.887 & $* *$ & 1.281 & $* *$ & 0.984 & $* *$ & 0.039 & \\
\hline Perceived there are off-street bike paths & -1.421 & $* *$ & & & -1.341 & $* *$ & -1.362 & $\begin{array}{l}* * \\
*\end{array}$ \\
\hline Perceived there are bike lanes & -0.076 & & & & -0.160 & & -0.303 & \\
\hline $\begin{array}{l}\text { Perceived there are quiet streets easy for } \\
\text { bicycling }\end{array}$ & 1.993 & $* *$ & & & 1.700 & $* *$ & 1.735 & $* *$ \\
\hline $\begin{array}{l}\text { Perceived there are many bikeable } \\
\text { destinations }\end{array}$ & 1.980 & $* * *$ & & & 1.791 & $* * *$ & 1.158 & $\begin{array}{l}* * \\
*\end{array}$ \\
\hline Miles of off-street bike path (GIS) & & & 2.910 & $* * *$ & 3.027 & $* * *$ & 2.626 & $\begin{array}{l}* * \\
*\end{array}$ \\
\hline Miles of bike lane (GIS) & & & -0.233 & & 0.066 & & -0.356 & \\
\hline Miles of minor street (GIS) & & & 0.509 & $* * *$ & 0.308 & $* * *$ & 0.121 & \\
\hline Number of retail jobs (GIS) & & & 2.733 & $* * *$ & 1.331 & $*$ & 2.058 & $* *$ \\
\hline Pro-bike & & & & & & & 2.821 & $* *$ \\
\hline Pro-transit & & & & & & & 1.365 & $\begin{array}{l}* * \\
*\end{array}$ \\
\hline Car is safer than other modes & & & & & & & -1.400 & $* *$ \\
\hline $\begin{array}{l}\text { Focus on fuel efficiency and the } \\
\text { environment }\end{array}$ & & & & & & & 0.555 & \\
\hline Pro-walk & & & & & & & -0.163 & \\
\hline Pro-environment & & & & & & & -0.335 & \\
\hline Anti-car & & & & & & & 1.281 & $* *$ \\
\hline Limits driving & & & & & & & -1.044 & $*$ \\
\hline $\begin{array}{l}\text { Supporting social environment for } \\
\text { bicycling }\end{array}$ & & & & & & & -0.050 & \\
\hline$\%$ area with a slope $>25 \%$ & -2.248 & & 1.166 & & -0.099 & & -0.522 & \\
\hline Constant & 0.504 & & 0.847 & & -3.400 & & 1.612 & \\
\hline \multicolumn{9}{|l|}{ Model Statistics } \\
\hline Number of observations & 198 & & 198 & & 198 & & 176 & \\
\hline Adjust R2 & 0.164 & & 0.083 & & 0.184 & & 0.288 & \\
\hline
\end{tabular}

Note: $* \mathrm{p}<.1, * * \mathrm{p}<.05, * * * \mathrm{p}<.01$

SD: Socio-demographics; PE: Perceived environment; OE: Objective environment; AT: Attitudes 


\section{Discussion}

Social-cognitive theory (Bandura, 1986) has pointed to an important distinction between the built environment as it is objectively measured and the built environment as perceived by individuals. Exploring the relationship between the objective and perceived built environment and their relative effects on travel is an important research question in developing theories linking the built environment and travel behavior. Even so, very few empirical studies have examined this research question. To partially fill in the gap in the literature, this paper explored the relative effects of the perceived and objective environment on bicycling by modeling the bicycling behavior of 616 adults in Portland, Oregon.

Based on the model results of this study, we found that the perceived and objective builtenvironment have independent associations with bicycling propensity and bicycling frequency. Under some circumstances, models with only perceived measures could lead to completely different conclusions than models with only objective measures. This might be one of the reasons for the inconsistent findings among the current studies linking the built environment with bicycling behavior. This analysis also found that the models with both perceived and objective measures explain more than models with just one or the other. We, therefore, recommend future bicycling studies should include both types of measures when possible.

Further, by comparing model results, we found that when the models do not control for attitudes, perceived measures of the built environment sometimes have a stronger association with bicycling than objective measures. This result is expected because 
theoretically human behavior is directly determined by perceptions rather than actual environment (Boulding, 1956). Also, the objective built environment may influence bicycling behavior through affecting one's perception of the environment (Ma, et al., 2014). A structural equation modeling approach would allow us to explore that possibility. Future studies should further test the possible mediation effect of perceptions between the objective built environment and bicycling behavior.

Given these findings, interventions aimed at improving people's perceptions of the built environment should be a complement to the current policies focusing on the physical design of the built environment. Our results are consistent with findings from recent studies that interventions aimed at changing perceptions can be as important as built environmental support in influencing bicycling (Emond \& Handy, 2012; Forsyth \& Oakes, 2013). Programs distributing marketing materials containing information about where safe bike routes are, safety tips for bicycling, and bicycle-accessible businesses and destinations in the neighborhood, along with regular public bicycling activities can familiarize residents with the bike-friendly designs within their neighborhood. This may help residents improve their perceptions of the bicycling environment.

In addition, this study found there are similarities as well as differences between models for bicycling propensity and models for bicycling frequency. Most of the sociodemographic characteristics and attitudes were important and consistent factors in determining both whether and how much people bicycle for commuting and/or daily errands. However, there were some differences. For example, having children in the household was negatively associated with bicycling frequency, but did not affect the odds 
of bicycling. After controlling for attitudes, perceptions of the environment were not significant predictors of bicycling propensity, butwas associated with bicycling frequency — though in one case (bike paths) in an unexpected way. Also after controlling for attitudes, all four objective measures of the environment were associated with bicycling propensity, but only two of them (paths and retail jobs) were associated with bicycling frequency. This may indicate that other factors not measured here, such as the complexity of travel patterns and other constraints, have a greater influence on bicycling frequency. In other words, a good physical environment may be necessary to bicycle at all, but it may not be enough for some people to overcome other barriers and bicycle frequently.

Consistent with previous studies on bicycling (Handy \& Xing, 2011; Heinen, Maat, \& van Wee, 2011), we also found that people's attitudes and social environment play important roles on their bicycling behavior, and therefore interventions programs aiming to encourage positive attitudes and supportive culture for bicycling are necessary.

This study has several limitations and future studies are needed. First, more complete and precise measures of the objective and perceived environment would be useful. The objective and perceived measures do not match up perfectly in this study. Measurement error in GIS measures may also contribute to the mismatch between objective and perceived measures. Major measurement error in GIS-based measures can be introduced by incomplete records of the built environmental data, lack of information on the quality and size of the infrastructure and business establishments, and different buffer size used for defining the neighborhood. In particular, our objective measures only capture the 
quantity of bike infrastructure; however, the quality of the infrastructure may also affect the perceptions of the environment and bicycling. In addition, studies have found that there are significant discrepancies between researcher and resident-defined neighborhood boundaries (Coulton, Jennings, \& Chan, 2013; Coulton, Korbin, Chan, \& Su, 2001). Further, individuals who live in close proximity can differ markedly from one another in how they define the spatial dimension of their neighborhoods (Coulton, et al., 2001). In this study, we used a fixed buffer size (half-mile) as objective neighborhood boundary for all the residents. This brings another challenge to compare the objective and perceived neighborhood environment.

Second, longitudinal studies are necessary to make rigorous causal inferences among such factors as the physical environment, perceptions, and behavior. Longitudinal studies measuring perceptions before and after changes in the physical environment are very rare, yet would be valuable in understanding these relationships. Third, further investigations into the characteristics of people whose perceptions do not match the objectivelymeasured environment are needed. In particular is the question of why people living in presumably high-bikeable environments perceive it as a low-bikeable environment. Fourth, this study only measured bicycling behavior and not other travel modes or forms of physical activity. It would be useful to examine how the use of other modes and participation in other physical activities affects bicycling behavior. Also, comparing bicycling behavior to other modes (walking, transit, driving) using similar objective and perceived measures could be enlightening. 


\section{Conclusions}

The perceived and objective built-environment have independent associations with bicycling propensity and bicycling frequency, future bicycling studies should include both types of measures when possible. Both actual and perceived built environment are important for bicycling for transportation purposes. Installation of bicycling infrastructure, such as bicycle lanes, off-street bicycle paths, and low traffic streets, and improvements on accessibility encourage utilitarian bicycling. In addition to the actual changes of the built environment, interventions aimed at improving people's perceptions of the built environment are also necessary. Programs, such as neighborhood-based marketing and public bicycling events, may help residents improve their perceptions of the bicycling environment. In addition to the built environment, interventions programs aiming to encourage positive attitudes and supportive culture for bicycling are also necessary. Finally, factors associated with bicycling propensity and bicycling frequency are different, this suggest that it is useful to model them separately. 


\section{Chapter 6. Paper 2: The Objective vs. the Perceived Environment: What Matters for Bicycling? ${ }^{1}$}

\section{Introduction}

Bicycling has been well recognized as a sustainable travel mode and an important form of physical activity because of its environmental, economic, social and health benefits (Pucher \& Buehler, 2012). Among the factors influencing bicycling behavior, the built environment has attracted attention from both transportation and public health researchers. A growing number of studies link various features of the built environment to bicycling behavior, typically relying upon traditional utility theory (Cervero \& Duncan, 2003; Jennifer Dill \& Carr, 2003; Forsyth \& Oakes, 2013; Krizek \& Johnson, 2006; Nelson \& Allen, 1997; Parkin, et al., 2008; Vernez-Moudon, et al., 2005; Winters, et al., 2010). Most of these studies, particularly those at individual level, however, estimate models that leave a great deal unexplained. Moreover, while this literature establish correlations between the built environment and bicycling behavior, many people, even in "bike friendly" environments, choose not to bicycle for transportation. This implies that there are other important factors, in addition to the built environment, that may affect bicycling behavior.

According to socio-ecological model (Sallis, et al., 2002) and socio-cognitive model (Bandura, 1986), behavior is affected by intrapersonal factors such as attitudes and perceptions as well as by socio-demographics and the built environment. Using these

\footnotetext{
${ }^{1}$ Chapter 6. Paper 2. has been published by Springer in Transportation. Ma, L., Dill, J., \& Mohr, C. (2014). The objective versus the perceived environment: what matters for bicycling? Transportation, 41(6), 11351152. [DOI: 10.1007/s11116-014-9520-y].
} 
theoretical models, several recent studies on bicycling behavior (Emond \& Handy, 2012; Handy \& Xing, 2011; Handy, et al., 2010; Heinen, et al., 2011; Xing, et al., 2010) incorporated such intrapersonal factors as attitudes and perceptions into their statistical models. These studies found that intrapersonal factors had stronger effects on bicycling behavior than the built environment, even when accounting for socio-demographics. However, few of these studies explored the interactions between these intrapersonal factors and the built environment. For example, how might the built environment shape the attitudes and perceptions towards travel behavior? Exploring the associations between the built environment and intrapersonal factors could be important for understanding the mechanism underlying the built environment-behavior relationship and for identifying potential interventions (McMillan, 2005; Sallis, et al., 2006). One intrapersonal factor - a person's perception of the environment - may be a key link in this relationship. The often low explanatory power of models linking the environment and behavior may reveal the possible mismatch between the actual built environment and people's perceptions of the environment (Van Acker, et al., 2010). For example, an individual who lives in a neighborhood objectively evaluated as bicycle-friendly might not perceive the environment as safe and comfortable for bicycling because of their attitudes towards bicycling, and therefore may not bicycle.

This paper aims to explore this dimension of the research gap - the relationship between the objective (actual) environment and people's perceptions of the environment - which has not been studied extensively (Handy, 2005; Handy, et al., 2006). We begin by reviewing recent studies that use objective and perceived measures of the environment 
and that examine the mismatch between the two, followed by our conceptual model that draws on socio-cognitive models of behavior in order to account for the relationship between the objectively-measured built environment, subjective perceptions of the built environment, and bicycling behavior. The paper goes on to describe our data, variables and modeling approaches ("Methodology"). We use structural equation modeling (SEM) to model the bicycling behavior of 830 adults from three neighbourhoods in Portland, Oregon, USA. Finally, the paper summarizes the key findings, proposes policy implications, and discusses limitations and future research in the "Results and Discussion', section.

\section{Literature Review}

Among the studies linking the built environment to travel behavior or physical activity, three categories of built environment measures are generally used: perceived (selfreported) measures, observational measures, and GIS-based measures (Brownson, et al., 2009; Sallis, 2009). Perceived measures are generally obtained from interviews or selfadministered questionnaires, observational measures are typically derived from systematic observations or audits, and GIS-based measures are derived primarily from existing spatial data (e.g. street network, land-use data). The observational and GIS-based measures are generally considered objective measures because such measures objectively and unobtrusively quantify the built environmental attributes, while the perceived measures examine the way in which individuals perceive the reality of the built environment (Brownson, et al., 2009). Many previous studies on built environment and travel behavior or physical activity have included either perceived measures or objective 
measures, but few have considered both simultaneously. Further, some studies use objective and perceived measures interchangeably rather than distinguishing between them, in part because the perceived environment is typically assumed to be largely reflective of objective conditions (Wen, Hawkley, \& Cacioppo, 2006). Little previous research, however, questions whether perceptions of the built environment correspond to the objectively-measured built environment (Van Acker, et al., 2010).

Only recently are attempts being made to explore the relationship between the objective and perceived environment. Several recent empirical studies have found that the agreement between the two is poor to moderate based on kappa statistics (Ball, et al., 2008; Kirtland, et al., 2003; Lackey \& Kaczynski, 2009; McCormack, et al., 2007; McGinn, et al., 2007; 2009). Several of these studies further explored the factors contributing to the mismatch, and most concluded that levels of physical activity, sociodemographic characteristics of respondents, and quantity and quality of amenities in the built environment can influence the relationship between perceptions and objective reality. For example, McCormack et al. (2007) explored the moderating effect of age, gender, and walking behavior on the agreement between objective and perceived distance, and found the following: men tended to overestimate distance to the nearest supermarket compared to women; people who walked for utilitarian purposes for more than 25 minutes per week overestimated distance to the nearest supermarket compared with those walking less than 25 minutes per week; and those who walked for recreation for less than 130 minutes per week overestimated distance to the closest shop to a larger extent than those walking more than 130 minutes per week. Ball et al. (2008) found that mismatches 
between perceived and objectively-measured environments were more frequent among women who were younger, older, lower-income, less active, using fewer facilities, and living in the neighborhood for less than two years. In their research related to parks, Lackey and Kaczynski (2009) found that perceptions and the objective environment matched more often when people had some level of park-based physical activity and when there were more parks nearby; other important factors had to do with specific features of the parks. Gebel et al. (2009) identified that adults with lower educational attainment and lower income and those who were less physically active or overweight were more likely to perceive a highly walkable neighborhood as not very walkable.

Studies that include both perceptions and objective measures of the environment report a range of findings about the effects of both measures on physical activity. Several studies found that perceptions may play a much larger role than the objective environment. Scott et al. (2007), for example, used both perceived and objective measures of proximity to a variety of facilities to predict girls' physical activity and found that only the perception of easy access to facilities was associated with increased physical activity, while the objectively-measured number of facilities within a half- and one- mile area was not significantly related with physical activity. Prins et al. (2009) examined adolescent engagement in physical activities and also found that the perceived (but not objective) availability of sports facilities and parks was significantly associated with sports activities, walking, and cycling in leisure time. By comparing the characteristics of adults living in neighborhoods with objectively-defined high and low walkability, Gebel et al. (2009) found that participants living in neighborhoods with low walkability but who perceived it 
as high participated in more walking than those who lived in a highly walkable neighborhood but who perceived it as low. In their follow-up study (Gebel, et al., 2011), longitudinal survey data revealed that persons who perceived their highly walkable neighborhood as having low walkability decreased their walking and increased their body mass index (BMI) significantly more than those with perceptions that matched the objectively-measured environment. Similar findings are also reported in research on bicycling. For example, Dill and Voros (2007) found that objective measures of proximity to off-street trails and bike lanes were not associated with higher level of bicycling, while positive perceptions of the availability of bike lanes was associated with more bicycling. By analyzing the changes in behavior of people moving to new homes, Beenackers et al. (2012) found that if people perceived that there was better accessibility to a mix of services (shops, many places, public transit stops) after relocation, they would be more likely to take up bicycling after relocation; however, the objective measure destination accessibility was not significant in predicting the odds of taking up bicycling.

However, not all studies show a stronger correlation between perception and behavior than between objective environmental features and behavior. Lin and Moudon (2010), for example, found that objective measures of built environment had stronger associations with walking than subjective measures, and they suggested future studies should further investigate the potential relationship between objective and subjective measures by using socio-ecological approaches. By comparing the effects of objectively-measured accessibility to retail and self-reported proximity of destinations on walking for transportation and exercise, Rodriguez et al. (2009) found that perceived measures of 
proximity had weaker associations with walking than objective measures. They further concluded that objective features of neighborhoods may influence residents' behavior independently of their perceptions.

There are also studies that conclude that the perceived and objective environment have independent effects on behavior, and that both are important for interventions. In their study of a city with low walkability and a city with high walkability, Hoehner et al. (2005a) found that levels of physical activity for transportation and recreation are associated with different perceived and objective environmental measures after controlling for age, gender and education. The authors concluded that modifications of both actual and perceived environmental characteristics may change physical activity behavior. McGinn et al. (2007) also found independent effects of perceptions and objective measures on physical activity and recommended evaluating both. Handy et al. (2006) found that the accessibility to potential destinations, both objective and perceived, played an important role in promoting walking. There are also two studies that found independent effects of the objective and perceived built environment on bicycling behavior. Moudon et al. (2005) found that both an objective measure (distance to nearest trail) and a perception (perceived presence of combined trails and bicycle lanes in the neighborhood) were associated with the likelihood of bicycling. Emond and Handy (2012) also found that both objective and perceived distance to school was negatively associated with the probability of a student usually bicycling to and/or from school.

The mixed results in the literature regarding perceived and objective measures of environment may be due to characteristics of the environmental features studied, 
measurement error, different behavioral variables and different statistical methods. They also imply the relationships between the objective and perceived environment are complex. In addition, most of these studies are about walking or general physical activity, while similar research on bicycling is rather sparse.

\section{Conceptual Model}

Social cognitive models of behavior, including both socio-cognitive theory (Bandura, 1986) and theory of planned behavior (Ajzen, 1991), inherently recognize the important distinction between the built environment as it is objectively measured and the built environment as perceived by individuals. According to these models, the built environment may influence behavior but it will probably do so by influencing the perceptions of individuals. Perceptions may therefore, mediate the associations between the objective built-environment and behavior. Mediation effects of perception and other psychological factors (e.g. attitude, norms, intention) in environment-behavior studies have recently attracted attention (Heinen, et al., 2010; McCormack, Spence, Berry, \& Doyle-Baker, 2009; Van Acker, et al., 2013; Van Acker, et al., 2010; Weden, Carpiano, \& Robert, 2008).

Perceptions of the environment reflect an individual's interaction with the actual environment, involving an awareness and perception of the outside world through their primary receptive senses. All these sensory inputs are then integrated to form a spatial cognitive representation of the environment, which has been called a mental map of the environment by geographers (Golledge \& Stimson, 1997; Sherrington, 1961). Further, a mix of individual and societal factors, such as gender, social class, personal values, place 
attachment, local culture, social norms, past experiences, physical capacity, and individual personal characteristics may influence the individual's perception of the built environment. Therefore, different people might form different mental maps of the same built environment and consequently behave differently (Ewing \& Handy, 2009). Many factors, some of which were identified in the literature above, can influence the translation process from objective environment to subjective perceptions of the environment.

Based on these theories and empirical studies reviewed above, we constructed the conceptual model illustrated in Figure 5, in which we hypothesize that a person's perception of the environment directly affects their bicycling behavior while the objective environment may only have an indirect effect through influencing their perceptions. In other words, perception is a mediator between the objective environment and bicycling behavior. In addition to positing a connection between perceptions of the environment and bicycling behavior, we hypothesize that there is a feedback effect from bicycling behavior to perceptions. For example, frequent cyclists may be more familiar with the bicycling facilities and environment in their neighborhoods than those never bike and, therefore, have more positive perceptions of the environment. The model also includes individual and household socio-demographic characteristics. 


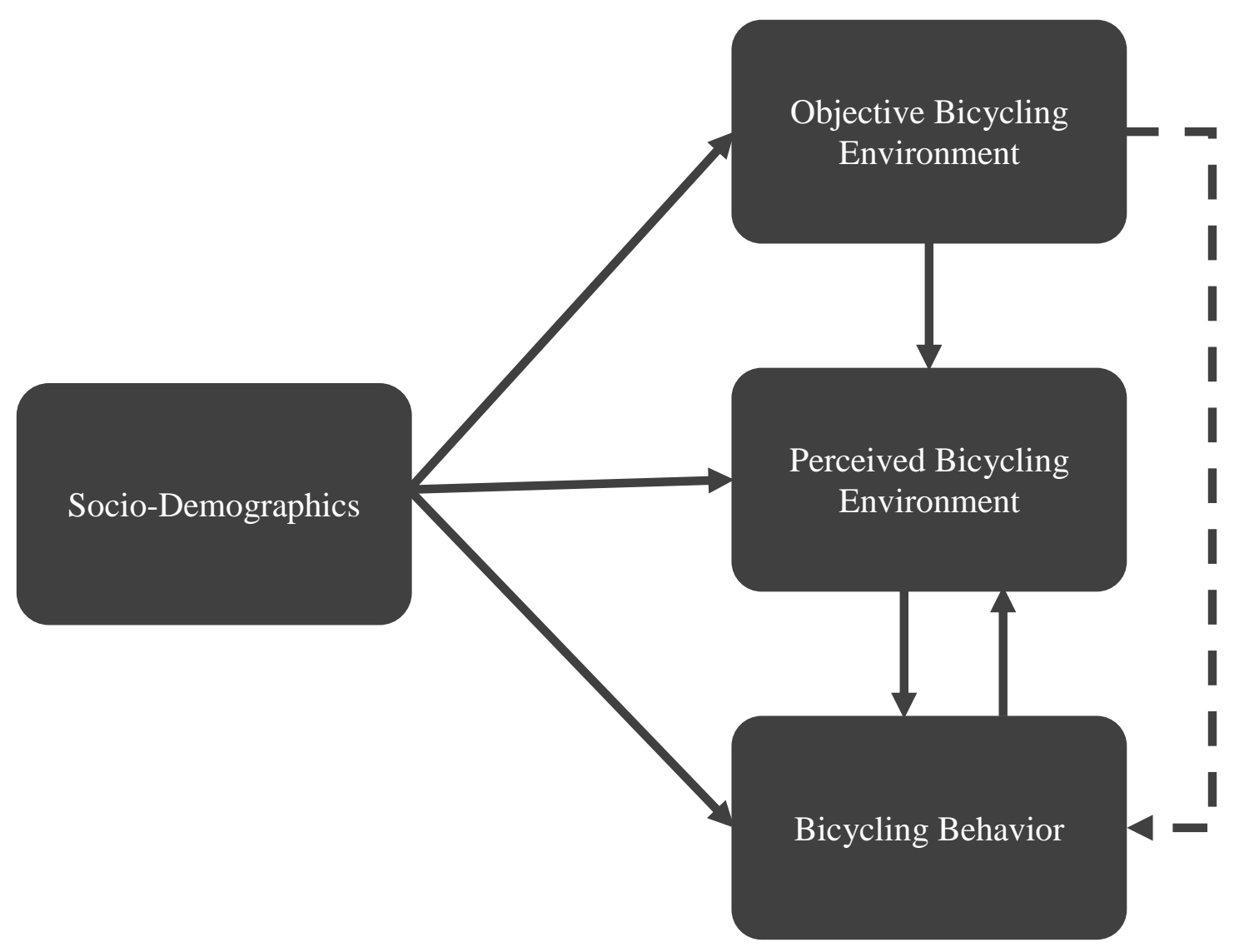

Figure 5: Conceptual Model

\section{Methodology}

\section{Data and Variables}

This paper uses data from a 2008 phone survey of adult residents in three neighborhoods in Portland, Oregon, USA. The survey targeted three neighborhoods located in the Southwest (SW), Northeast (NE) and Southeast (SE) quadrants of the city, all of which have distinct built environment characteristics (Figure 6). The Southwest neighborhood is characteristic of a post-WWII suburb, with curved streets and many culs-de-sacs, while the Northeast and Southeast neighborhoods are more "traditional" neighborhoods with a grid street pattern and remnants of streetcar suburbs. All three neighborhoods are within 
10 miles of downtown Portland. The Southwest neighborhood is much hillier than either the Northeast or Southeast.

The data collection effort was part of a larger evaluation of a City of Portland marketing program (SmartTrips) aimed at reducing driving by providing information and events for residents during summer months encouraging walking, bicycling, transit, and trip chaining. All three neighborhoods were targeted by the program - SW in 2008, SE in 2007, and NE in 2006. The survey collected information such as socio-demographic characteristics, perceptions of the built environment, bicycling frequency in the last month, and the nearest intersection. Details on the sampling methods can be found in Dill and Mohr (2010). In total, we received 1,159 responses to this survey from the three neighborhoods. After deleting respondents with missing data, 830 observations were used in model estimation. The spatial distribution of the responding households is shown in Figure 6.

Objective environmental data used in the study, such as street network and land use information, come from the Regional Land Information System (RLIS) from Portland Metro, the region's transportation and land use planning agency. Information about business establishments was acquired from ReferenceUSA. For this study, we extracted the following business types that are likely to be destinations that people would bicycle to in their neighborhoods: bank, restaurant, library, post office, grocery store, pharmacy, bars, bookstore, convenient store, fitness center, theater, and church. A one-mile radius Euclidean buffer was created for each respondent based on the household location. The 
objective measures of the environment were calculated by intersecting the household buffer with the spatial data from RLIS and ReferenceUSA.

Descriptions of variables are listed in Table 12. Some characteristics of this sample are presented in Table 13, and most of them differ significantly between the neighborhoods.

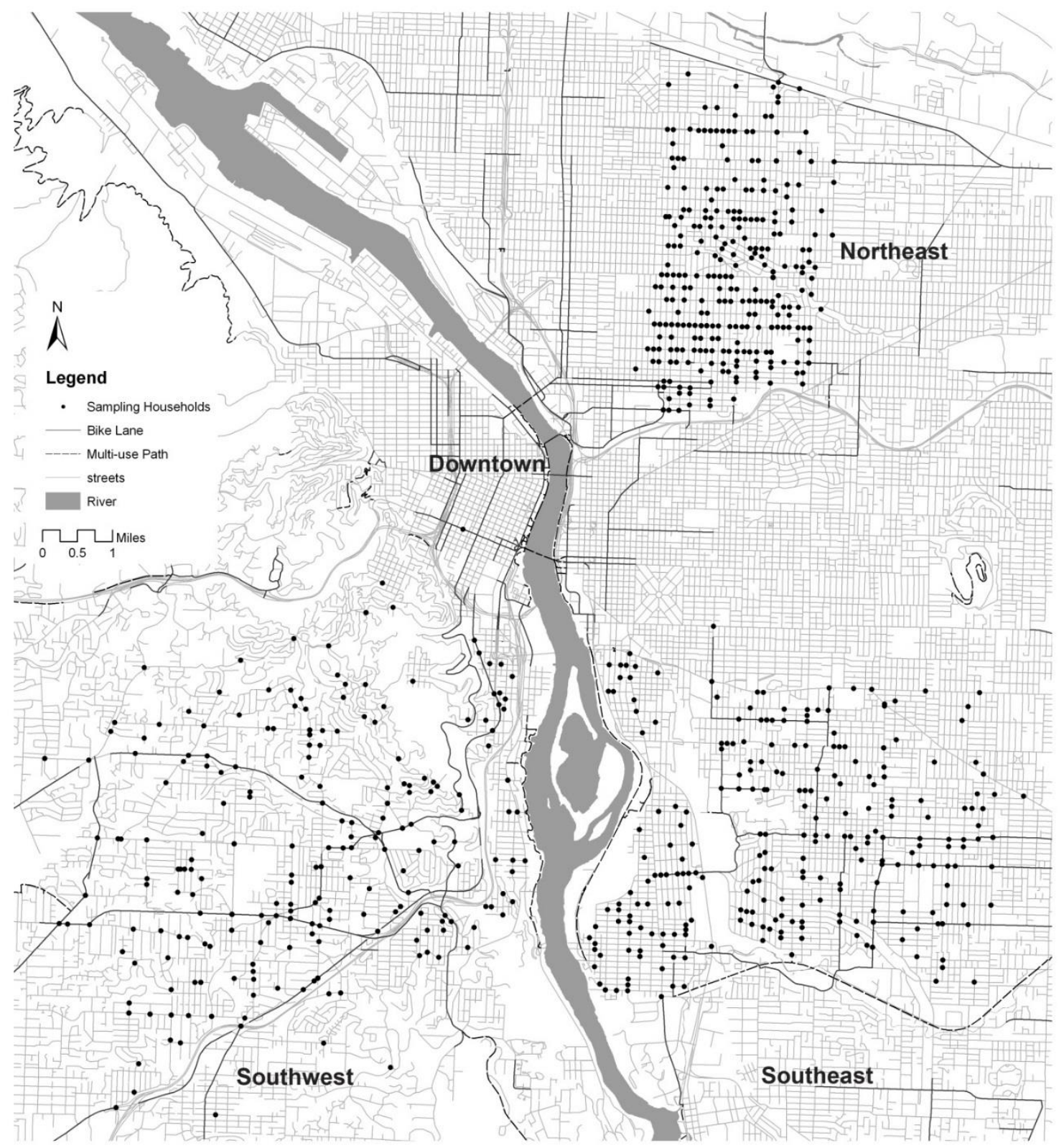

Figure 6: Household Sampling Distribution 
Table 12: Variable Descriptions

\begin{tabular}{|c|c|c|}
\hline Variable & Statement & Code or Unit \\
\hline \multicolumn{3}{|l|}{ Bike Behavior } \\
\hline Bicycling & $\begin{array}{l}\text { In the past month how often have you } \\
\text { ridden a bicycle from your home to } \\
\text { destinations nearby? }\end{array}$ & $\begin{array}{l}\text { 1=never; } 2=\text { Less than once a month; } 3=\text { One to } \\
\text { three times a month; } 4=\text { About once per week; } \\
5=\text { More than once a week }\end{array}$ \\
\hline \multicolumn{3}{|c|}{ Demographic Characteristics } \\
\hline Age & Age & Years (18-99) \\
\hline Education & $\begin{array}{l}\text { What is the last year of education you had } \\
\text { the opportunity to complete? }\end{array}$ & $\begin{array}{l}\text { 1=Less than 12th grade (not a high school } \\
\text { graduate); } 2=\text { High school graduate; } 3=\text { Some } \\
\text { college or other post-secondary education; } \\
\text { 4=College graduate; } 5=\text { Some post-graduate; } \\
6=\text { Master's degree or higher }\end{array}$ \\
\hline Income & Yearly total household income & $\begin{array}{l}1=\text { Less than } \$ 15,000 ; 2=\$ 15,000 \text { to less than } \\
\$ 25,000 ; 3=\$ 25,000 \text { to less than } \$ 35,000 ; \\
4=\$ 35,000 \text { to less than } \$ 50,000 ; 5=\$ 50,000 \text { to } \\
\text { less than } \$ 75,000 ; 6=\$ 75,000 \text { to less than } \\
\$ 100,000 ; 7=\$ 100,000 \text { to less than } \$ 150,000 ; \\
8=\$ 150,000 \text { or more }\end{array}$ \\
\hline Female & Gender of respondent & $0=$ male; $1=$ female \\
\hline Vehicle & Number of vehicles per adult in household & Count \\
\hline Child & $\begin{array}{l}\text { Whether there is at least one child in } \\
\text { household }\end{array}$ & Dummy: $1=$ yes \\
\hline \multicolumn{3}{|c|}{ Objective Environment } \\
\hline $\begin{array}{l}\text { Bike-friendly } \\
\text { Infrastructure }\end{array}$ & $\begin{array}{l}\text { Total miles of striped bike lanes, multi-use } \\
\text { path and low-traffic through streets (Daily } \\
\text { traffic volumes of less than } 3,000 \text { vehicles } \\
\text { and speeds of less than } 25 \mathrm{mph} \text { ) within one } \\
\text { mile of home }\end{array}$ & Mile \\
\hline Street Connectivity & $\begin{array}{l}\text { Number of street intersections with three or } \\
\text { more valences divided by total number of } \\
\text { intersections within one mile of home }\end{array}$ & Percentage \\
\hline Accessibility & $\begin{array}{l}\text { Number of business establishments within } \\
\text { one mile of home (bank, restaurant, library, } \\
\text { post office, grocery store, pharmacy, bars, } \\
\text { bookstore, convenient store, fitness center, } \\
\text { theater, and church) }\end{array}$ & Count \\
\hline Terrain & $\begin{array}{l}\text { Ratio of area with a slope less than } 25 \\
\text { percent within one mile of home }\end{array}$ & Percentage \\
\hline \multicolumn{3}{|c|}{ Perceived Environment } \\
\hline Easy & $\begin{array}{l}\text { For me to ride a bicycle for daily travel } \\
\text { from home would be easy }\end{array}$ & $\begin{array}{l}\text { 1=strongly disagree; } 2=\text { Somewhat Disagree; } \\
\text { 3=Neither Agree nor Disagree; } 4=\text { Somewhat } \\
\text { Agree; } 5=\text { Strongly Agree }\end{array}$ \\
\hline Safe & $\begin{array}{l}\text { I know where safe bike routes are in my } \\
\text { neighborhood }\end{array}$ & $\begin{array}{l}\text { 1=strongly disagree; } 2=\text { Somewhat Disagree; } \\
3=\text { Neither Agree nor Disagree; } 4=\text { Somewhat } \\
\text { Agree; } 5=\text { Strongly Agree }\end{array}$ \\
\hline Accessible & $\begin{array}{l}\text { Many of the places I need to get to } \\
\text { regularly are within bicycling distance of } \\
\text { my home }\end{array}$ & $\begin{array}{l}\text { 1=strongly disagree; } 2=\text { Somewhat Disagree; } \\
3=\text { Neither Agree nor Disagree; } 4=\text { Somewhat } \\
\text { Agree; } 5=\text { Strongly Agree }\end{array}$ \\
\hline
\end{tabular}


Table 13: Sample Characteristics

\begin{tabular}{|c|c|c|c|c|c|}
\hline & $\begin{array}{l}\text { Modern } \\
\text { SW }\end{array}$ & $\begin{array}{l}\text { Traditional } \\
\text { NE }\end{array}$ & $\begin{array}{l}\text { Traditional } \\
\text { SE }\end{array}$ & Combined & $\begin{array}{c}\text { p- } \\
\text { valu } \\
\mathbf{e}^{*}\end{array}$ \\
\hline \multicolumn{6}{|l|}{ Demographic Characteristics } \\
\hline Age & 55.7 & 54.2 & 53.3 & 54.3 & .153 \\
\hline Education & $\begin{array}{c}4.6 \\
\text { (above } \\
\text { college } \\
\text { grad) }\end{array}$ & $\begin{array}{l}4.6 \\
\text { (above college } \\
\text { grad) }\end{array}$ & $\begin{array}{l}3.8 \\
\text { (below college } \\
\text { grad) }\end{array}$ & $\begin{array}{c}4.4 \\
(\text { above } \\
\text { college grad) }\end{array}$ & .000 \\
\hline Income & $\begin{array}{c}5.7 \\
(\$ 50,000- \\
\$ 75,000)\end{array}$ & $\begin{array}{c}5.6 \\
(\$ 50,000- \\
\$ 75,000) \\
\end{array}$ & $\begin{array}{c}4.8 \\
(\$ 35,000- \\
\$ 50,000) \\
\end{array}$ & $\begin{array}{c}5.3 \\
(\$ 50,000- \\
\$ 75,000)\end{array}$ & .000 \\
\hline Ratio of Female & $52 \%$ & $50 \%$ & $51 \%$ & $51 \%$ & .912 \\
\hline Vehicles per adult & 1.13 & 0.92 & 0.96 & 0.99 & .000 \\
\hline Households with children & $32 \%$ & $44 \%$ & $35 \%$ & $37 \%$ & .018 \\
\hline \multicolumn{6}{|l|}{ Objective Environment } \\
\hline Miles of bike-friendly infrastructure & 9.2 & 15.0 & 11.6 & 12.3 & .000 \\
\hline$\%$ connected street & $72 \%$ & $95 \%$ & $89 \%$ & $86 \%$ & .000 \\
\hline \# business establishments & 51.1 & 136.5 & 65.5 & 90.0 & .000 \\
\hline $\begin{array}{l}\% \text { area with a slope less than } 25 \\
\text { percent }\end{array}$ & $88 \%$ & $99 \%$ & $98 \%$ & $96 \%$ & .000 \\
\hline \multicolumn{6}{|l|}{ Perceived Environment } \\
\hline $\begin{array}{l}\text { For me to ride a bicycle for daily } \\
\text { travel from home would be easy }\end{array}$ & 2.0 & 3.0 & 2.7 & 2.6 & .000 \\
\hline $\begin{array}{l}\text { I know where safe bike routes are in } \\
\text { my neighborhood }\end{array}$ & 3.2 & 3.9 & 4.0 & 3.7 & .000 \\
\hline $\begin{array}{l}\text { Many of the places I need to get to } \\
\text { regularly are within bicycling distance } \\
\text { of my home }\end{array}$ & 2.9 & 3.9 & 3.5 & 3.5 & .000 \\
\hline \multicolumn{6}{|l|}{ Bike Behavior } \\
\hline $\begin{array}{l}\text { In the past month how often have you } \\
\text { ridden a bicycle from your home to } \\
\text { destinations nearby? }\end{array}$ & $\begin{array}{l}1.8 \\
\text { (between } \\
\text { never and } \\
\text { <once) }\end{array}$ & $\begin{array}{l}2.6 \\
\text { (between } \\
\text { <once and 1-3 } \\
\text { times) }\end{array}$ & $\begin{array}{l}2.2 \\
\text { (between } \\
\text { <once and 1-3 } \\
\text { times) }\end{array}$ & $\begin{array}{l}2.2 \\
\text { (between } \\
\text { <once and 1- } \\
3 \text { times) }\end{array}$ & .000 \\
\hline $\mathrm{n}$ & 236 & 334 & 260 & 830 & \\
\hline
\end{tabular}




\section{Statistical Analysis}

\section{Mediation Effect Test}

The first purpose of this paper is to test the mediation effect of the perceived bicycling environment (PE) between the predictor, objectively measured bicycling environment (OE), and the outcome, bicycling behavior (Bicycling). Mediation is depicted in Figure 7.

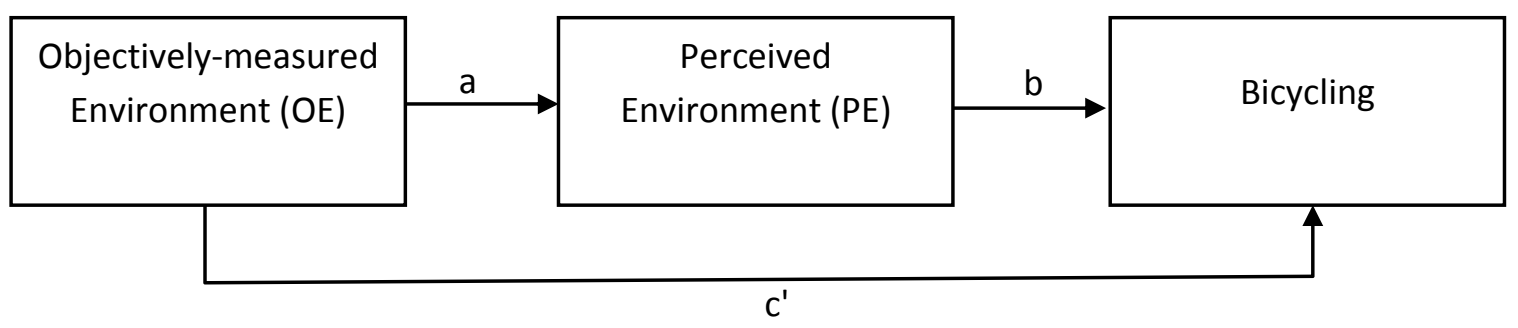

Figure 7: Mediation Effect

Paths $b$ and c' are direct effects of perceived environment and objective environment on bicycling, respectively, and the objective environment's influence on bicycling behavior through perception is called an indirect effect, which can be calculated by multiplying the coefficients of paths $a$ and $b$. The indirect effect indicates the portion of the relationship between objective environment and bicycling behavior that is mediated by perception. A four step approach proposed by Baron and Kenny (1986) has been the most common method to test the mediation effect (Hayes, 2009). This approach first requires the researcher to test whether the zero-order relationships among the variables exist. If these relationships are significant, and if the effect of the objective environment on bicycling (path c') becomes non-significant after controlling for perceptions, the findings support full mediation. However, if the objective environment's effect on bicycling (path c') 
remains significant after controlling for perceptions, the findings support partial mediation.

Even though the Baron and Kenny approach is the most widely-used method, recent developments with bootstrapping techniques afford higher power for testing indirect effects (Hayes, 2009; MacKinnon, Fairchild, \& Fritz, 2007). Also, bootstrapping methods are already implemented in some Structural Equation Model (SEM) software, and it is easy to obtain the indirect effects and confidence intervals in SEM. A bootstrapping method, therefore, was also used to test mediation hypothesis as a supplement to the Baron and Kenny approach. Bootstrapping is a process that resamples the data many times with replacement to generate an empirical representation of the entire sampling distribution (Hayes, 2009). In this study, we set to generate 5,000 samples, and the biascorrected bootstrap confidence intervals were used to detect mediation effects.

\section{Structural Equation Modeling}

Structural Equation Modeling (SEM) was used to test the mediation effect and estimate the conceptual model. Traditionally, we estimate a regression model by simply putting all causal factors as independent variables and behavior as the dependent variable. However, this method overlooks the significant interactions between these causal factors, which hinders our ability to explore the mechanism of travel behavior. For example, does the built environment directly affect bicycling behavior, or does it affect people's perceptions of the environment which then influences bicycling behavior? Compared with typical multivariate regression models, SEM enables researchers to solve simultaneous equations 
to disentangle these relationships between many independent variables and many dependent variables. Another advantage of SEM is its latent variable structure, which allows researchers to use several measured indicators to represent an unobserved factor. Using a latent variable also helps to remove the measurement and specification error from variables (Maruyama, 1997).

SEM assumes that observed variables are multivariate normal and violating this assumption can lead to underestimation of standard errors, even though it does not affect parameter estimates (Kline, 2005). We therefore conducted normal distribution tests for each model in AMOS 19.0, which can assess the univariate skewness and kurtosis of each variable contained in the model, as well as the joint multivariate kurtosis. Results showed that multivariate kurtosis values for all our tested models are less than 3.00, indicating that no severe non-normality exists. We also tested the Bollen-Stine bootstrap process and the bootstrapped parameter estimates to get the corrected model fit and standard errors; the model results, however, were very similar with the results from maximum likelihood estimation.

\section{Latent Constructs for Objective and Perceived Bicycling environment}

The primary purpose of this study is to explore the relationships among the objectivelymeasured environment, perceptions of the environment, and bicycling behavior. Latent constructs are therefore employed to represent the overall objective and perceived bicycling environment. This construct has two advantages. First, it avoids multicollinearity among the individual environmental elements. Second, the latent construct 
allows the conceptual variables (i.e. objective/perceived bicycling environment) to be defined in terms of the commonalities among the measured indicators, thereby removing error and unique variance from the construct (Maruyama, 1997).

In this study, two latent variables were created: the objective bicycling environment and the perceived bicycling environment. For objective bicycling environment, there are four measured indicators: bicycle-friendly infrastructure, street connectivity, accessibility, and terrain. For the perceived environment, there are three items measured: whether the individual feels it is easy to bicycle from home (Easy); whether they know where safe bike routes are nearby (Safe); and whether there are places they need to get to regularly within reasonable bicycling distance of their home (Accessible). Each item was scored using a 5-point Likert-type scale ranging from strongly disagree (1) to strongly agree (5). The latent constructs for objective and perceived bicycling environment was illustrated in Figure 8 , where $\lambda$ is the regression coefficient and $\delta$ is the residual (uniqueness) for the observed measures. 


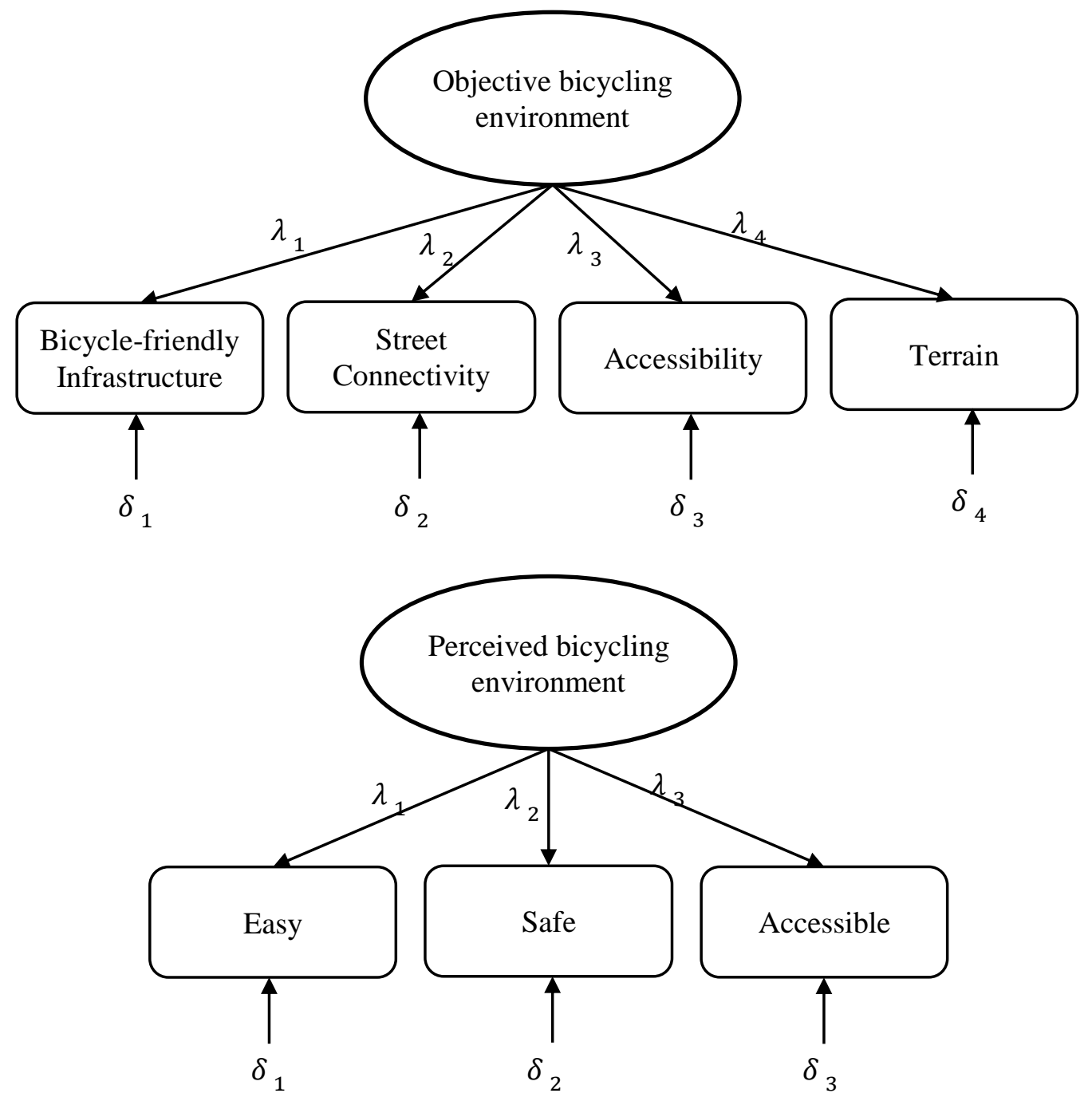

Figure 8: Latent Constructs for Objective and Perceived Bicycling Environment 


\section{Results and Discussion}

\section{Testing the Mediation Effect of the Perceived Environment}

The mediation model (see Figure 9) was estimated in AMOS using the bootstrapping method described above. The direct and indirect effects and the bias-corrected bootstrap confidence intervals of the effects were calculated. The direct path from objective environment to bicycling was first tested without controlling for perceived environment, and the path is significant $(\beta=.301, \mathrm{P}<.01)$. However, this path was no longer significant, as soon as the perceived environment was entered into the model $(\beta=-.017$, $\mathrm{P}=.57)$. Instead, perceived environment was significantly associated with objective environment $(\beta=.402, \mathrm{P}<.01)$ and was predictive of bicycling $(\beta=.792, \mathrm{P}<.01)$. All of the model fit indices were very good $(\mathrm{CFI}=0.982, \mathrm{SRMR}=0.0396)$. The bootstrapping estimate revealed a significant indirect effect $(\beta=.319,95 \% \mathrm{CI}=.247$ to $.394, \mathrm{P}<.01)$. These results support the full mediation hypothesis. 


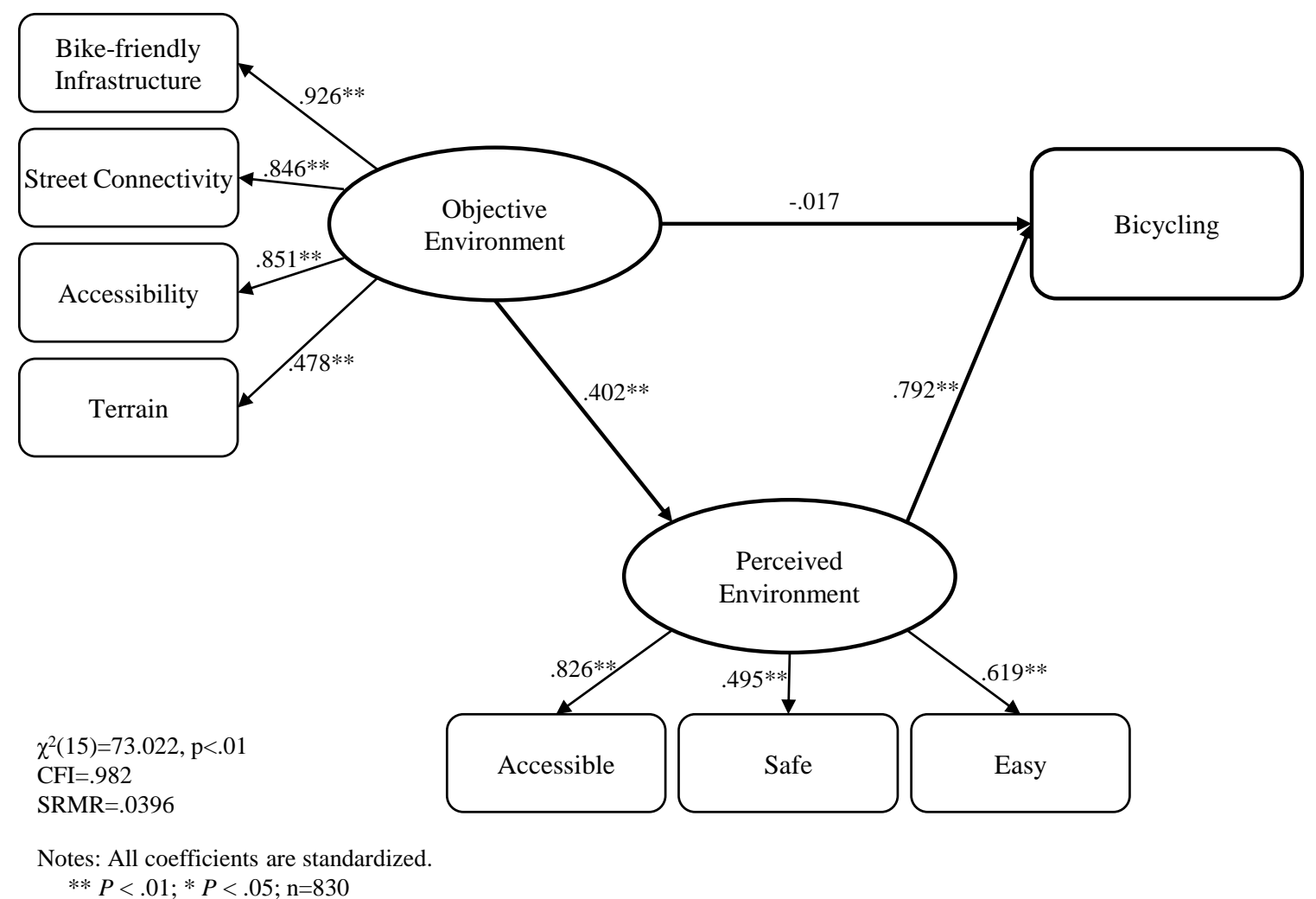

Figure 9: Model Results for Mediation Test

\section{Results of the Full Conceptual Model}

Results from the mediation test confirm that the objective environment affects bicycling behavior through influencing one's perceptions of the environment, and that the direct effect from the objective environment to bicycling behavior does not exist after controlling for perceptions. In our final conceptual model, therefore, we deleted the direct link from objective environment to bicycling behavior.

Model structure and model results, including model fits, standardized coefficients and significance, are provided in Figure 10. Only the coefficients significant at 95\% confidence level are shown. The fit indices suggest a good fit $(\mathrm{CFI}=0.957, \mathrm{SRMR}=$ 
0.0375). Model results indicate that the standardized loadings for three indicators assessing the objective environment and three indicators measuring the perceived environment are of sufficient magnitude, ranging from 0.405 to 0.927 . This suggests that our two latent variable structures are reasonable.

Overall, the model explains $53.8 \%$ of the variation in bicycling and $58.7 \%$ of the variation in perceptions. As expected, the objective environment has a positive and significant association with perceptions, indicating that a bicycle-friendly neighborhood improves residents' perceptions of the bicycling environment; in particular, a neighborhood with connected streets, nearby business establishments, and low-traffic streets could make residents feel that bicycling in the neighborhood is easy and safe, with nearby destinations. Moreover, perceptions of the environment have a significant positive association with bicycling behavior, indicating that residents who perceive their neighborhood as bikeable actually bicycle more often. In addition, the feedback link from bicycling to perceptions is significant, indicating that frequent cyclists have better perceptions of the bicycling environment than those who occasionally or never bike. Even though the direct effect of the objectively-measured bicycling environment on bicycling behavior is not significant, the indirect effect is significant. This indicates that the objective environment does influence bicycling, through influencing people's perceptions of the physical environment. 


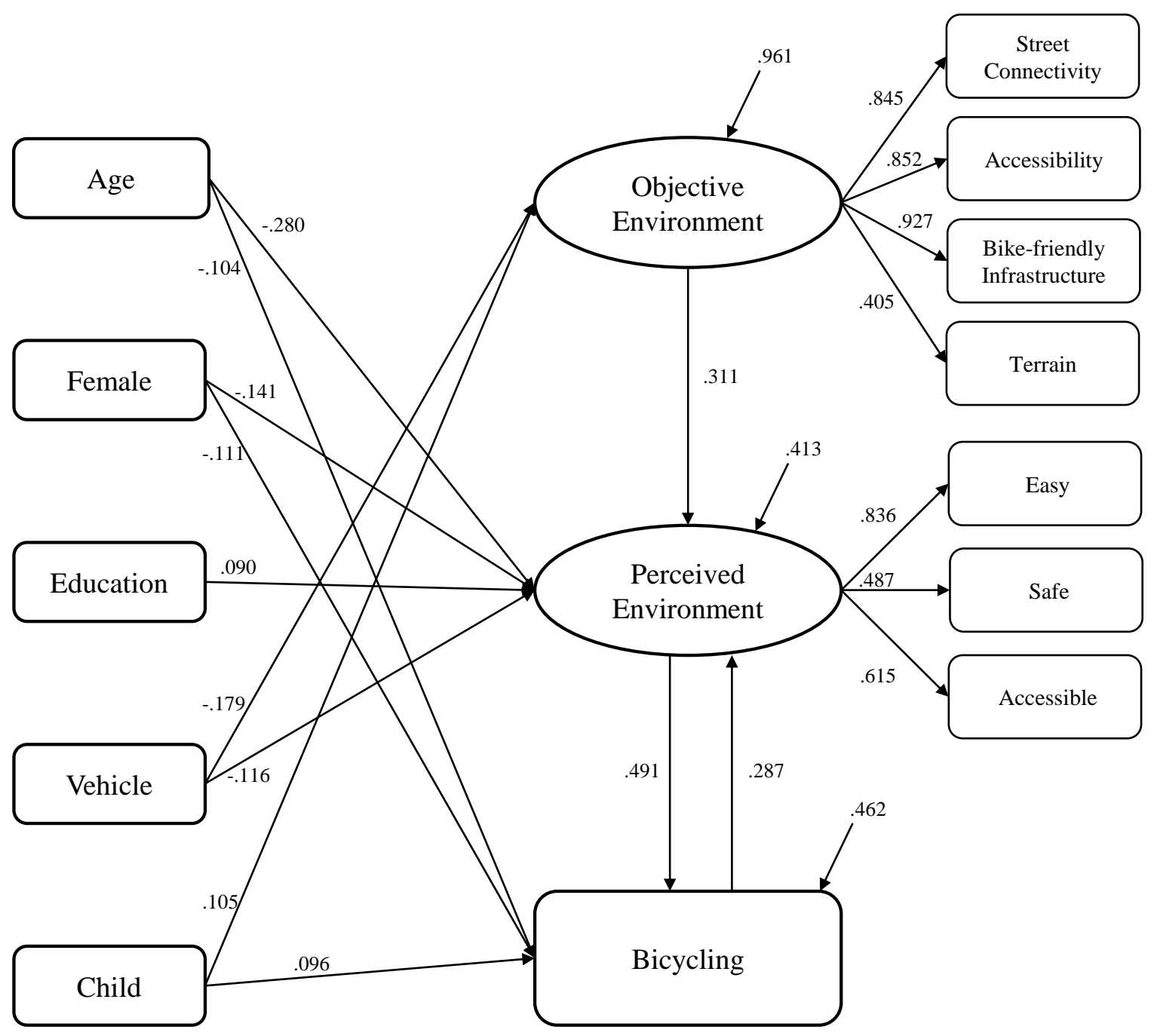

Notes: All coefficients are standardized; $n=830$

Figure 10: Results of the Full Conceptual Model

Individual characteristics play an important role in the model. Two socio-demographic variables, the number of vehicles owned and having children, are negatively and positively associated with objective bicycling environment, respectively. This indicates that households with fewer vehicles and households with children may self-select to live in a bicycle-friendly neighborhood. Four of five socio-demographic variables have significant associations with perceptions of the bicycling environment. Age, being female, 
and owning more vehicles are negatively associated with perceptions, while education level is positively associated with perceptions. Finally, four socio-demographic variables also have a direct effect on bicycling. Older people and women tend to bicycle less often, while people with higher levels of education and with children are more likely to bicycle.

\section{Conclusions and Policy Implications}

Policies aimed at promoting walking and bicycling through changing the built environment are increasingly being proposed and implemented in U.S. cities, and many empirical studies have shown significant associations between changes in the built environment and changes in travel behavior. The mechanism between built environment and bicycling behavior specifically, however, is less recognized and explored. Socioecological theory asserts that many factors including intrapersonal, interpersonal, and external physical environment factors, play a role in walking and bicycling behavior and that all these factors interact with each other. Because of these interactions, the landscape of environment-behavior theory can be very complicated. This study explored one dimension of the complex system: the relationship between the external physical environment (measured objectively) and intrapersonal perceptions of the environment, and how they affect people's bicycling behavior.

Through our structural equation models, we found that the objectively-measured bicycling environment had only an indirect effect on bicycling frequency through influencing one's perceptions of the environment. In other words, even if people live in a highly-bikeable neighborhood, they might not bicycle more until they recognize the 
advantages of these bicycle-friendly characteristics. Given this finding, interventions aimed at improving people's perceptions of the environment may be necessary as a complement to current efforts which focus primarily on the physical design of the built environment. These conclusions are consistent with the findings from recent studies that show that interventions focusing on perceptions can be as important as built environment support on bicycling (Emond \& Handy, 2012; Forsyth \& Oakes, 2013). Possible interventions to change perceptions include neighborhood-based marketing materials that include information on the location of safe bicycle routes, bicycle safety facts and tips, and locations of bicycle-accessible businesses and destinations. Public bicycling events, such "ciclovias" and the city of Portland's Sunday Parkways, that close streets to cars for several hours can also familiarize residents with the bicycle-friendly designs in their neighborhood. Wayfinding signage that includes bicycling distances and travel times to key destinations may also change perceptions. Our findings about the relationships between demographic characteristics and perceptions and behavior indicate that programs aimed at changing perceptions may want to target women and older adults. Meanwhile, it is also worth noting that our model found that the objective environment had a direct and significant influence on perceptions of the environment, and therefore changes to the physical environment and infrastructure for bicycling are still very important and necessary. Interventions that improve perceptions of the environment will serve as a complement that helps reap the full potential of built environment interventions.

Further, our study found a positive feedback effect of bicycling behavior on perceptions of the environment. This finding indicates that interventions focused on changing the 
perceptions may foster a virtuous cycle that has a positive impact on bicycling behavior; such interventions could result in more bicycling behavior, which in turn reinforces positive perceptions. However, it is worth noting that our perception measures only focus on positive qualities of the environment, such as safe bike routes and accessible destinations. Several studies measuring negative aspects of the environment have reported the opposite relationship, where people who are active within their neighborhood are more likely to have negative perceptions, such as being unclean and untidy (Duncan \& Mummery, 2005), lacking sidewalks (McCormack, et al., 2009), and having heavy traffic (Humpel, Marshall, Leslie, Bauman, \& Owen, 2004). These authors posited that individuals who are active in their neighborhood may be more aware of their neighborhood problems compared with those who are less active. Taken together, it is possible that bicyclists might have stronger perceptions of the environment, positive and negative, given their greater interaction with it.

This study has several limitations. First, more complete and precise measurements of the objective and perceived environment are needed. The objective and perceived measures do not match up perfectly in this study. In particular, our measures of perceptions may also be measuring things unrelated to the physical environment. For example, the "easy" variable could be capturing aspects of the person's own physical abilities or other constraints (e.g. time, child care, etc.). Second, longitudinal studies are necessary to make rigorous causal inferences among such factors as the physical environment, perceptions, and behavior. Longitudinal studies measuring perceptions before and after changes in the physical environment are very rare, yet would be valuable in understanding these 
relationships. Third, further investigations into the characteristics of people whose perceptions do not match the objectively-measured environment are needed. In particular is the question of why people living in presumably highly-bikeable environments perceive it as a low-bikeable environment. Fourth, this study only includes bicycling behavior. The conceptual model proposed in this study needs to be tested by studying other types of travel behavior, particularly walking. 


\section{Chapter 7. Paper 3: Mismatch between Objective and Perceived Bicycling Environment}

\section{Introduction}

Studies linking the built environment to travel behavior or physical activity generally use two categories of built-environment measures: perceived (self-reported) and objective (Brownson, et al., 2009; Sallis, 2009). Perceived measures are generally obtained from interviews or self-administered questionnaires; objective measures are typically derived from systematic observations, audits, or GIS-based measures relying on existing spatial data (e.g. street network, land-use data). Though many studies use objective and perceived measures interchangeably, the mismatch between the perceived and objective environment and their different effects on travel behavior and physical activity have recently been recognized (Ball, et al., 2008; Gebel, et al., 2009; Gebel, et al., 2011; Handy, et al., 2006; Kirtland, et al., 2003; Lackey \& Kaczynski, 2009; Lin \& Moudon, 2010; Ma, et al., 2014; McCormack, et al., 2007; McGinn, et al., 2007; Prins, et al., 2009; Van Acker, et al., 2013).

The mismatch between the perceived and objective environment is one of the reasons leading to mixed findings from the travel behavior-built environment studies (Ma \& Dill, 2014; Van Acker, et al., 2013; Van Acker, et al., 2010). This is also one of the reasons that not all people, even in "pedestrian-friendly" and "bike-friendly" environments, choose not to walk and bicycle (Van Acker, et al., 2013; Van Acker, et al., 2010). Improved understanding of the relationships between the objective and perceived environment and travel behavior could be important for understanding the mechanism 
underlying the built environment- behavior relationship and for identifying potential interventions (Handy, et al., 2006; McMillan, 2005; Sallis, et al., 2006). However, few empirical studies have explored the magnitude and effects of the mismatch on active travel behavior, particularly bicycling behavior. Further, there is little known about the factors contributing to the mismatch between the objective and perceived environment.

This study aims to (1) explore the mismatch between the perceived and objective bicycling environment; and (2) investigate the characteristics of the people whose perceptions do not match the objectively measured environment. In particular is the question of why people living in presumably highly bikeable environments perceive it as a low-bikeable environment. We do so using survey data from a large random sample survey of adults in the Portland, OR, metropolitan area.

\section{Methodology}

The data were obtained through a random phone survey of adults in the Portland region. The sample included both land-line and mobile phone numbers and was conducted July 19-Aug. 10, 2011. A total of 902 interviews were completed. Of those, 130 (14 percent) were completed on mobile phones. The mobile phone sample was used to help reduce sampling bias, particularly among younger adults. The overall response rate was 20 percent. More details about the survey are available in Dill and McNeil (2013b).

To analyze the mismatch between objective and perceived bikeability, we first need to categorize each participant into distinct groups with different combinations of objective and perceived bikeability. To do so, we followed a method used by Van Acker, et al. 
(2013) that combined factor and cluster analysis to identify different land-use and perception clusters. The task of factor analysis is to extract underlying dimensions of objective and perceived bikeability from a list of observed indicators. The task of a cluster analysis is to assign each participant to clusters that are relatively homogeneous within and relatively heterogeneous in relation to other clusters. Cluster analysis has been widely used in social science (Blashfield \& Aldenderfer, 1978).

Our measures of bikeability are based upon the growing literature linking bicycle infrastructure, the built environment and bicycling. A number of studies have found that striped bicycle lanes (Buehler \& Pucher, 2012; Jennifer Dill \& Carr, 2003; Krizek \& Johnson, 2006); off-street bike paths (Akar, et al., 2013; Jennifer Dill \& Voros, 2007; Parkin, et al., 2008); bicycle boulevards (Broach, et al., 2012); and low-traffic streets are associated with more bicycling (Emond, et al., 2009; Winters, et al., 2010). In addition to the bicycle infrastructure, more and more studies find that other aspects of the built environment may support bicycling. Street connectivity, for example, is positively associated with odds of bicycling for both utilitarian and recreational purpose (Beenackers, et al., 2012; Cervero, et al., 2009). Also, accessibility is consistently found to be associated with both bicycling propensity and bicycling frequency (Emond \& Handy, 2012; Handy \& Xing, 2011; Parkin, et al., 2008; Xing, et al., 2010).

For perception of bikeability, we included the following indicators in the factor analysis: (1) "There are off-street bike trails or paved paths in or near my neighborhood that are easy to get to"; (2) "There are bike lanes that are easy to get to"; (3) "There are quiet streets, without bike lanes, that are easy to get to on a bike"; (4) "There is so much traffic 
along nearby streets that it would make it difficult or unpleasant to bike"; (5) "Many of the places I need to get to regularly are within biking distance of my home"; and (6) "How satisfied are you with your neighborhood design in terms of bike safety?" The first five items are scored using a five-point Likert scale from strongly disagree to strongly agree; the last item is scored using a five-point Likert scale from very dissatisfied to very satisfied.

Corresponding to these perception indicators, we created different objective measures to line up with perceived measures. For example, several objective measures, including miles of off-street bike paths within one-eighth-mile, quarter-mile, half-mile and onemile circular and network buffers and distance to the nearest off-street bike path, were created to match with the perceived off-street path. After a series of comparisons of different sets of variables, we finally decided to use the following objective indicators to measure objective bikeability because they have better associations with the perception measures: miles of off-street bike paths within a one-mile network buffer; miles of bike lanes within a one-mile network buffer; miles of minor streets within a one-mile network buffer; number of common destinations (e.g., convenience stores, grocery stores, restaurants and bars, beauty salons, postal service, etc.) within a one-mile network buffer; street connectivity (defined as number of street intersections with three or more valences divided by total number of intersections) within a one-mile network buffer; and hilliness (defined as the ratio of area with a slope equal or higher than 25 percent) within a onemile network buffer. These objective measures have been proved to be associated with bicycling behavior in previous research. Objective environmental data, such as street 
network and land-use information, are from the Regional Land Information System (RLIS) from Portland Metro, the region's transportation and land-use planning agency.

Even though we put much effort into trying to match the perceived and objective measures, they cannot perfectly line up because of data limitations. For example, we do not have good objective measures that correspond to the perceptions of traffic and perceptions of neighborhood design for bicycling safety. Instead, we use street connectivity and miles of minor streets as the approximate objective measures. However, this limitation is not expected to materially affect the analysis and results. The composite measures based on factor analysis help to reduce the mismatching errors from individual variables.

Through the factor analysis based on the six indicators of perceived bikeability, one principal factor was extracted and it explained 43 percent of the variance (see Table 14). By analyzing its loadings on each indicator, we found this factor represents an overall positive perception of the bicycling environment. For example, this factor has positive loadings on perceptions of the presence of bike lanes, bike paths and quiet streets, and also on satisfaction of safety design and destination accessibility. However, it has negative loadings on the perception of traffic which is unpleasant to bicycle. Through the factor analysis (Varimax rotation method was used) based on the seven indicators of objective bikeability, two principal factors were extracted, which explained 65 percent of the variance (see Table 15). The two extracted factors represent two underlying dimensions of bicycling environment: (1) land use and design: accessibility, street network, quiet streets, and (2) dedicated bicycling infrastructure: bicycle lane and paths. 
Table 14: Factor Analysis for Perceived Bikeability

Factor 1

There are off-street bike trails or paved paths in or near .751

my neighborhood that are easy to get to.

There are bike lanes that are easy to get to.

to get to on a bike.

There is so much traffic along nearby streets that it would make it difficult or unpleasant to bike.

How satisfied are you with your neighborhood design in terms of bike safety?

Many of the places I need to get to regularly are within biking distance of my home.

Table 15: Factor Analysis for Objective Bikeability

\begin{tabular}{lcc}
\hline & $\begin{array}{c}\text { Factor 1 } \\
\text { Land use } \\
\text { and design }\end{array}$ & $\begin{array}{c}\text { Factor 2 } \\
\text { Dedicated } \\
\text { bicycling } \\
\text { infrastructure }\end{array}$ \\
\hline $\begin{array}{l}\text { Total number of destinations within one-mile network } \\
\text { buffer }\end{array}$ & .650 & .482 \\
\hline $\begin{array}{l}\text { Number of street intersections with three or more } \\
\text { valences divided by total number of intersections within } \\
\text { one-mile network buffer }\end{array}$ & .863 & .112 \\
\hline $\begin{array}{l}\text { Ratio of area with a slope equal or higher than 25 } \\
\text { percent within one-mile network buffer }\end{array}$ & -.408 & -.405 \\
\hline $\begin{array}{l}\text { Miles of minor street within one-mile network buffer } \\
\text { Miles of bike boulevard within one-mile network buffer }\end{array}$ & .893 & .114 \\
\hline $\begin{array}{l}\text { Miles of bike lane within one-mile network buffer } \\
\text { Miles of off-street bike path within one-mile network } \\
\text { buffer }\end{array}$ & .100 & -.169 \\
\hline
\end{tabular}

Two cluster analyses were then conducted based on the extracted factors from perceived and objective indicators. The hierarchical cluster with Wald's method was used. This procedure aims to assign participants who shared similar characteristics in perception or 
who lived in similar bicycling environments to a cluster. The cluster analysis based on the perception factor lead to the identification of two groups. The two groups have a clear contrast in perceptions of the bicycling environment (see Table 16). Group 1 has significantly higher perceptions of the bicycling environment than Group 2. We, therefore, named Group 1 as high perception and Group 2 as low perception.

By the same method, three distinct groups were identified using cluster analysis based on the two factors from objective environment indicators. Also, the three groups suggest distinct characteristics in the bicycling environment (see Table 17). To clarify their cluster-specific differentiation in terms of objective bikeability, we gave them three group names:

- High objective bikeability (Group 1): High percentage of connected streets, good accessibility, high density of low-traffic streets, some bike lanes and paths, relatively high number of bicycle boulevards, and mostly flat area.

- Moderate objective bikeability (Group 2): Higher density of bike lanes and paths, moderate accessibility, moderate density of low-traffic streets, relatively lower percentage of connected streets, and mostly flat area.

- Low objective bikeability (Group 3): Low level of connected streets, accessibility, low-traffic streets, bike lanes and paths, and many hilly areas.

Even though Group 1 was labeled more bikeable than Group 2, the two groups may represent two different types of a "good" environment for bicycling. The environment of Group 1 is better in terms of bicycling accessibility and interaction with traffic, while 
Group 2's environment has more dedicated bicycling infrastructure. It is possible that some bicyclists prefer the environment of Group 2 than that of Group 1. It is also possible that one type is superior to the other one in terms of different bicycling purposes. Based on these data, we cannot identify a group that combines the merits of Group 1 and Group 2. It seems there is a difference between the underlying built environment and bicycling infrastructure. We chose to label Group 1 as "high" in this analysis because our previous work with a different data set found that the physical characteristics found in Group 1 had stronger associations with neighborhood bicycling than did the presence of striped bike lanes (J. Dill, Mohr, \& Ma, 2014). That study also found that it is useful to look at bicycling infrastructure separately from other built-environment characteristics.

Table 16: Different Perceptions between Group 1 and Group 2

\begin{tabular}{|c|c|c|c|c|}
\hline Perception measure & $\begin{array}{l}\text { Perceived } \\
\text { bikeability }\end{array}$ & $\mathrm{n}$ & Mean & P-value \\
\hline \multirow{2}{*}{$\begin{array}{l}\text { There are off-street bike trails or paved } \\
\text { paths in or near my neighborhood that are } \\
\text { easy to get to. }\end{array}$} & Group 1 & 327 & 3.50 & \multirow[b]{2}{*}{.000} \\
\hline & Group 2 & 363 & 1.93 & \\
\hline \multirow[t]{2}{*}{ There are bike lanes that are easy to get to. } & Group 1 & 327 & 3.56 & \multirow{2}{*}{.000} \\
\hline & Group 2 & 363 & 1.97 & \\
\hline \multirow{2}{*}{$\begin{array}{l}\text { There are quiet streets, without bike lanes, } \\
\text { that are easy to get to on a bike. }\end{array}$} & Group 1 & 327 & 3.88 & \multirow{2}{*}{.000} \\
\hline & Group 2 & 363 & 3.00 & \\
\hline \multirow{2}{*}{$\begin{array}{l}\text { There is so much traffic along the street I } \\
\text { live on that it would make it difficult or } \\
\text { unpleasant to bike. }\end{array}$} & Group 1 & 327 & 1.46 & \multirow[b]{2}{*}{.000} \\
\hline & Group 2 & 362 & 2.00 & \\
\hline \multirow{2}{*}{$\begin{array}{l}\text { There is so much traffic along nearby streets } \\
\text { that it would make it difficult or unpleasant } \\
\text { to bike. }\end{array}$} & Group 1 & 327 & 1.82 & \multirow[b]{2}{*}{.000} \\
\hline & Group 2 & 363 & 2.93 & \\
\hline \multirow{2}{*}{$\begin{array}{l}\text { How satisfied are you with your } \\
\text { neighborhood design in terms of bike } \\
\text { safety? }\end{array}$} & Group 1 & 327 & 4.33 & \multirow[b]{2}{*}{.000} \\
\hline & Group 2 & 363 & 2.90 & \\
\hline \multirow{2}{*}{$\begin{array}{l}\text { Many of the places I need to get to regularly } \\
\text { are within biking distance of my home. }\end{array}$} & Group 1 & 327 & 3.56 & \multirow{2}{*}{.000} \\
\hline & Group 2 & 363 & 2.71 & \\
\hline
\end{tabular}


Table 17: Different Built-environment Attributes among Group 1, Group 2 and Group 3

\begin{tabular}{|c|c|c|c|c|}
\hline Objective measure & Objective bikeability & $\mathrm{n}$ & Mean & P-value \\
\hline \multirow{3}{*}{$\begin{array}{l}\text { Ratio of connected street within one- } \\
\text { mile network buffer }\end{array}$} & Group 1 & 174 & $93 \%$ & \multirow{3}{*}{.000} \\
\hline & Group 2 & 191 & $76 \%$ & \\
\hline & Group 3 & 513 & $71 \%$ & \\
\hline \multirow{3}{*}{$\begin{array}{l}\text { Total number of destinations within } \\
\text { one-mile network buffer }\end{array}$} & Group 1 & 174 & 156 & \multirow{3}{*}{.000} \\
\hline & Group 2 & 191 & 105 & \\
\hline & Group 3 & 513 & 28 & \\
\hline \multirow{3}{*}{$\begin{array}{l}\text { Ratio of area with a slope equal or } \\
\text { greater than } 25 \text { percent within one-mile } \\
\text { network buffer }\end{array}$} & Group 1 & 174 & $7 \%$ & \multirow{3}{*}{.000} \\
\hline & Group 2 & 191 & $9 \%$ & \\
\hline & Group 3 & 513 & $26 \%$ & \\
\hline \multirow{3}{*}{$\begin{array}{l}\text { Miles of minor street within one-mile } \\
\text { network buffer }\end{array}$} & Group 1 & 174 & 42.19 & \multirow{3}{*}{.000} \\
\hline & Group 2 & 191 & 23.62 & \\
\hline & Group 3 & 513 & 17.18 & \\
\hline \multirow{3}{*}{$\begin{array}{l}\text { Miles of bike boulevard within one- } \\
\text { mile network buffer }\end{array}$} & Group 1 & 174 & 2.43 & \multirow{3}{*}{.000} \\
\hline & Group 2 & 191 & .12 & \\
\hline & Group 3 & 513 & .01 & \\
\hline \multirow{3}{*}{$\begin{array}{l}\text { Miles of bike lane within one-mile } \\
\text { network buffer }\end{array}$} & Group 1 & 174 & 2.19 & \multirow{3}{*}{.000} \\
\hline & Group 2 & 191 & 4.36 & \\
\hline & Group 3 & 513 & 1.96 & \\
\hline \multirow{3}{*}{$\begin{array}{l}\text { Miles of off-street bike path within } \\
\text { one-mile network buffer }\end{array}$} & Group 1 & 174 & .23 & \multirow{3}{*}{.000} \\
\hline & Group 2 & 191 & 1.13 & \\
\hline & Group 3 & 513 & .19 & \\
\hline
\end{tabular}




\section{Results}

To explore the relationship between perceived and objective bikeability, we first conducted an ANOVA analysis to test the difference in perceptions among the three objective groups. The results suggested that respondents of the three groups have distinct perceptions of the bicycling environment (see Table 17). In particular, respondents of Group 1 (high objective bikeability) had the highest perceptions in all aspects of the bicycling environment except perceptions of off-street bike trails/paths. Respondents of Group 2 (moderate objective bikeability) perceived highest in off-street bike trails/paths, and had relatively higher perceptions of bicycle lanes, neighborhood design for bike safety, accessibility, and overall neighborhood environment than Group 3 (low objective bikeability). Those in Group 3 had the lowest perceptions of the bicycling environment. This result indicates that, in general, there is consistency between objective and perceived bikeability. Residents had higher perceptions in an environment with bicycle-friendly design (low-traffic streets, connected streets, accessibility) and bicycling infrastructure than in an environment without these features. Further, perceptions are higher in bicyclefriendly environments (low-traffic, connected street, accessibility) with relatively little bicycling infrastructure than in an environment with bike lanes and paths, but without other bicycle-friendly design features. 
Table 18: Comparison of Perceptions among the Three Groups of Objective Bikeability

\begin{tabular}{|c|c|c|c|c|}
\hline Perceptions of bicycling environment & $\begin{array}{l}\text { Objective } \\
\text { bikeability }\end{array}$ & $\mathbf{N}$ & Mean & P-value \\
\hline \multirow{3}{*}{$\begin{array}{l}\text { There are off-street bike trails or paved paths in } \\
\text { or near my neighborhood that are easy to get to. }\end{array}$} & Group 1 & 132 & 2.63 & \multirow{3}{*}{0.000} \\
\hline & Group 2 & 144 & 3.06 & \\
\hline & Group 3 & 411 & 2.58 & \\
\hline \multirow{3}{*}{ There are bike lanes that are easy to get to. } & Group 1 & 134 & 3.16 & \multirow{3}{*}{0.000} \\
\hline & Group 2 & 146 & 2.91 & \\
\hline & Group 3 & 414 & 2.52 & \\
\hline \multirow{3}{*}{$\begin{array}{l}\text { There are quiet streets, without bike lanes, that } \\
\text { are easy to get to on a bike. }\end{array}$} & Group 1 & 135 & 3.74 & \multirow{3}{*}{0.000} \\
\hline & Group 2 & 145 & 3.32 & \\
\hline & Group 3 & 414 & 3.36 & \\
\hline \multirow{3}{*}{$\begin{array}{l}\text { There is so much traffic along nearby streets that } \\
\text { it would make it difficult or unpleasant to bike. }\end{array}$} & Group 1 & 135 & 2.17 & \multirow{3}{*}{0.009} \\
\hline & Group 2 & 146 & 2.57 & \\
\hline & Group 3 & 414 & 2.43 & \\
\hline \multirow{3}{*}{$\begin{array}{l}\text { How satisfied are you with your neighborhood } \\
\text { design in terms of bike safety? }\end{array}$} & Group 1 & 133 & 3.92 & \multirow{3}{*}{0.002} \\
\hline & Group 2 & 146 & 3.58 & \\
\hline & Group 3 & 413 & 3.47 & \\
\hline \multirow{3}{*}{$\begin{array}{l}\text { Many of the places I need to get to regularly are } \\
\text { within biking distance of my home. }\end{array}$} & Group 1 & 135 & 3.74 & \multirow{3}{*}{0.000} \\
\hline & Group 2 & 144 & 3.26 & \\
\hline & Group 3 & 415 & 2.86 & \\
\hline \multirow{3}{*}{$\begin{array}{l}\text { Overall perception of bikeability (Factor score of } \\
\text { above perception indicators) }\end{array}$} & Group 1 & 128 & 0.39 & \multirow{3}{*}{0.000} \\
\hline & Group 2 & 141 & 0.08 & \\
\hline & Group 3 & 406 & -0.14 & \\
\hline
\end{tabular}

However, a further disaggregate exploration of different groups of participants reveals that not all residents who live in a high-bikeable neighborhood perceive it as high, nor do all the residents living in a low-bikeable neighborhood perceive it as low (see Table 19). About 47 percent of the participants perceived their environment at the same level with the objective measure of the bikeable environment, while about 7 percent perceived their relatively good cycling environment as bad and about 25 percent perceived their bad cycling environment as good. In addition, about 10 percent perceived the moderate 
bikeability environment as high, while about 11 percent perceived it as low. Again, the moderate bikeability group defined in this study could also be a good cycling environment for some people. Therefore, it is more difficult to clearly define a "match" and "mismatch" in this environment.

Table 19: Match and Mismatch between Perceived and Objective Bikeability

\begin{tabular}{|c|c|c|c|c|}
\hline & \multicolumn{2}{|c|}{ Perception of Bicycling Environment } & \multirow{2}{*}{ Total } \\
\hline & & High & Low & \\
\hline \multirow{6}{*}{$\begin{array}{l}\text { Objectively } \\
\text { Measured } \\
\text { Bicycling } \\
\text { Environment }\end{array}$} & \multirow[t]{2}{*}{ High } & 83 & 46 & 129 \\
\hline & & $12 \%$ & $7 \%$ & $19 \%$ \\
\hline & \multirow[t]{2}{*}{ Moderate } & 70 & 71 & 141 \\
\hline & & $10 \%$ & $11 \%$ & $21 \%$ \\
\hline & \multirow[t]{2}{*}{ Low } & 170 & 236 & 406 \\
\hline & & $25 \%$ & $35 \%$ & $60 \%$ \\
\hline \multirow{2}{*}{\multicolumn{2}{|c|}{ Total }} & 323 & 353 & 676 \\
\hline & & $48 \%$ & $52 \%$ & $100 \%$ \\
\hline
\end{tabular}

\section{Mismatch and Bicycling Behavior}

The average number of days that the respondents bicycled for different purposes in the past month was used to compare the bicycling behavior among the match and mismatch groups (Table 20). It is evident that, for overall and utilitarian bicycling, the bicycling frequency goes down as the objective bicycling environment becomes worse. It is interesting to note that bicycling frequency for recreational purposes does not vary significantly among different levels of the objective environment. Moreover, persons with more positive perceptions of the environment generally bicycled more than those with low perceptions, no matter what actual environment existed where they lived. This is true for both utilitarian and recreational bicycling. 
The relative effects of the objective and perceived environment on bicycling behavior vary among different bicycling purpose (Table 20). For bicycling for daily errands, the objective environment is strongly correlated with the frequency of bike trips. Those who have high perceptions but live in a moderate or low bikeability environment bicycle less often for daily errands than those who have low perceptions but live in high bikeability environments. For commuting, those who live in high bikeability environments biked more often to work than those who lived in moderate and low bikeability environments. The exception is the group living in moderate bikeability environments with high perceptions. They had the same bicycling frequency with the group that lived in high bikeability environments but had low perceptions. By contrast, those who live in moderate bikeability environments and have low perceptions and those who live in low bikeability environments have much lower bicycling frequency, less than one day per month. This implies that objective bikeability is very important for commuting by bicycle, and strong perceptions are needed to bicycle in moderate bikeability environments. For recreational bicycling, the variations of bicycling frequency among different bikeability environments are not significant, while the perceptions do matter in affecting bicycling frequency for recreational purposes. It is also worth noting that the effects of perceptions on recreational bicycling are only significant for the low objective bikeability group. In summary, for utilitarian bicycling, both objective and perceived environment matter, while for recreational bicycling the perceptions may play a more important role than the objective environment. 
Table 20: Comparisons of Bicycling Frequency among Different Groups

\begin{tabular}{lrrrr}
\hline & mean & mean & mean & p-value \\
\hline \#days of overall bicycling & & & & \\
HO vs. MO vs. LO & $\mathbf{8 . 7 2}$ & $\mathbf{5 . 2 3}$ & $\mathbf{4 . 3 4}$ & $\mathbf{0 . 0 0}$ \\
HP vs. LP & $\mathbf{6 . 5 9}$ & $\mathbf{4 . 3 7}$ & & $\mathbf{0 . 0 0}$ \\
HOHP vs. HOLP & $\mathbf{1 0 . 3 6}$ & $\mathbf{5 . 9 7}$ & & $\mathbf{0 . 0 2}$ \\
MOHP vs. MOLP & 6.45 & 4.26 & & 0.12 \\
LOHP vs. LOLP & 4.68 & 4.09 & & 0.41 \\
\#days of bicycling for commuting & & & & \\
HO vs. MO vs. LO & $\mathbf{2 . 1 3}$ & $\mathbf{0 . 6 7}$ & $\mathbf{0 . 4 1}$ & $\mathbf{0 . 0 0 0}$ \\
HP vs. LP & $\mathbf{1 . 3 0}$ & $\mathbf{0 . 6 2}$ & & $\mathbf{0 . 0 2 6}$ \\
HOHP vs. HOLP & 3.03 & 1.68 & & 0.237 \\
MOHP vs. MOLP & $\mathbf{1 . 7 0}$ & $\mathbf{0 . 0 3}$ & & $\mathbf{0 . 0 1 8}$ \\
LOHP vs. LOLP & 0.33 & 0.60 & & 0.310 \\
\#days of bicycling for daily errands & & & & \\
HO vs. MO vs. LO & $\mathbf{4 . 1 8}$ & $\mathbf{1 . 4 3}$ & $\mathbf{1 . 4 3}$ & $\mathbf{0 . 0 0 0}$ \\
HP vs. LP & $\mathbf{2 . 9 8}$ & $\mathbf{1 . 6 9}$ & & $\mathbf{0 . 0 0 3}$ \\
HOHP vs. HOLP & $\mathbf{5 . 9 6}$ & $\mathbf{3 . 2 0}$ & & $\mathbf{0 . 0 5 0}$ \\
MOHP vs. MOLP & 2.18 & 1.34 & & 0.290 \\
LOHP vs. LOLP & 1.84 & 1.52 & & 0.517 \\
\#days of bicycling for recreation & & & & \\
HO vs. MO vs. LO & 3.91 & 4.23 & 3.11 & 0.100 \\
HP vs. LP & $\mathbf{4 . 0 8}$ & $\mathbf{2 . 9 3}$ & & $\mathbf{0 . 0 1 1}$ \\
HOHP vs. HOLP & 4.40 & 3.23 & & 0.293 \\
MOHP vs. MOLP & 4.76 & 3.90 & & 0.500 \\
LOHP vs. LOLP & $\mathbf{3 . 6 8}$ & $\mathbf{2 . 5 9}$ & & $\mathbf{0 . 0 3 6}$ \\
\hline N & &
\end{tabular}

Note: $\mathrm{HO}=$ High Objective Environment; $\mathrm{MO}=$ Moderate Objective Environment; LO=Low Objective Environment; HP=High Perceptions; LP=Low Perceptions.

*p-value is derived from ANOVA tests.

\section{Mismatch and socio-demographics, attitudes, social environment and neighborhood} safety

A mix of individual and societal factors likely contributes to the mismatch between the objective and perceived environment. The social-demographic attributes of participants, their attitudes, and the social environment within each match and mismatch category 
(Table 21) indicate that older adults, women, less-educated and lower-income persons, and those who do not have children tend to perceive high-bikeable environments as low, while young adults, men, higher-income persons and those with children are more likely to perceive low-bikeable environments as high. In contrast to previous studies (Ball, et al., 2008; Gebel, et al., 2009), this study did not find significant differences in respondents' health condition and years they lived in current neighborhood between matched and mismatched groups.

Through comparing the means, we found that people who like biking and transit are more likely to perceive high-bikeable environments as high, whereas those who like driving and walking tend to perceive high-bikeable environments as low. Also, a supportive social environment helps people to have better perceptions of the bicycling environment. Finally, those who perceive a high crime rate in the neighborhood tend to perceive highbikeable environments as low. 
Table 21: Socio-demographics of Participants in Matched and Mismatched Groups

\begin{tabular}{|c|c|c|c|c|c|c|}
\hline & \multicolumn{2}{|c|}{ High Bikeability } & \multicolumn{2}{|c|}{ Moderate Bikeability } & \multicolumn{2}{|c|}{ Low Bikeability } \\
\hline & $\begin{array}{l}\text { High } \\
\text { Perc. }\end{array}$ & $\begin{array}{l}\text { Low } \\
\text { Perc. }\end{array}$ & $\begin{array}{l}\text { High } \\
\text { Perc. }\end{array}$ & $\begin{array}{l}\text { Low } \\
\text { Perc. }\end{array}$ & $\begin{array}{l}\text { High } \\
\text { Perc. }\end{array}$ & $\begin{array}{l}\text { Low } \\
\text { Perc. } \\
\end{array}$ \\
\hline \multicolumn{7}{|l|}{ Socio-demographics } \\
\hline$\%$ Female & $54 \%$ & $65 \%$ & $53 \%$ & $65 \%$ & $56 \%$ & $59 \%$ \\
\hline Age & 47.4 & $53.0 * *$ & 50.9 & 50.8 & 49.9 & $54.7 * * *$ \\
\hline Children in household & $46 \%$ & $28 \% *$ & $33 \%$ & $37 \%$ & $40 \%$ & $29 \% * *$ \\
\hline Education & 6.2 & 5.8 & 5.3 & 5.2 & 5.8 & 5.9 \\
\hline Income & 4.5 & $2.8 * * *$ & 3.8 & 3.5 & 4.6 & 4.6 \\
\hline Self-reported health condition & 3.7 & 3.5 & 3.5 & 3.3 & 3.7 & 3.8 \\
\hline Years living in current home & 13.6 & 13.2 & 14.5 & 14.6 & 14.9 & 14.7 \\
\hline \multicolumn{7}{|l|}{ Travel attitudes } \\
\hline Pro-bike & 0.77 & $0.22 * * *$ & 0.16 & -0.03 & 0.42 & $-0.08 * * *$ \\
\hline Pro-transit & 0.20 & 0.03 & -0.04 & 0.06 & -0.01 & -0.07 \\
\hline Pro-walk & 0.33 & 0.36 & 0.13 & -0.05 & -0.01 & 0.01 \\
\hline Pro-car & -0.3 & -0.32 & -0.01 & -0.12 & 0.05 & 0.26 \\
\hline Negative travel & -0.14 & 0.06 & -0.01 & 0.06 & -0.16 & $0.07 * *$ \\
\hline \multicolumn{7}{|l|}{ Social environment } \\
\hline Social norms & 3.4 & $2.95 * *$ & 2.69 & 2.47 & 2.75 & $2.36 * * *$ \\
\hline \multicolumn{7}{|l|}{ Neighborhood safety } \\
\hline $\begin{array}{l}\text { There is a high crime rate in my } \\
\text { neighborhood }\end{array}$ & 1.59 & $1.87 *$ & 1.75 & $2.17 * *$ & 1.41 & 1.33 \\
\hline
\end{tabular}

$*, * *$ and $* * *$ denote the value is different from the value on the left at $10 \%, 5 \%$, and $1 \%$ level respectively

\section{Regression Analysis}

People who live in a high-bikeable neighborhood but who perceive it as low bikeable (HOLP) are of particular interest because they are the likely targets of intervention programs. To identify the characteristics of this group, a binary logistic model was conducted comparing them to people living in a high-bikeable neighborhood with high perceptions. The model captures different aspects of factors contributing to the mismatch, including residents' socio-demographics, attitudes towards transportation, social environment, and bicycling behavior. 
Table 22 presents the model, which overall explains about 25 percent of the variation of the dependent variable.

The model suggests that women with children are one times more likely to perceive their high-bikeable neighborhoods as low bikeable, compared with men without children.

Compared with people aged 18-34, middle aged (35-54) people are less likely to hold low perceptions in high-bikeable neighborhoods; by contrast, older people (55 and over) are nearly three times more likely to perceive high-bikeable environments as low. Those without a college degree are 68 percent more likely to perceive a high-bikeable environment as low. Those with lower household incomes (less than $\$ 50,000$ per year) are nearly three times more likely to perceive high-bikeable environments as low than those with a relatively high income (equal to or above $\$ 50,000$ per year). In addition, those who reported good health and have lived in their neighborhood for a longer time are less likely to perceive high-bikeable environments as low.

As for the attitudinal factors, residents who like walking are less likely to perceive their high-bikeable neighborhoods as low, while those who dislike travel are more likely to have a mismatch. It is surprising to note that the attitude towards bicycling was not significant. This is probably due to the significant associations between the sociodemographic variables and bicycling attitude. The social environment does play a role in the relationship between the objective and perceived environment. A supportive social environment for bicycling helps to reduce the mismatch, while high crime rates in a neighborhood are much more likely to induce the mismatch. Finally, as expected, 
frequent bicyclists are less likely to perceive high-bikeable environments as low compared with occasional bicyclists and non-bicyclists.

A binary logistic model that predicts the respondents who lived in moderate-bikeable environments but perceived them as low bikeable (MOLP), and the model that predicts the respondents who lived in low-bikeable environments but perceived them as high bikeable (LOHP), were also tested and the model results are reported in Table 22. Similar with the characteristics of HOLP, the model results indicated that those who prefer a car for daily travel, hold negative attitudes towards walking, and perceive a high crime rate in their neighborhood are more likely to be a MOLP, while those with a lower education level and more vehicles are less likely to be a MOLP. Furthermore, females without children and males with children are more likely to live in low-bikeability neighborhoods but perceive them as high bikeable (LOHP), compared to males without children. People with good health who have more vehicles and hold negative attitudes towards travel are less likely to be a LOHP, while those who receive more social support for bicycling and who cycle regularly are more likely to be a LOHP. It is also interesting to note that probike attitude was not significant in either of the three models. This is partially because of the correlations between the pro-bike attitude and the variables interacting gender and children. Finally, by comparing with the $\mathrm{R}^{2}$ of the three models, HOLP model has more explanation power than the models of MOLP and LOHP. This implies that some important factors that are associated with the perceptions of the people living in moderate and low level of bikeable environment were not specified in my model structure. Further qualitative study is needed to better know these two special groups of people. 
Table 22: Binary Logistic Models for HOLP, MOLP, and LOHP

\begin{tabular}{|c|c|c|c|c|c|c|}
\hline \multirow[b]{4}{*}{ Social demographics } & \multicolumn{2}{|l|}{ HOLP } & \multicolumn{2}{|l|}{ MOLP } & \multicolumn{2}{|l|}{ LOHP } \\
\hline & \multicolumn{2}{|l|}{ Odds } & \multirow{2}{*}{\multicolumn{2}{|c|}{$\begin{array}{l}\text { Odds } \\
\text { Ratio }\end{array}$}} & \multirow{2}{*}{\multicolumn{2}{|c|}{$\begin{array}{l}\text { Odds } \\
\text { Ratio }\end{array}$}} \\
\hline & Ratio & & & & & \\
\hline & \multirow{2}{*}{\multicolumn{2}{|c|}{ ref. }} & & \\
\hline Male without children & & & ref. & & ref. & \\
\hline Female without children & 0.508 & $* *$ & 1.315 & & 1.818 & $* *$ \\
\hline Male with children & 0.199 & $* * *$ & 1.310 & & 2.292 & $* * *$ \\
\hline Female with children & 2.344 & $* * *$ & 1.859 & & 1.401 & \\
\hline Age: $18-34$ & ref. & & ref. & & ref. & \\
\hline Age:35-54 & 0.525 & $* * *$ & 1.080 & & 1.559 & \\
\hline Age: 55 or older & 3.680 & $* * *$ & 0.764 & & 1.098 & \\
\hline Education: college degree or above & ref. & & ref. & & ref. & \\
\hline Education: below college degree & 1.683 & $* * *$ & 0.369 & $*$ & 1.096 & \\
\hline Income: $\$ 50,000$ or higher & ref. & & ref. & & ref. & \\
\hline Income: less than $\$ 50,000$ & 3.883 & $* * *$ & 0.759 & & 0.731 & \\
\hline Self-reported health condition $(1-5)$ & 0.805 & $* *$ & 0.897 & & 0.743 & $* * *$ \\
\hline Years lived in current neighborhood & 0.952 & $* * *$ & 1.010 & & 1.018 & \\
\hline Number of vehicles in the home & 1.606 & $* * *$ & 0.594 & $* * *$ & 0.785 & $* *$ \\
\hline \multicolumn{7}{|l|}{ Attitudes } \\
\hline Pro-bike & 0.903 & & 1.181 & & 1.156 & \\
\hline Pro-transit & 1.074 & & 1.261 & & 1.067 & \\
\hline Pro-car & 0.956 & & 1.324 & $*$ & 1.150 & \\
\hline Pro-walk & 0.928 & $* * *$ & 0.614 & $* * *$ & 1.118 & \\
\hline Travel is negative & 1.122 & $* * *$ & 0.999 & & 0.767 & $* *$ \\
\hline \multicolumn{7}{|l|}{ Social environment } \\
\hline $\begin{array}{l}\text { Supportive social environment for } \\
\text { bicycling }\end{array}$ & 0.899 & $*$ & 0.658 & & 1.367 & $* *$ \\
\hline Perceived crime rate in the neighborhood & 2.148 & $* * *$ & 1.895 & $* * *$ & 1.077 & \\
\hline Behavior & & & & & 1.000 & \\
\hline I never ride a bike & ref. & & ref. & & ref. & \\
\hline I ride a bike occasionally & 0.343 & $* * *$ & 1.261 & & 1.873 & $*$ \\
\hline I ride a bike regularly & 0.225 & $* *$ & 0.377 & & 3.020 & $* * *$ \\
\hline Constant & 0.378 & & 6.009 & $* *$ & 0.388 & \\
\hline \multicolumn{7}{|l|}{ Model Statistics } \\
\hline Number of observations & 101 & & 108 & & 311 & \\
\hline Log-likelihood at 0 & -65.173 & & -74.786 & & -213.815 & \\
\hline Log-likelihood at convergence & -47.682 & & -60.992 & & -192.205 & \\
\hline Pseudo R2 & 0.268 & & 0.184 & & 0.101 & \\
\hline
\end{tabular}




\section{Conclusions and Policy Implications}

This study aimed to explore the environment-behavior mechanism by investigating the mismatch between the objective and perceived environment, and factors contributing to this mismatch. The mismatch between perceptions and the actual environment might be one of the reasons for the lower rates of active travel behavior among the residents living in objectively defined walkable and bikeable neighborhoods. Exploring the mismatch problem, therefore, could be important for identifying potential interventions for promoting active travel behavior. Even though several recent studies have examined the mismatch problem under the context of walking behavior, there is little such research on bicycling. Relying on the data from a random phone survey of adults in the Portland, OR, region, this study empirically tested the potential relationships between the objective and perceived built environment and bicycling behavior, as well as factors that may intervene in these relationships.

Results of this study indicate that there was some agreement between perceptions and the objectively measured bicycling environment, but that inconsistencies exist. Several methodological challenges can explain the mismatches. First, it is difficult to objectively define and measure bikeability. A good bicycling environment may mean different environmental attributes for different people for different bicycling purposes. For example, a bicycle commuter may prefer an environment featuring dedicated bicycle infrastructure, while another bicyclist riding for daily errands may like an accessible environment. A better understanding of the built environment is needed for different types of bicyclists and for different bicycling purposes. Second, measurement error in 
GIS measures may also contribute to the weak associations. Major measurement error in GIS-based measures can be introduced by incomplete records of the built-environment data, lack of information on the quality and size of the infrastructure and business establishments, and different buffer size used for defining the neighborhood. Third, perception-based measures may also be subject to measurement error. All of the perception measures are derived from surveys in this study. However, the survey instruments may not have exactly captured the perceptions of the environment, and individuals may not correctly interpret the survey questions.

In addition, perceptions of the environment reflect an individual's interaction with the environment, involving an awareness and perception of the outside world through primary receptive senses such as sight, smell, hearing, taste and touch. All of these sensory inputs are then integrated to form our cognitive representation of the environment (Sherrington, 1961). A mix of individual and societal factors, such as gender, social class, personal values, place attachment, local culture, social norms, past experiences, physical capacity, and individual personal characteristics may influence the understanding of these cognitive representations, and perceptions of environment may not correspond to objective reality. Therefore, different people might form different mental maps of the same built environment and consequently behave differently (Ewing \& Handy, 2009). Studies have found that there are significant discrepancies between researcher- and resident-defined neighborhood boundaries (Coulton, et al., 2013; Coulton, et al., 2001). Further, individuals who live in close proximity can differ markedly from one another in how they define the spatial dimension of their neighborhoods (Coulton, et al., 2001). In 
this study, we used a fixed buffer size (one mile) as an objective neighborhood boundary for all residents. This brings another challenge to compare the objective and perceived neighborhood environment. Finally, the objective and perceived measures do not match up perfectly in this study. For example, we could not include a specific objective measure to correspond to the perceived measure of overall satisfaction with neighborhood design in terms of bike safety.

Even if these methodological challenges are solved, people's perceptions and objective measures are unlikely to always match. Further analysis of the factors contributing to the mismatches we found identify that certain demographic, attitudinal, social, and behavioral factors are associated with a mismatch as we measured it. On the one hand, this indicated that interventions aimed at changing perceptions may be most effective if tailored to people with the following characteristics: lower socioeconomic status, women having children in the household, older adults, and people in bad health. On the other hand, this implies that our defined walkable or bikeable environments may not well meet the needs of this group of people. Special facilities and environment amenities may be needed in the neighborhoods to encourage this group of people to walk and bicycle. This group of people, who are more likely to have low perceptions even if they lived in highbikeable neighborhoods, is underrepresented in many bike advocacy efforts and local transportation decisions (Aimen \& Morris, 2012).

This study also found that social environment can play a role in the relationship between the objective and perceived environment. For example, receiving less support for bicycling from family and friends and a perception of high crime in the neighborhood 
prevent residents living in high-bikeable neighborhoods to have positive perceptions of the environment. This implies that strategies aiming to encourage a supportive culture for bicycling and reduce neighborhood crime (and perceptions of crime) are necessary for promoting bicycling. This is consistent with other bicycling studies that find social culture is important in encouraging bicycling (Handy, et al., 2010; Pucher \& Buehler, 2012).

Results of this study also indicate that both the actual and perceived built environment are associated with bicycling behavior, particularly for utilitarian bicycling. For recreational bicycling, the objective environment attributes measured in this study are not significant factors, while the perceptions do matter. It is possible that people drive to places far from their home to bike for recreation, and therefore their neighborhood environment may not be relevant for their recreational bicycling. It is also possible that the bicycling environment measured in this study is not well applicable for recreational bicycling. Further, the relative effects of the objective and perceived environment on bicycling behavior vary among different bicycling purposes.

For utilitarian bicycling, the objective environment is more important than the perceived environment. This is evidenced by the fact that the respondents who live in low objective bikeability environments have consistently low levels of utilitarian bicycling no matter how high or low the perceptions are. The perceptions only matter for utilitarian bicycling in a high or moderate bicycling environment. By contrast, perceptions may have a stronger effect on recreational bicycling than the objective environment. Even though the differences are not statistically significant, the labeled moderate-bicycling environment, 
featured with many bicycle lanes and off-street bicycle paths/trails, seems more supportive for recreational bicycling than the labeled high-bicycling environment with more utilitarian destinations and low-traffic streets. Moreover, persons with more positive perceptions of the environment generally bicycled more than those with low perceptions, no matter what actual environment they lived. This is true for both utilitarian and recreational bicycling. This finding indicates that perceptions are as important as the built environment in promoting bicycling behavior.

Many of our findings indicate that intervention programs to improve people's perceptions of the environment will further help to reap the full potential of planning and design policies, especially targeting the population group with low perceptions but living in an objectively high-bikeable environment. Possible interventions to change perceptions include neighborhood-based marketing materials that include information on the location of safe bicycle routes, bicycle safety facts and tips, and locations of bicycle-accessible businesses and destinations. Public bicycling events, such "ciclovias" and the city of Portland's Sunday Parkways, which close streets to cars for several hours, can also familiarize residents with the bicycle-friendly designs in their neighborhood. Wayfinding signage that includes bicycling distances and travel times to key destinations may also change perceptions. More hands-on programs involving matching experienced and new bicyclists may also help change perceptions. Meanwhile, it is worth note that only a small share of the population lived in high bikeable areas (Table 19). Therefore, changing perceptions of people in those areas will have a limited overall effect. Changing the objective environment is still very important. 
The findings of this study also help to explain the mixed findings from recent work on walking behavior and/or physical activity. Several recent studies found that perceptions may play a much larger role than the objective environment (Gebel, et al., 2009; Prins, et al., 2009; Scott, et al., 2007). However, other studies found that the objective environment had stronger associations with walking and/or physical activity than perceptions (Lin \& Moudon, 2010; Rodriguez, et al., 2009). Based on the findings of this study, one of the factors contributing to the inconsistent findings is that previous studies did not differentiate the behavior based on purpose. Results of this study indicate that the relative effects of the objective and perceived environment on behavior may vary depending on the purpose of the travel.

This study also confirms the result from a recent study (Van Acker, et al., 2013) that found the relative effects of perceptions on travel-mode choice depend on residential neighborhood type. In particular, they found the travel-mode choice is more determined by urban characteristics and not by personal perceptions in urban settings, but perceptions do become more important in the suburban and rural areas. In our study, however, we found that perceptions of the environment only matter for utilitarian bicycling in high and/or moderate levels of an objective bikeability environment, while for recreational bicycling perceptions do become more important in a low-bikeability environment.

The present work begins to investigate the relationship between the mismatch of the objective and perceived built environment and bicycling behavior. Future research can improve this study by including more precise and matched measures of the objective and perceived environment. Exploring the variations of the mismatch among different socio- 
demographic groups and at different contexts (e.g., urban vs. suburban/rural) would also be enlightening. 


\section{Chapter 8. Paper 4: Does The Installation of Bicycle Boulevards Improve Residents' Perceptions of The Bicycling and Walking Environment? A Panel Study}

\section{Introduction}

Changing the built environment as an intervention to increase walking and bicycling behavior has attracted attention in both transportation and public health disciplines over the last decade (Ewing \& Cervero, 2010; Saelens \& Handy, 2008; Saelens, Sallis, \& Frank, 2003; Sallis, et al., 2004). There has been growing evidence about the relationship between the built environment and walking and bicycling behavior. However, the behavioral mechanisms of walking and bicycling behavior remains less well understood.

One important part of the puzzle is the relationship between the objectively measured environment and people's perceptions of the environment. Socio-cognitive theory (Bandura, 1986) has pointed to an important distinction between the built environment as it is objectively measured and the built environment as perceived by individuals. According to this theory, the built environment may influence behavior but it will do so by influencing the perception of individuals. The perceived environment may, therefore, mediate associations between the built environment and behavior. Mediation by perception may provide a plausible explanation for why some studies fail to find a strong association between the built environment and walking or bicycling behavior. It is therefore important to understand the relationship between the objective and perceived environment, and exploring the pathway from the built environment to the perceptions may help to better understand the environment-behavioral mechanism (Handy, et al., 2006). Although there has been some work on the mismatch between the objective and 
perceived environment (Gebel, et al., 2009; Gebel, et al., 2011; Van Acker, et al., 2013), there has been little consideration of the causal relationship between them. Further, most previous studies relied on cross-sectional designs. However, longitudinal data are required to explore how changes in the built environment may change perceptions and behavior.

To fill this research gap, this study explores the causal relationship between the built environment and perceptions of the environment. In particular, this study aims to evaluate the effects of traffic-calming infrastructure (bicycle boulevards) on improving residents' perceptions of the bicycling and walking environment, relying on data from a longitudinal study with a treatment and control group in Portland, OR. A bicycle boulevard, also known as a neighborhood greenway, is a low-traffic street with traffic calming devices that reduce the volume and speed of motor vehicle traffic and treatments at intersections with major streets that facilitate safe crossing. Some studies have suggested that bicyclists may prefer to use low-traffic or quiet streets. One GPS-revealed preference study confirmed that bicyclists went out of their way to use bicycle boulevards (Broach, et al., 2012).

\section{Methods}

\section{Data}

This analysis uses data from the Family Activity Study, a longitudinal study of the effects of traffic calming infrastructure (bicycle boulevards) on behavior. The study started with 335 households with children living in 19 study sites (nine treatments and 10 controls). 
Households within 1,000 feet of the selected streets were recruited to participate through a flyer left at the front door of every accessible housing unit and mailed invitations for inaccessible units $(\mathrm{n}=54,381)$. Potential participants were screened for eligibility. At least one child aged 5-17 and one adult parent or guardian had to agree to participate for the length of the study; both had to be physically able to ride a bicycle, have access to a working bicycle, and not intend to move in the near future. Only adults were included for this analysis.

Surveys were conducted at three points in time: Pre, Post, and Interim. Since the Interim survey was conducted during the construction period, this paper only uses the data from Pre and Post surveys. The Pre ( $\mathrm{n}=491$ adults) and Post $(\mathrm{n}=385)$ surveys are approximately two years apart, with bicycle boulevard construction occurring in between. The surveys include personal and household socio-demographics, subjective perceptions of the neighborhood environment, travel attitudes, social norms, self-efficacy towards travel behavior, and self-reported biking and walking behavior. Only the individuals who finished both the Pre and Post survey were included in the analysis (n=???). Table 23 compares the socio-demographics of the participants between the treatment and control group at the time of recruitment. Even though some of the differences were statistically significant, the magnitude of the differences in socio-demographic characteristics between the treatment and control group are small. 
Table 23: Sampling Characteristics at Time of Recruitment

\begin{tabular}{|c|c|c|c|}
\hline & $\begin{array}{c}\text { Contro } \\
1\end{array}$ & $\begin{array}{c}\text { Treatmen } \\
\mathrm{t}\end{array}$ & $\mathrm{p}$ \\
\hline Age in years at time of recruitment & 41.0 & 43.3 & 0.00 \\
\hline$\%$ Female & $64 \%$ & $63 \%$ & 0.79 \\
\hline$\%$ Hold a valid driver's license at time of recruitment & $93 \%$ & $97 \%$ & 0.08 \\
\hline$\%$ Employed or student at time of recruitment & $72 \%$ & $86 \%$ & 0.00 \\
\hline $\begin{array}{l}\text { Education level at time of recruitment (1-7, high school to } \\
\text { college or higher) }\end{array}$ & 5.0 & 5.4 & 0.04 \\
\hline BMI at time of recruitment (self-reported height \& weight) & 26.3 & 25.8 & 0.45 \\
\hline $\begin{array}{l}\text { Self-reported health condition at time of recruitment ( } 1-5, \text { poor- } \\
\text { excellent) }\end{array}$ & 2.8 & 2.9 & 0.34 \\
\hline
\end{tabular}

\section{Perception Measures}

The survey questions measuring respondents' perceptions of their neighborhood are developed based on the Neighborhood Environment Walkability Scale (NEWS) (Cerin, Conway, Saelens, Frank, \& Sallis, 2009; Cerin, Saelens, Sallis, \& Frank, 2006; Saelens, Sallis, Black, \& Chen, 2003). To further explore the effects of bicycle boulevards on different dimensions of environmental perceptions, four perception measures were developed based on survey questions: traffic safety, neighborhood attractiveness, walking accessibility, and bicycling accessibility. In addition to these four perception measures, the overall perception measure was calculated by averaging all of the perception measures derived from survey questions. Each survey question is scored using a fourpoint scale from strongly disagree (1) to strongly agree (4). The details of survey questions included in each measure are provided in Table 24. The descriptive analysis of the perception measures is provided in Table 25. 


\section{Modeling}

The five perception measures are the outcome variables. Since the outcome variables are bounded at one on the left and four on the right, we employed the Tobit model to estimate the changes of perceptions in response to the installation of the bicycle boulevard. The Tobit model is based on an unobserved (latent) continuous dependent variable $y_{i}^{*}$ that can take on any value:

$$
y_{i}=\left\{\begin{array}{lr}
y_{i}^{*} & \text { if } 1<y_{i}^{*}<4 \\
1 & \text { if } y_{i}^{*} \leq 1 \\
4 & \text { if } y_{i}^{*} \geq 4
\end{array}\right.
$$

where $\mathrm{y}_{\mathrm{i}}$ is the observed variable (perception measures in our case) for individual $i$. The Tobit model can be estimated with a maximum likelihood estimation. Further, the difference-in-differences estimator was used to evaluate whether there are significant differences between the treatment and control groups in terms of the changes of perceptions before and after the installation of the bicycle boulevard. When there are only two time points, the model can be specified as follows:

$$
y_{i}^{*}=\beta_{0}+\beta_{1} T_{i t}+\beta_{2} A_{i t}+\beta_{3} T_{i t} A_{i t}+\varepsilon
$$

where $T_{i t}=1$ if obs $i$ belongs to the treatment group, $A_{i t}=1$ if obs $i$ belongs to the Post period, $T_{i t} A_{i t}$ is the interaction term and the difference-in-differences estimator. Finally, considering the sampling households are clustered in 19 study sites, clustered standard errors were calculated in all models that helped to account for the possible spatial errors. 


\section{Table 24: Descriptions of Perception Measures}

\section{Perceptions of Traffic Safety}

${ }^{a}$ There is so much traffic along nearby streets that it makes it difficult or unpleasant for me to ...

a. walk in our neighborhood without my children

b. bike in our neighborhood without my children

c. walk in our neighborhood with my children

d. bike in our neighborhood with my children

a There is so much traffic along nearby streets that it makes it difficult or unpleasant for my child(ren) to ...

a. walk alone in our neighborhood

b. bike alone in our neighborhood

c. walk with other children in our neighborhood

d. bike with other children in our neighborhood

The speed of traffic on most nearby streets is usually slow ( $25 \mathrm{mph}$ or less)

${ }^{a}$ Most drivers exceed the posted speed limits in our neighborhood

There are crosswalks and signals to help walkers cross busy streets in our neighborhood

\section{Perceptions of Neighborhood Attractiveness}

There are trees along the streets in our neighborhood

There are many interesting things to look at in our neighborhood

There are many attractive sights in our neighborhood (such as landscaping, views)

There are attractive buildings/homes in our neighborhood

\section{Perceptions of Walking Accessibility}

The following are within easy walking distance of home for me without kids along: Park

The following are within easy walking distance of home for me without kids along: Shops

The following are within easy walking distance of home for me without kids along: Transit (Bus or MAX) stop

The following are within easy walking distance of home for me without kids along: Many places to go

The following are within easy walking distance of home for me with kids along: Park

The following are within easy walking distance of home for me with kids along: Shops

The following are within easy walking distance of home for me with kids along: Transit (Bus or MAX) stop

The following are within easy walking distance of home for me with kids along: Many places to go

\section{Perceptions of Bicycling Accessibility}

The following are within easy biking distance of home for me without kids along: Park

The following are within easy biking distance of home for me without kids along: Shops

The following are within easy biking distance of home for me without kids along: Transit (Bus or MAX) stop

The following are within easy biking distance of home for me without kids along: Many places to go

The following are within easy biking distance of home for me with kids along: Park

The following are within easy biking distance of home for me with kids along: Shops

The following are within easy biking distance of home for me with kids along: Transit (Bus or MAX) stop

The following are within easy biking distance of home for me with kids along: Many places to go

${ }^{a}$ Reverse coded, larger number means safer. 
Table 25: Descriptive Analysis of Perception Measures

\begin{tabular}{lcccccc}
\hline & \multicolumn{2}{c}{ Pre-Survey } & \multicolumn{3}{c}{ Post-Survey } \\
\hline & $\begin{array}{c}\text { Cronbach's } \\
\text { Alpha }\end{array}$ & mean & $\begin{array}{c}\text { Std. } \\
\text { Deviation }\end{array}$ & $\begin{array}{c}\text { Cronbach's } \\
\text { Alpha }\end{array}$ & $\begin{array}{c}\text { Std. } \\
\text { mean }\end{array}$ & Deviation \\
\hline $\begin{array}{l}\text { Perceptions of traffic } \\
\text { safety (Mean score of 11 } \\
\text { survey questions) }\end{array}$ & 0.90 & 2.84 & 0.67 & 0.90 & 2.90 & 0.65 \\
$\begin{array}{l}\text { Perceptions of } \\
\text { neighborhood }\end{array}$ & & & & & & \\
$\begin{array}{l}\text { attractiveness (Mean score } \\
\text { of } 4 \text { survey questions) }\end{array}$ & 0.86 & 3.19 & 0.71 & 0.88 & 3.20 & 0.71 \\
$\begin{array}{l}\text { Perceptions of walking } \\
\text { accessibility (Mean score } \\
\text { of 8 survey questions) }\end{array}$ & 0.84 & 3.47 & 0.51 & 0.87 & 3.46 & 0.55 \\
$\begin{array}{l}\text { Perceptions of bicycling } \\
\text { accessibility (Mean score } \\
\text { of 8 survey questions) }\end{array}$ & 0.85 & 3.70 & 0.46 & 0.89 & 3.66 & 0.51 \\
$\begin{array}{l}\text { Overall Perceptions of the } \\
\text { Environment (Mean score } \\
\text { of all perception questions) }\end{array}$ & 0.92 & 3.30 & 0.44 & 0.93 & 3.30 & 0.47 \\
\hline
\end{tabular}

\section{Results}

Table 26 presents the results of the five Tobit models with difference-in-differences estimators, which predict perceptions of traffic safety, neighborhood attractiveness, walking accessibility, bicycling accessibility, and overall perceptions of the environment, respectively. First of all, the variable of interest of this study is the interaction term between Post and Treatment, which is the difference-in-differences estimator. The model results indicated that three of the five interaction terms were statistically significant, suggesting that changes in perceptions of neighborhood attractiveness, walking accessibility and overall perceptions of the neighborhood environment were significantly different between the treatment and control groups. Based on the model results, Figure 
11was generated to better illustrate the different changes in perceptions between the treatment and control groups before and after the installation of bicycle boulevards. It is evident that the perceptions of residents in the treatment group increased after the treatment, while the perceptions of residents in the control group decreased.

In addition to the difference-in-differences estimators, each model accounted for sociodemographics and attitudes towards walking and bicycling. As expected, some of these variables were associated with the perceptions. For example, the model results indicated that age was positively associated with more positive perceptions of traffic safety and overall environment. Compared with males, females perceived their neighborhood as more attractive and accessible for walking. However, there were no significant differences between males and females in perceptions of traffic safety and bicycling accessibility. Not surprisingly, attitudes about walking and biking were significantly associated with perceptions, but with different perception dimensions. In particular, positive attitudes towards walking were associated with positive perceptions of neighborhood attractiveness and walking accessibility, while positive attitudes towards bicycling were associated with positive perceptions of traffic safety and bicycling accessibility. Both walking and bicycling attitudes were associated with overall perceptions of the neighborhood environment. Finally, the previous walking and bicycling behaviors were also associated with perception measures. For example, people who walk regularly at stage one were more likely to have positive perceptions of traffic safety, neighborhood attractiveness and bicycling accessibility.

Should note somewhere the low explanatory power of the models. 
In addition to the models for the five composite measures of perceptions, repeatedmeasures linear models were also tested for each individual perception measure. Explain why this was done. The model results are reported in Appendix B. Move the paragraph to after the table and figure. And, add some text about the highlights from that analysis. 
Table 26: Results of Tobit Models with Difference-in-differences Specification

\begin{tabular}{|c|c|c|c|c|c|c|c|c|c|c|}
\hline & \multicolumn{2}{|c|}{$\begin{array}{l}\text { Perception of } \\
\text { Traffic Safety }\end{array}$} & \multicolumn{2}{|c|}{$\begin{array}{l}\text { Perception of } \\
\text { Neighborhood } \\
\text { Attractiveness }\end{array}$} & \multicolumn{2}{|c|}{$\begin{array}{l}\text { Perception of } \\
\text { Walking } \\
\text { Accessibility }\end{array}$} & \multicolumn{2}{|c|}{$\begin{array}{l}\text { Perception of } \\
\text { Bicycling } \\
\text { Accessibility }\end{array}$} & \multicolumn{2}{|c|}{$\begin{array}{c}\text { Overall } \\
\text { Perception of } \\
\text { the } \\
\text { Environment }\end{array}$} \\
\hline & Coef. & $\mathrm{P}>\mathrm{t}$ & Coef. & $\mathrm{P}>\mathrm{t}$ & Coef. & $\mathrm{P}>\mathrm{t}$ & Coef. & $\mathrm{P}>\mathrm{t}$ & Coef. & $\mathrm{P}>\mathrm{t}$ \\
\hline Phase: Post (pre is ref) & 0.03 & 0.71 & -0.04 & 0.54 & -0.04 & 0.06 & -0.06 & 0.53 & -0.03 & 0.27 \\
\hline Treatment (control is ref) & 0.00 & 0.97 & 0.01 & 0.96 & -0.10 & 0.44 & 0.01 & 0.97 & -0.02 & 0.84 \\
\hline Post x Treatment & 0.06 & 0.48 & 0.18 & 0.02 & 0.11 & 0.00 & 0.02 & 0.87 & 0.07 & 0.01 \\
\hline Age at phase I & 0.02 & 0.00 & 0.00 & 0.83 & 0.00 & 0.49 & 0.00 & 0.67 & 0.01 & 0.09 \\
\hline BMI & 0.00 & 0.61 & -0.01 & 0.55 & -0.01 & 0.17 & -0.01 & 0.46 & 0.00 & 0.40 \\
\hline Female & 0.05 & 0.28 & 0.20 & 0.03 & 0.12 & 0.03 & 0.08 & 0.26 & 0.09 & 0.03 \\
\hline WalkAttitudes & -0.04 & 0.45 & 0.12 & 0.18 & 0.22 & 0.00 & 0.04 & 0.75 & 0.04 & 0.36 \\
\hline BikeAttitudes & 0.11 & 0.02 & 0.01 & 0.83 & 0.02 & 0.71 & 0.19 & 0.01 & 0.07 & 0.07 \\
\hline Walk regularly at phase 1 & 0.29 & 0.00 & 0.52 & 0.00 & 0.15 & 0.20 & 0.32 & 0.00 & 0.26 & 0.00 \\
\hline Bike regularly at phase 1 & 0.07 & 0.30 & 0.20 & 0.09 & -0.05 & 0.57 & 0.10 & 0.40 & 0.05 & 0.35 \\
\hline Constant & 1.61 & 0.00 & 2.19 & 0.00 & 2.61 & 0.00 & 2.91 & 0.00 & 2.50 & 0.00 \\
\hline Log-Lik Intercept Only & -692.74 & & -852.57 & & -682.05 & & -650.59 & & -420.01 & \\
\hline Log-Lik Full Model & -644.22 & & -801.64 & & -637.57 & & -607.83 & & -350.29 & \\
\hline McFadden's R2 & 0.07 & & 0.06 & & 0.07 & & 0.07 & & 0.17 & \\
\hline Number of obs & 686 & & 685 & & 686 & & 683 & & 686 & \\
\hline
\end{tabular}



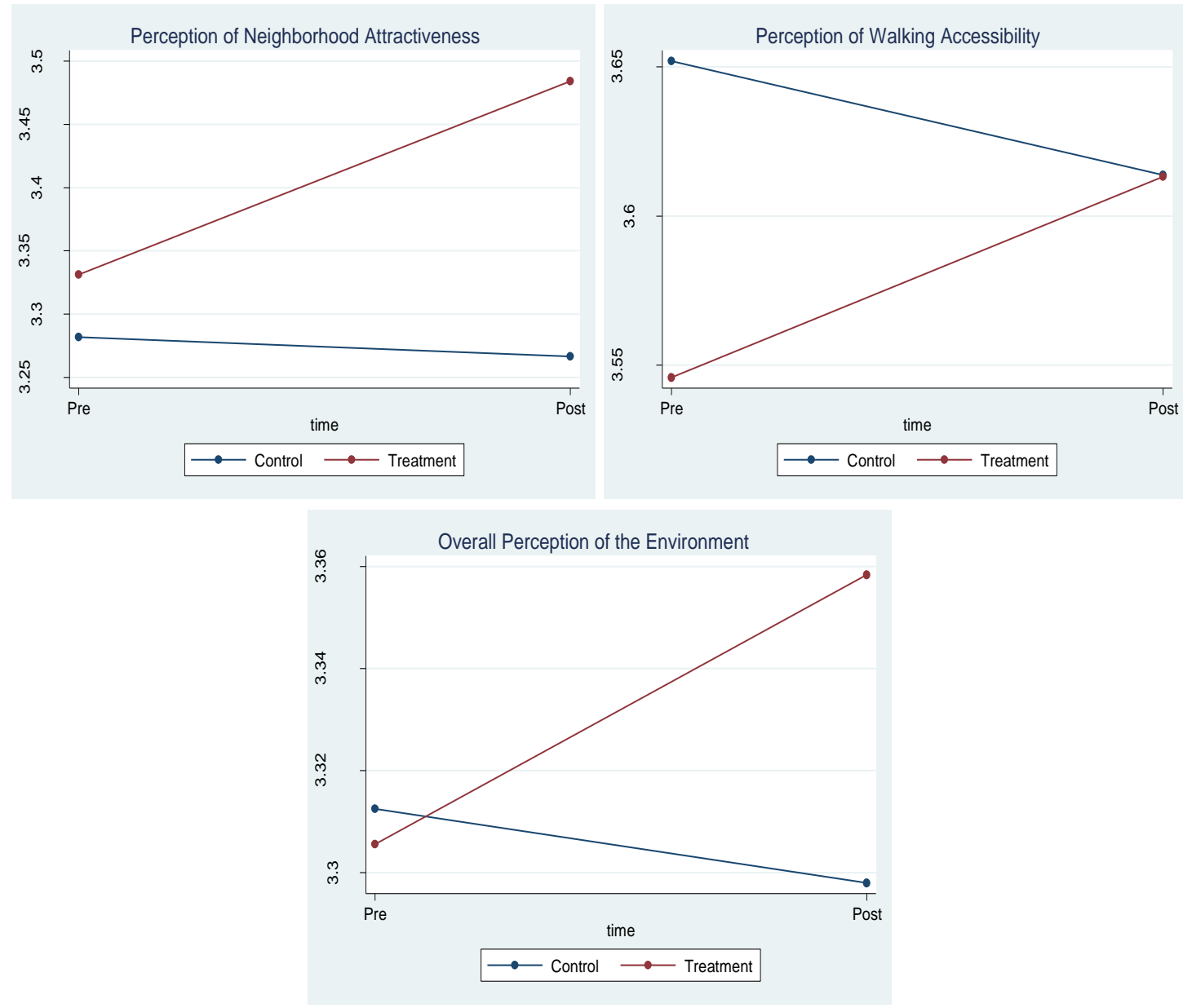

Figure 11: Predicted Values of Perceptions for Treatment and Control Groups at Pre and Post

\section{Conclusions}

Relying on longitudinal data, this study evaluated the effects of traffic-calming infrastructure (bicycle boulevards) on people's perceptions of their neighborhood environment for walking and bicycling. Five different Tobit models with difference-indifferences estimators evaluated different dimensions of the perceptions, and the model results indicated that installation of bicycle boulevards might help to improve residents' perceptions of their neighborhood environment for walking and attractiveness. This is 
particularly evident for improved perceptions of neighborhood attractiveness and walking accessibility.

Surprisingly, this study did not find significant effects of bicycle boulevards on improving people's perceptions of traffic safety, which was thought to be a direct effect considering most of its elements are associated with traffic calming. This finding suggested that the installation of bicycle boulevards in neighborhoods might not have immediate effects on improving perceptions of traffic safety, at least in the short term. It is possible that changes in perceptions of traffic safety take longer than the treatment time of this study, which varied between 2-12 months.

It is also interesting to note that the installation of bicycle boulevards improved perceptions of walking accessibility, but not perceptions of bicycling accessibility. This may imply that the spatial extent of the effects of a bicycle boulevard is limited, probably within a reasonable walking distance. It is also possible that there are relatively small numbers of bicyclists, and therefore most of the respondents, who are non-bicyclists, may not change their perceptions of the bicycling environment corresponding to the actual changes of the built environment because they never bike. The empirical evidence from article one has suggested that bicyclists and non-bicyclists have different perceptions of the same environment. Moveover, some of the most visible elements of a bicycle boulevard, such as traffic control devices to aid crossing busy streets (including rectangular rapid flash beacons, crosswalks, signage, bulb-outs) can benefit pedestrians as well as bicyclists. 
The findings of this study suggest that the pathway from the built environment to perceptions of the bicycling environment is not straightforward. This means that changes in the built environment may not directly translate to changes in perceptions about the environment. However, as indicated by Chapter 6, Paper 2 (Ma, et al., 2014), the perception is the mediator between the built environment and bicycling behavior. Solely changing the built environment, therefore, may not increase bicycling effectively unless perceptions of the environment improved in response to changes in the built environment. Family Activity Study (Jennifer Dill, McNeil, Broach, \& Ma, 2014) found that the amount of walking and bicycling, measured using GPS, did not significantly increase after the installation of bicycle boulevards. No significant improvement in the perceptions of traffic safety, found in this study, may help to explain the insignificant effects of bicycle boulevards on walking and bicycling behavior.

This study has limitations. First of all, the construction of the bicycle boulevards often took more than one year, and other significant changes in the built environment within the study sites may not be captured. This may introduce the omitted variable bias when estimating the difference-in-differences models. Secondly, the actual treatments for each site were not the same. Some treatment sites included more substantial investments, such as a pocket park, flashing beacons and even landscaping, while others only installed the basic elements of a bicycle boulevard, such as speed humps, sharrow markings, changed stop signs, and signage. The variations of the treatments may also lead to over/under estimate the treatment effects. Third, this study did not test other factors that may influence the effects of the built environment on perceptions, such as socio-demographics, 
attitudes, previous behavior, distance to the infrastructure (bicycle boulevard in this study), and amount of treatment time. 


\section{Chapter 9: Conclusions}

This study systematically explored the relationship between the objective (actual) environment and people's perceptions of the environment, and their relative effects on travel behavior. Because there are fewer empirical studies on bicycling behavior, this research has focused on the bicycling environment and its associations with bicycling behavior. However, the methods, conceptual model and findings from should be useful to investigate other modes of travel and physical activity. The major findings of this study are summarized below and in Table 27:

First of all, this study found that the perceived environment and objective environment had independent effects on bicycling. Under some circumstances, models with only perceived measures could lead to completely different conclusions than models with only objective measures. This might be one of the reasons for the inconsistent findings among the current studies linking the built environment with bicycling behavior. This analysis also found that the models with both perceived and objective measures explain more than models with just one or the other.

Second, this study further explored the relationship between the perceived environment and objective environment, and found that the objectively measured bicycling environment had only an indirect effect on bicycling behavior through influencing one's perceptions of the environment. In other words, even if people live in a highly bikeable neighborhood, they might not bicycle more until they recognize the advantages of these bicycle-friendly characteristics. 
Third, this study further asked the question about to what extent the objectively measured environment corresponds to the perceived environment and what factors lead to the mismatch between them, and found that there was only a fair agreement between perceptions and the objectively measured bicycling environment. Further analysis of the factors contributing to the mismatch between the perceived and objective environment revealed that people with the following characteristics are more likely to perceive an objectively assessed high-bikeable environment as low bikeable: lower socioeconomic status, as measured in educational attainment and household income; women having children in the household; elder adults; people with bad health; new movers into the neighborhood; families with high levels of car ownership; negative attitudes towards bicycling and walking; and lower levels of bicycling.

Finally, relying on longitudinal data, this study found that changes in the actual built environment may change perceptions of the environment. In particular, this study found that the installation of bicycle boulevards might help to improve residents' perceptions of their neighborhood environment for walking. This is particularly evident for improved perceptions of neighborhood attractiveness and walking accessibility. However, this study found that the pathway from the built environment to perceptions of the bicycling environment is not straightforward. Surprisingly, this study did not find significant effects of bicycle boulevards on improving people's perceptions of traffic safety; bicycle boulevards are thought to be directly associated with traffic calming. It is also interesting to note that the installation of bicycle boulevards improved the perceptions of walking accessibility, but not the perceptions of bicycling accessibility. This means changes in the 
built environment may not directly translate to changes in perceptions of a bicycling environment. Other intervention programs that aim to improve people's perceptions of the environment may be needed.

The four empirical studies in this dissertation consistently found significant and independent effects on perceptions of the environment, in addition to the objective environment, on active travel, particularly bicycling. This implies that interventions aimed at improving people's perceptions of the environment may be necessary as a complement to current efforts which focus primarily on the physical design of the built environment. Our findings about the relationships between demographic characteristics and perceptions and behavior indicate that programs aimed at changing perceptions may want to target women and older adults. Meanwhile, it is also worth noting that our model found that the objective environment had a direct and significant influence on perceptions of the environment, and therefore changes to the physical environment and infrastructure for bicycling are still very important and necessary. Interventions that improve perceptions of the environment will serve as a complement that helps reap the full potential of built-environment interventions. 
Table 27: Summary of the Main Findings of This Study

\begin{tabular}{lll}
\hline Research questions & Hypothesis & $\begin{array}{l}\text { Main } \\
\text { Findings }\end{array}$ \\
\hline $\begin{array}{l}\text { 1. Do perceived and objective environment attributes have } \\
\text { different effects on active travel behavior? }\end{array}$ & $\begin{array}{l}\text { Independent } \\
\text { effects }\end{array}$ & Confirmed \\
$\begin{array}{l}\text { 2. Do perceptions mediate the effects of the objective environment } \\
\text { on active travel behavior? }\end{array}$ & $\begin{array}{l}\text { Yes } \\
\text { 3. How does the objectively measured built environment }\end{array}$ & $\begin{array}{l}\text { There is a } \\
\text { correspond to the perceived built environment? }\end{array}$ \\
$\begin{array}{lll}\text { 4. Do changes in the built environment change perceptions, and in } \\
\text { turn change travel behavior? }\end{array}$ & Confirmed \\
\hline
\end{tabular}

Finally, this study has limitations. First, given the data limitations, the objective and perceived measures do not match up perfectly in this study. This may overestimate the discrepancy between the objective and perceived environment. Second, more complete and precise measurements of the objective and perceived environment are needed. Both the perceived and objective measures in this study have measurement errors. Major measurement error in objective measures can be introduced by incomplete records of the built-environmental data, lack of information on the quality and size of the infrastructure and business establishments, and different buffer size used for defining the neighborhood. Perception-based measures may also be subject to measurement error. All the perception measures are derived from surveys in this stud. However, the survey instruments may not have exactly captured the perceptions of the environment, and individuals may not correctly interpret the survey questions. Recent technology advances in neuroscience, computer science and physiology may help better measure human perceptions. Third, this study is based on Portland, OR. Given the region's unique characteristics, some findings 
of this study may not be applicable to other regions. The hypothesis and conceptual models proposed in this study, therefore, need to be tested in other cities and regions.

Even with the above limitations, this study makes several contributions to the literature linking the built environment and travel behavior. First, this study is one of the first to explore the mismatch between the objective and perceived bicycling environment, and the different effects of objective and perceived environment on bicycling behavior, whereas previous studies focus on walking environment and walking behavior. Second, this study developed and confirmed the mediation effects of perceptions on the relationship between the built environment and active travel. This study expands the current understanding on the relationship between the built environment and active travel by using the socio-cognitive theories. Third, this study investigated the causality between the built environment and perceptions and relied on longitudinal data, whereas most previous studies are of cross-sectional design. 


\section{References}

Aimen, D., \& Morris, A. (2012). Practical Approaches for Involving Traditionally Underserved Populations in Transportation Decisionmaking. Washington, DC: Transportation Research Board.

Ajzen, I. (1991). The theory of planned behavior. Organizational Behavior and Human Decision Processes, 50(2), 179-211.

Akar, G., Fischer, N., \& Namgung, M. (2013). Bicycling Choice and Gender Case Study: The Ohio State University. International Journal of Sustainable Transportation, 7(5), 347-365.

Allison, P. D. (1999). Logistic regression using the SAS system theory and application. Cary, N.C.: SAS Institute.

Alton, D., Adab, P., Roberts, L., \& Barrett, T. (2007). Relationship between walking levels and perceptions of the local neighbourhood environment. Archives of disease in childhood, 92(1), 29-33.

Bagley, M. N., \& Mokhtarian, P. L. (2002). The impact of residential neighborhood type on travel behavior: A structural equations modeling approach. The Annals of Regional Science, 36(2), 279-297.

Baker, J. (1987). The Role of Environment in Marketing Services: The Consumer Perspective. In J. A. Czepiel, C. A. Congram, J. Shanahan \& A. American Marketing (Eds.), The Services challenge : integrating for competitive advantage (pp. 79-84). Chicago, Ill.: American Marketing Association.

Ball, K., Jeffery, R. W., Crawford, D. A., Roberts, R. J., Salmon, J., \& Timperio, A. F. (2008). Mismatch between perceived and objective measures of physical activity environments. Preventive Medicine, 47(3), 294-298. doi: 10.1016/j.ypmed.2008.05.001

Bandura, A. (1986). Social foundations of thought and action: a social cognitive theory. Englewood Cliffs, N.J.: Prentice-Hall.

Baron, R. M., \& Kenny, D. A. (1986). The moderator-mediator variable distinction in social psychological research: conceptual, strategic, and statistical considerations. Journal of Personality and Social Psychology, 51(6), 1173-1182.

Beenackers, M., Foster, S., Kamphuis, C. B., Titze, S., Divitini, M., Knuiman, M., et al. (2012). Taking up cycling after residential relocation: built environment factors. American Journal of Preventive Medicine, 42(6), 610-615.

Bettman, J. R. (1979). An information processing theory of consumer choice. Reading, Mass.: Addison-Wesley Pub. Co.

Bitner, M. J. (1992). Servicescapes: The Impact of Physical Surroundings on Customers and Employees. The Journal of Marketing, 56(2), 57-71.

Blashfield, R. K., \& Aldenderfer, M. S. (1978). The Literature On Cluster Analysis. Multivariate Behavioral Research, 13(3), 271-295.

Boarnet, M., \& Crane, R. (2001). Travel by design : the influence of urban form on travel. Oxford; New York: Oxford University Press.

Boarnet, M., Greenwald, M., \& McMillan, T. E. (2008). Walking, urban design, and health: Toward a cost-benefit analysis framework. J. Plann. Educ. Res. Journal of Planning Education and Research, 27(3), 341-358. 
Boarnet, M., Joh, K., Siembab, W., Fulton, W., \& Mai Thi Nguyen, W. (2010). Retrofitting the Suburbs to Increase Walking: Evidence from a Land-use-Travel Study. Urban Studies, 48(1), 129-159.

Boarnet, M., \& Sarmiento, S. (1998). Can Land-use Policy Really Affect Travel Behaviour? A Study of the Link between Non-work Travel and Land-use Characteristics. Urban Studies, 35(7), 1155-1170.

Bopp, M., Wilcox, S., Laken, M., Butler, K., Carter, R. E., McClorin, L., et al. (2006). Factors Associated with Physical Activity Among African-American Men and Women. American journal of preventive medicine, 30(4), 340-346.

Boulding, K. E. (1956). The image; knowledge in life and society. Ann Arbor: University of Michigan Press.

Broach, J., Dill, J., \& Gliebe, J. (2012). Where do cyclists ride? A route choice model developed with revealed preference GPS data. Transportation Research Part A: Policy \& Practice, 46(10), 1730-1740.

Bronfenbrenner, U. (1977). Toward an experimental ecology of human development. American Psychologist American Psychologist, 32(7), 513-531.

Bronfenbrenner, U. (1979). The ecology of human development : experiments by nature and design. Cambridge, Mass.: Harvard University Press.

Brownson, R. C., Hoehner, C. M., Day, K., Forsyth, A., \& Sallis, J. F. (2009). Measuring the built environment for physical activity: state of the science. American journal of preventive medicine, 36(4), 99-123.

Buehler, R., \& Pucher, J. (2012). Cycling to work in 90 large American cities: new evidence on the role of bike paths and lanes. Transportation, 39(2), 409-432.

Burbidge, S. K., \& Goulias, K. G. (2008). ACTIVE TRAVEL BEHAVIOR. Paper presented at the The 88th Annual Meeting of the Transportation Research Board, Washington, D.C.

Burton, N. W., Turrell, G., Oldenburg, B., \& Sallis, J. F. (2005). The Relative Contributions of Psychological, Social, and Environmental Variables to Explain Participation in Walking, Moderate-, and Vigorous-Intensity Leisure-Time Physical Activity. Journal of Physical Activity \& Health, 2(2), 181-196.

Cao, X. J., Mokhtarian, P. L., \& Handy, S. L. (2009). The relationship between the built environment and nonwork travel: A case study of Northern California. Transportation Research Part A: Policy and Practice, 43(5), 548-559.

Carver, A., Salmon, J., Campbell, K., Baur, L., Garnett, S., \& Crawford, D. (2005). How do perceptions of local neighborhood relate to adolescents' walking and cycling? American journal of health promotion : AJHP, 20(2).

Centers for Disease Control and Prevention, C. (2005). Trends in leisure-time physical inactivity by age, sex, and race/ethnicity--United States, 1994-2004 MMWR. Morbidity and mortality weekly report (Vol. 54, pp. 991-994).

Cerin, E., Conway, T. L., Saelens, B. E., Frank, L. D., \& Sallis, J. F. (2009). Crossvalidation of the factorial structure of the Neighborhood Environment Walkability Scale (NEWS) and its abbreviated form (NEWS-A). International Journal of Behavioral Nutrition and Physical Activity, 6. 
Cerin, E., Saelens, B. E., Sallis, J. F., \& Frank, L. D. (2006). Neighborhood environment walkability scale: Validity and development of a short form. Medicine and Science in Sports and Exercise, 38(9), 1682-1691.

Cervero, R., \& Duncan, M. (2003). Walking, bicycling, and urban landscapes: evidence from the San Francisco Bay Area. American Journal of Public Health, 93(9), 1478-1483.

Cervero, R., Sarmiento, O., Jacoby, E., Gomez, L., \& Neiman, A. (2009). Influences of Built Environments on Walking and Cycling: Lessons from Bogota. International Journal of Sustainable Transportation, 3(4), 203-226.

Chatman, D. G. (2009). Residential choice, the built environment, and nonwork travel: Evidence using new data and methods. Environment and Planning A, 41(5), 10721089.

Coulton, C. J., Jennings, M. Z., \& Chan, T. (2013). How big is my neighborhood? Individual and contextual effects on perceptions of neighborhood scale. American Journal of Community Psychology, 51(1-2), 140-150. doi: 10.1007/s10464-0129550-6

Coulton, C. J., Korbin, J., Chan, T., \& Su, M. (2001). Mapping residents' perceptions of neighborhood boundaries: a methodological note. American Journal of Community Psychology, 29(2), 371-383.

Crane, R. (1996). On Form versus Function: Will the New Urbanism Reduce Traffic, or Increase It? Journal of Planning Education and Research, 15(2), 117-126.

De Bourdeaudhuij, I., Teixeira, P. J., Cardon, G., \& Deforche, B. (2005). Environmental and psychosocial correlates of physical activity in Portuguese and Belgian adults. Public health nutrition, 8(7), 886-895.

Dill, J. (2009). Bicycling for Transportation and Health: The Role of Infrastructure. Journal of Public Health Policy, 30, S95-S110.

Dill, J., \& Carr, T. (2003). Bicycle commuting and facilities in major U.S. cities : if you build them, commuters will use them. Transportation Research Record: Journal of the Transportation Research Board(1828), 116-123.

Dill, J., \& McNeil, N. (2013a). Four types of cyclists? Examination of typology for better understanding of bicycling behavior and potential. Transportation Research Record: Journal of the Transportation Research Board, 2387(1), 129-138. doi: $10.3141 / 2387-15$

Dill, J., \& McNeil, N. (2013b). Four Types of Cyclists? Examining a Typology to Better Understand Bicycling Behavior and Potential. Transportation Research Record: Journal of the Transportation Research Board(Forthcoming).

Dill, J., McNeil, N., Broach, J., \& Ma, L. (2014). Bicycle boulevards and changes in physical activity and active transportation: Findings from a natural experiment. Preventive Medicine, Under review.

Dill, J., \& Mohr, C. (2010). Long term evaluation of individualized marketing programs for travel demand management: Oregon Transportation Research and Education Consortium (OTREC).

Dill, J., Mohr, C., \& Ma, L. (2014). How can psychological theory help cities increase walking and bicycling? Journal of the American Planning Association, Forthcoming. 
Dill, J., \& Voros, K. (2007). Factors affecting bicycling demand : initial survey findings from the Portland, Oregon, region. Transportation Research Record: Journal of the Transportation Research Board, 2031(1), 9-17. doi: 10.3141/2031-02

Duncan, M., \& Mummery, K. (2005). Psychosocial and environmental factors associated with physical activity among city dwellers in regional Queensland. Preventive Medicine, 40(4), 363-372.

Emond, C. R., \& Handy, S. (2012). Factors associated with bicycling to high school: insights from Davis, CA. Journal of Transport Geography, 20(1), 71-79. doi: 10.1016/j.jtrangeo.2011.07.008

Emond, C. R., Tang, W., \& Handy, S. L. (2009). Explaining Gender Difference in Bicycling Behavior. Transportation Research Record: Journal of the Transportation Research Board, 2125, 16-25.

Evenson, K., Birnbaum, A., Bedimo-Rung, A., Sallis, J., Voorhees, C., Ring, K., et al. (2006). Girls' perception of physical environmental factors and transportation: reliability and association with physical activity and active transport to school. International Journal of Behavioral Nutrition and Physical Activity, 3(1).

Ewing, R., \& Cervero, R. (2001). Travel and the Built Environment: A Synthesis. Transportation Research Record: Journal of the Transportation Research Board(1780), 87-112.

Ewing, R., \& Cervero, R. (2010). Travel and the built environment. Journal of the American Planning Association, 76(3), 265-294. doi: 10.1080/01944361003766766

Ewing, R., \& Handy, S. (2009). Measuring the unmeasurable: Urban design qualities related to walkability. Journal of Urban Design, 14(1), 65-84.

Ewing, R., Handy, S., Brownson, R. C., Clemente, O., \& Winston, E. (2006). Identifying and Measuring Urban Design Qualities Related to Walkability. Journal of Physical Activity \& Health, 3, S223-S240.

Forsyth, A., Hearst, M., Oakes, J. M., \& Schmitz, K. H. (2008). Design and destinations: Factors influencing walking and total physical activity. Urban Studies, 45(9), 1973-1996.

Forsyth, A., \& Oakes, J. M. (2013). Cycling, the Built Environment, and Health: Results of a Midwestern Study. [Forthcoming]. International Journal of Sustainable Transportation. doi: 10.1080/15568318.2012.725801

Frank, L., \& Engelke, P. (2005). Multiple Impacts of the Built Environment on Public Health: Walkable Places and the Exposure to Air Pollution. International Regional Science Review, 28(2), 193-216.

Fuzhong, L., Fisher, K. J., Brownson, R. C., \& Bosworth, M. (2005). Multilevel modelling of built environment characteristics related to neighbourhood walking activity in older adults. Journal of Epidemiology \& Community Health, 59(7).

Gärling, T., Gillholm, R., \& Gärling, A. (1998). Reintroducing attitude theory in travel behavior research: The validity of an interactive interview procedure to predict car use. Transportation, 25(2), 129-146.

Garrard, J., Rissel, C., \& Bauman, A. (2012). Health benefits of cycling. In J. Pucher \& R. Buehler (Eds.), City cycling (pp. 31-55). Cambridge, Massachusetts: MIT Press. 
Gebel, K., Bauman, A., \& Owen, N. (2009). Correlates of Non-Concordance between Perceived and Objective Measures of Walkability. Annals of Behavioral Medicine, 37(2), 228-238.

Gebel, K., Bauman, A. E., Sugiyama, T., \& Owen, N. (2011). Mismatch between perceived and objectively assessed neighborhood walkability attributes:

Prospective relationships with walking and weight gain. Health \& Place, 17(2), 519-524. doi: 10.1016/j.healthplace.2010.12.008

Golledge, R. G., Brown, L. A., \& Williamson, F. (1972). Behavioural approaches in geography: an overview. Australian Geographer Australian Geographer, 12(1), 59-79.

Golledge, R. G., \& Stimson, R. J. (1997). Spatial behavior : a geographic perspective. New York: Guilford Press.

Haines, A., McMichael, A. J., Smith, K. R., Roberts, I., Woodcock, J., Markandya, A., et al. (2009). Health and Climate Change 6 Public health benefits of strategies to reduce greenhouse-gas emissions: overview and implications for policy makers. Lancet, 374(9707), 2104-2114. doi: Doi 10.1016/S0140-6736(09)61759-1

Handy, S. (2005). Critical Assessment of the Literature on the Relationships Among Transportation, Land Use, and Physical Activity Does the Built Environment Influence Physical Activity? Examining the Evidence--TRB Special Report 282.

Handy, S., Boarnet, M. G., Ewing, R., \& Killingsworth, R. E. (2002). How the built environment affects physical activity: views from urban planning. American journal of preventive medicine, 23(2), 64-73.

Handy, S., Cao, X., \& Mokhtarian, P. (2005). Correlation or causality between the built environment and travel behavior? Evidence from Northern California.

Transportation Research Part D: Transport and Environment, 10(6), 427-444. doi: 10.1016/j.trd.2005.05.002

Handy, S., Cao, X., \& Mokhtarian, P. (2006). Self-selection in the relationship between the built environment and walking: Empirical evidence from Northern California. Journal of the American Planning Association, 72(1), 55-74. doi: 10.1080/01944360608976724

Handy, S., \& Xing, Y. (2011). Factors Correlated with Bicycle Commuting: A Study in Six Small U.S. Cities. International Journal of Sustainable Transportation, 5(2), 91-110. doi: 10.1080/15568310903514789

Handy, S., Xing, Y., \& Buehler, T. J. (2010). Factors associated with bicycle ownership and use: a study of six small U.S. cities. Transportation, 37(6), 967-985.

Haskell, W. L., Lee, I. M., Pate, R. R., Powell, K. E., Blair, S. N., Franklin, B. A., et al. (2007). Physical activity and public health: updated recommendation for adults from the American College of Sports Medicine and the American Heart Association. Medicine and science in sports and exercise, 39(8), 1423-1434.

Hayes, A. F. (2009). Beyond Baron and Kenny: Statistical Mediation Analysis in the New Millennium. Communication Monographs, 76(4).

Heinen, E., Maat, K., \& van Wee, B. (2011). The role of attitudes toward characteristics of bicycle commuting on the choice to cycle to work over various distances. Transportation Research Part D: Transport and Environment, 16(2), 102-109. doi: 10.1016/j.trd.2010.08.010 
Heinen, E., van Wee, B., \& Maat, K. (2010). Commuting by Bicycle: An Overview of the Literature. Transport Reviews, 30(1), 59-96.

Hess, P. M. (1999). Site design and pedestrian travel. Transportation research record.(1674).

Hoehner, C. M., Brennan Ramirez, L. K., Elliott, M. B., Handy, S. L., \& Brownson, R. C. (2005a). Perceived and objective environmental measures and physical activity among urban adults. American journal of preventive medicine, 28(2), 105-116. doi: 10.1016/j.amepre.2004.10.023

Hoehner, C. M., Brennan Ramirez, L. K., Elliott, M. B., Handy, S. L., \& Brownson, R. C. (2005b). Perceived and objective environmental measures and physical activity among urban adults. American journal of preventive medicine, 28(2), 105-116.

Hooker, S. P., Wilson, D. K., Griffin, S. F., \& Ainsworth, B. E. (2005). Perceptions of environmental supports for physical activity in African American and white adults in a rural county in South Carolina. Preventing chronic disease, 2(4).

Hough, J. A., Cao, X., \& Handy, S. L. (2008). Exploring travel behavior of elderly women in rural and small urban north dakota an ecological modeling approach. Transportation Research Record: Journal of the Transportation Research Board, 2082(1), 125-131.

Humpel, N., Marshall, A. L., Leslie, E., Bauman, A., \& Owen, N. (2004). Changes in neighborhood walking are related to changes in perceptions of environmental attributes. Annals of Behavioral Medicine : a publication of the Society of Behavioral Medicine, 27(1), 60-67.

Kirtland, K. A., Porter, D. E., Addy, C. L., Neet, M. J., Williams, J. E., Sharpe, P. A., et al. (2003). Environmental measures of physical activity supports: Perception versus reality. American Journal of Preventive Medicine, 24(4), 323-331. doi: 10.1016/s0749-3797(03)00021-7

Kitamura, R., Mokhtarian, P. L., \& Daidet, L. (1997). A micro-analysis of land use and travel in five neighborhoods in the San Francisco Bay Area. Transportation, 24(2), 125-158.

Kline, R. B. (2005). Principles and practice of structural equation modeling. New York: Guilford Press.

Krizek, K. J., Handy, S. L., \& Forsyth, A. (2009). Explaining changes in walking and bicycling behavior: Challenges for transportation research. Environment and Planning B: Planning and Design, 36(4), 725-740.

Krizek, K. J., \& Johnson, P. J. (2006). Proximity to Trails and Retail: Effects on Urban Cycling and Walking. Journal of the American Planning Association, 72(1), 3342.

Lackey, K. J., \& Kaczynski, A. T. (2009). Correspondence of perceived vs. objective proximity to parks and their relationship to park-based physical activity. The International Journal of Behavioral Nutrition and Physical Activity, 6.

Lin, L., \& Moudon, A. V. (2010). Objective versus subjective measures of the built environment, which are most effective in capturing associations with walking? Health \& Place, 16(2), 339-348. doi: 10.1016/j.healthplace.2009.11.002 
Lund, H. (2003). Testing the Claims of New Urbanism: Local Access, Pedestrian Travel, and Neighboring Behaviors. Journal of the American Planning Association, 69(4), 414-429.

Lynch, K. (1960). The image of the city. Cambridge, Mass.: MIT Press.

Ma, L., \& Dill, J. (2014). Effects of the objective and perceived built environment on bicycling for transportation. Paper presented at the Transportation Research Board 93rd Annual Meeting, Washington, D.C.

Ma, L., Dill, J., \& Mohr, C. (2014). The objective versus the perceived environment: what matters for bicycling? Transportation, 1-18. doi: 10.1007/s11116-014-9520y

MacKinnon, D. P., Fairchild, A. J., \& Fritz, M. S. (2007). Mediation Analysis. Annual review of psychology, 58(1).

Maizlish, N., Woodcock, J., Co, S., Ostro, B., Fanai, A., \& Fairley, D. (2013). Health Cobenefits and Transportation-Related Reductions in Greenhouse Gas Emissions in the San Francisco Bay Area. American Journal of Public Health, 103(4), 703709. doi: Doi 10.2105/Ajph.2012.300939

Maruyama, G. (1997). Basics of structural equation modeling. Thousand Oaks, Calif.: Sage Publications.

McCormack, G., Cerin, E., Leslie, E., Du Toit, L., \& Owen, N. (2007). Objective Versus Perceived Walking Distances to Destinations: Correspondence and Predictive Validity. Environment and Behavior, 40(3), 401-425.

McCormack, G., Spence, J. C., Berry, T., \& Doyle-Baker, P. K. (2009). Does perceived behavioral control mediate the association between perceptions of neighborhood walkability and moderate- and vigorous-intensity leisure-time physical activity? Journal of Physical Activity \& Health, 6(5), 657-666.

McGinn, A., Evenson, K., Herring, A., Huston, S., \& Rodriguez, D. (2007). Exploring Associations between Physical Activity and Perceived and Objective Measures of the Built Environment. Journal of Urban Health, 84(2), 162-184.

McMillan, T. (2005). Urban Form and a Child's Trip to School: The Current Literature and a Framework for Future Research. Journal of Planning Literature, 19(4), 440-456.

Mehrabian, A., \& Russell, J. A. (1974). An approach to environmental psychology. Cambridge: M.I.T. Press.

Mokhtarian, P., \& Salomon, I. (2001). How derived is the demand for travel? Some conceptual and measurement considerations. Transportation Research Part A: Policy and Practice, 35(8), 695-719.

Mokhtarian, P., Salomon, I., \& Redmond, L. (2001). Understanding the Demand for Travel: It's Not Purely 'Derived'. Innovation: The European Journal of Social Sciences, 14(4), 355-380.

Mota, J., Gomes, H., Almeida, M., Ribeiro, J. C., Carvalho, J., \& Santos, M. P. (2007). Active versus passive transportation to school-differences in screen time, socioeconomic position and perceived environmental characteristics in adolescent girls. Annals of human biology, 34(3), 273-282.

Mullahy, J. (1986). Specification and Testing of Some Modified Count Data Models. Journal of Econometrics, 33(3), 341-365. doi: 10.1016/0304-4076(86)90002-3 
Nelson, A. C., \& Allen, D. (1997). If you build them, commuters will use them : association between bicycle facilities and bicycle commuting. Transportation Research Record: Journal of the Transportation Research Board, 1578(1), 79-83.

Noland, R., Deka, D., \& Walia, R. (2011). A Statewide Analysis of Bicycling in New Jersey. International Journal of Sustainable Transportation, 5(5), 251-269. doi: 10.1080/15568318.2010.501482

Parkin, J., Wardman, M., \& Page, M. (2008). Estimation of the determinants of bicycle mode share for the journey to work using census data. Transportation, 35(1), 93109.

Prins, R. G., Oenema, A., van der Horst, K., \& Brug, J. (2009). Objective and perceived availability of physical activity opportunities: differences in associations with physical activity behavior among urban adolescents. The International Journal of Behavioral Nutrition and Physical Activity, 6, 70. doi: 10.1186/1479-5868-6-70

Pucher, J., \& Buehler, R. (2012). City cycling. Cambridge, Mass.: MIT Press.

Pucher, J., Dill, J., \& Handy, S. (2010). Infrastructure, programs, and policies to increase bicycling: An international review. Preventive Medicine, 50, Supplement(0), S106-S125. doi: 10.1016/j.ypmed.2009.07.028

Ratner, Rebecca K., Kahn, Barbara E., \& Kahneman, D. (1999). Choosing LessPreferred Experiences For the Sake of Variety. Journal of Consumer Research, 26(1), 1-15.

Ridout, M., Demétrio, C. G., \& Hinde, J. (1998). Models for count data with many zeros. Paper presented at the the XIXth International Biometric Conference.

Rodriguez, D. A., Evenson, K. R., Diez Roux, A. V., \& Brines, S. J. (2009). Land Use, Residential Density, and Walking. American Journal of Preventive Medicine, 37(5), 397-404.

Saelens, B. E., \& Handy, S. L. (2008). Built environment correlates of walking: A review. Medicine \& Science in Sports \& Exercise, 40(7), S550-S566.

Saelens, B. E., Sallis, J. F., Black, J. B., \& Chen, D. (2003). Neighborhood-based differences in physical activity: An environment scale evaluation. American Journal of Public Health, 93(9), 1552-1558.

Saelens, B. E., Sallis, J. F., \& Frank, L. D. (2003). Environmental correlates of walking and cycling: findings from the transportation, urban design, and planning literatures. Annals of Behavioral Medicine : a publication of the Society of Behavioral Medicine, 25(2), 80-91.

Sallis, J. F. (2009). Measuring physical activity environments: a brief history. American Journal of Preventive Medicine, 36(4), 86-92.

Sallis, J. F., Conway, T. L., Dillon, L. I., Frank, L. D., Adams, M. A., Cain, K. L., et al. (2013). Environmental and demographic correlates of bicycling. Preventive Medicine, 57(5), 456-460. doi: 10.1016/j.ypmed.2013.06.014

Sallis, J. F., Frank, L. D., Saelens, B. E., \& Kraft, M. K. (2004). Active transportation and physical activity: opportunities for collaboration on transportation and public health research. Transportation Research Part A: Policy \& Practice, 38(4), 249268. doi: 10.1016/j.tra.2003.11.003

Sallis, J. F., Owen, N., \& Fisher, E. B. (2002). Ecological models of health behavior. In K. Glanz, B. K. Rimer \& F. M. Lewis (Eds.), Health behavior and health education : theory, research, and practice. San Francisco: Jossey-Bass. 
Sallis, J. F., Robert, C., Ascher, W., Henderson, K. A., Kraft, M. K., \& Kerr, J. (2006). An ecological approach to creating active living communities. Annual Review of Public Health, 27(1), 297-322.

Schellinck, D. A. (1983). Cue Choice As A Function of Time Pressure and Perceived Risk. In R. P. Bagozzi \& A. M. Tybout (Eds.), Advances in Consumer Research (Vol. 10, pp. 470-475).

Scott, M., Evenson, K., Cohen, D., \& Cox, C. (2007). Comparing perceived and objectively measured access to recreational facilities as predictors of physical activity in adolescent girls. Journal of Urban Health, 84(3), 346-359. doi: 10.1007/s11524-007-9179-1

Sherrington, C. S. (1961). The integrative action of the nervous system. New Haven: Yale University Press.

Simon, H. A. (1997). Administrative behavior : a study of decision-making processes in administrative organizations. New York: Free Press.

Spence, J. C., Plotnikoff, R. C., Rovniak, L. S., Martin Ginis, K. A., Rodgers, W., \& Lear, S. A. (2006). Perceived Neighbourhood Correlates of Walking Among Participants Visiting the Canada on the Move Website. Canadian Journal of Public Health/Revue Canadienne de Santé Publique., 97(1), S36-S40.

Steg, L. (2005). Car use: lust and must. Instrumental, symbolic and affective motives for car use. Transportation Research Part A: Policy and Practice, 39(2), 147-162.

Suminski, R. R., Poston, W. S., Petosa, R. L., Stevens, E., \& Katzenmoyer, L. M. (2005). Features of the neighborhood environment and walking by U.S. adults. American journal of preventive medicine, 28(2), 149-155.

Targa, F., \& Clifton, K. J. (2005). Built environment and nonmotorized travel: Evidence from Baltimore City using the NHTS. Journal of Transportation and Statistics, 8(3), 55-70.

Troiano, R. P., Berrigan, D., Dodd, K. W., Masse, L. C., Tilert, T., \& McDowell, M. (2008). Physical activity in the United States measured by accelerometer. Med. Sci. Sports Exerc. Medicine and Science in Sports and Exercise, 40(1), 181-188.

Turley, L., \& Milliman, R. (2000). Atmospheric Effects on Shopping Behavior: A Review of the Experimental Evidence. Journal of Business Research, 49(2), 193 211.

United States Department of Transportation. (2011). 2009 National Household Travel Survey, from http://nhts.ornl.gov/download.shtml

Van Acker, V., Derudder, B., \& Witlox, F. (2013). Why people use their cars while the built environment imposes cycling. Journal of Transport and Land Use, 6(1), 5362.

Van Acker, V., Van Wee, B., \& Witlox, F. (2010). When transport geography meets social psychology: Toward a conceptual model of travel behaviour. Transport Reviews, 30(2), 219-240. doi: 10.1080/01441640902943453

Van Dyck, D., Veitch, J., De Bourdeaudhuij, I., Thornton, L., \& Ball, K. (2013). Environmental perceptions as mediators of the relationship between the objective built environment and walking among socio-economically disadvantaged women. International Journal of Behavioral Nutrition and Physical Activity, 10. doi: 10.1186/1479-5868-10-108 
van Lenthe, F. J., Brug, J., \& Mackenbach, J. P. (2005). Neighbourhood inequalities in physical inactivity: the role of neighbourhood attractiveness, proximity to local facilities and safety in the Netherlands. Social Science \& Medicine, 60(4), 763775.

Vernez-Moudon, A., Lee, C., Cheadle, A. D., Collier, C. W., Johnson, D., Schmid, T. L., et al. (2005). Cycling and the built environment, a US perspective. Transportation Research Part D: Transport and Environment, 10(3), 245-261. doi: 10.1016/j.trd.2005.04.001

Wareham, N. J., van Sluijs, E. M. F., \& Ekelund, U. (2005). Symposium on 'Prevention of obesity': Physical activity and obesity prevention: a review of the current evidence. Proceedings of the Nutrition Society, 64(2), 229-247.

Weden, M. M., Carpiano, R. M., \& Robert, S. A. (2008). Subjective and objective neighborhood characteristics and adult health. Social Science \& Medicine Social Science \& Medicine, 66(6), 1256-1270.

Wen, M., Hawkley, L. C., \& Cacioppo, J. T. (2006). Objective and perceived neighborhood environment, individual SES and psychosocial factors, and selfrated health: An analysis of older adults in Cook County, Illinois. Social Science \& Medicine, 63(10), 2575-2590.

Winters, M., Brauer, M., Setton, M. E., \& Teschke, K. (2010). Built environment influences on healthy transportation choices: bicycling versus driving. Journal of Urban Health : bulletin of the New York Academy of Medicine, 87(6), 969-993. doi: 10.1007/s11524-010-9509-6

Woodcock, J., Edwards, P., Tonne, C., Armstrong, B. G., Ashiru, O., Banister, D., et al. (2009). Health and Climate Change 2 Public health benefits of strategies to reduce greenhouse-gas emissions: urban land transport. Lancet, 374(9705), 1930-1943. doi: Doi 10.1016/S0140-6736(09)61714-1

Xing, Y., Handy, S. L., \& Mokhtarian, P. L. (2010). Factors associated with proportions and miles of bicycling for transportation and recreation in six small US cities. Transportation Research Part D: Transport and Environment, 15(2), 73-81. doi: 10.1016/j.trd.2009.09.004

Yang, L., Sahlqvist, S., McMinn, A., Griffin, S. J., \& Ogilvie, D. (2010). Interventions to promote cycling: systematic review. British Medical Journal, 341. doi: 10.1136/Bmj.C5293 


\section{Appendix A. Survey Questions for Measuring Attitudes}

I like walking.

Walking can sometimes be easier for me than driving.

I prefer to walk rather than drive whenever possible.

Traveling by car is safer overall than walking.

I like taking transit.

I prefer to take transit rather than drive whenever possible.

Public transit can sometimes be easier for me than driving.

Traveling by car is safer overall than taking transit.

I like riding a bike.

I prefer to bike rather than drive whenever possible.

Biking can sometimes be easier for me than driving.

Traveling by car is safer overall than riding a bike.

I would like to travel by bike more than I do now.

Pollution from vehicles is a major problem.

Vehicles should be taxed on the basis of the amount of pollution they produce.

I try to limit my driving to help reduce pollution.

I like driving.

I need a car to do many of the things I like to do.

Travel time is generally wasted time.

I often use the telephone or the Internet to avoid having to travel somewhere.

The only good thing about traveling is arriving at your destination.

When I need to buy something, I usually prefer to get it at the closest store possible.

I prefer to organize my errands so that I make as few trips as possible.

The price of gasoline affects the choices I make about my daily travel.

Fuel efficiency is an important factor for me in choosing a vehicle.

It is important to me to get some physical exercise every day. 


\section{Appendix B. Repeated Measures ANOVA for all Perception Measures}

\begin{tabular}{|c|c|c|c|}
\hline \multirow[t]{2}{*}{ Dependent variables } & \multicolumn{2}{|c|}{ Within-Subjects Effects } & \multirow{2}{*}{$\begin{array}{c}\text { Tests of Between- } \\
\text { Subjects Effects } \\
\text { Treatment }\end{array}$} \\
\hline & Time & $\begin{array}{c}\text { Time * } \\
\text { Treatment }\end{array}$ & \\
\hline $\begin{array}{l}\text { There is so much traffic along nearby streets that it makes it difficult or unpleasant for me to...-walk in our neighborhood } \\
\text { without my children }\end{array}$ & .386 & .633 & .059 \\
\hline $\begin{array}{l}\text { There is so much traffic along nearby streets that it makes it difficult or unpleasant for me to....-bike in our neighborhood } \\
\text { without my children }\end{array}$ & .686 & .777 & .053 \\
\hline $\begin{array}{l}\text { There is so much traffic along nearby streets that it makes it difficult or unpleasant for me to....-walk in our neighborhood } \\
\text { with my children }\end{array}$ & .817 & .658 & .034 \\
\hline $\begin{array}{l}\text { There is so much traffic along nearby streets that it makes it difficult or unpleasant for me to....-bike in our neighborhood } \\
\text { with my children }\end{array}$ & .308 & .188 & .048 \\
\hline $\begin{array}{l}\text { There is so much traffic along nearby streets that it makes it difficult or unpleasant for my child(ren) to ...-walk alone in } \\
\text { our neighborhood }\end{array}$ & .000 & .995 & .079 \\
\hline $\begin{array}{l}\text { There is so much traffic along nearby streets that it makes it difficult or unpleasant for my child(ren) to ...-bike alone in our } \\
\text { neighborhood }\end{array}$ & .029 & .281 & .245 \\
\hline $\begin{array}{l}\text { There is so much traffic along nearby streets that it makes it difficult or unpleasant for my child(ren) to ...-walk with other } \\
\text { children in our neighborhood }\end{array}$ & .003 & .766 & .063 \\
\hline $\begin{array}{l}\text { There is so much traffic along nearby streets that it makes it difficult or unpleasant for my child(ren) to ...-bike with other } \\
\text { children in our neighborhood }\end{array}$ & .182 & .963 & .219 \\
\hline The speed of traffic on most nearby streets is usually slow ( $25 \mathrm{mph}$ or less) & .834 & .167 & .004 \\
\hline Most drivers exceed the posted speed limits in our neighborhood & .234 & .279 & .009 \\
\hline Walkers/bicyclists can easily be seen by people in their homes & .387 & .026 & .588 \\
\hline I often see bicyclists on my street & .924 & .766 & .134 \\
\hline There are crosswalks and signals to help walkers cross busy streets in our neighborhood & .004 & .362 & .051 \\
\hline There is a high crime rate in our neighborhood & 659 & .759 & .260 \\
\hline The crime rate in our neighborhood makes it unsafe for me to go on walks alone during the day & .017 & .238 & .159 \\
\hline The crime rate in our neighborhood makes it unsafe for me to go on walks alone at night & .092 & .118 & .109 \\
\hline The crime rate in our neighborhood makes it unsafe for my child(ren) to go on walks alone during the day & .088 & .550 & .073 \\
\hline The crime rate in our neighborhood makes it unsafe for my child(ren) to go on walks alone at night & .534 & .948 & .083 \\
\hline There are trees along the streets in our neighborhood & .172 & .845 & .375 \\
\hline There are many interesting things to look at in our neighborhood & .515 & .194 & .024 \\
\hline There are many attractive sights in our neighborhood (such as landscaping, views) & .260 & .050 & .007 \\
\hline
\end{tabular}

灾 
The following are within easy walking distance of home for me with kids along: Transit (Bus or MAX) stop 
$* \mathrm{p}<.1 ; * * \mathrm{p}<.05 ; * * * \mathrm{p}<.01$ 


\section{Appendix C. Plots of Repeated Measures ANOVA}
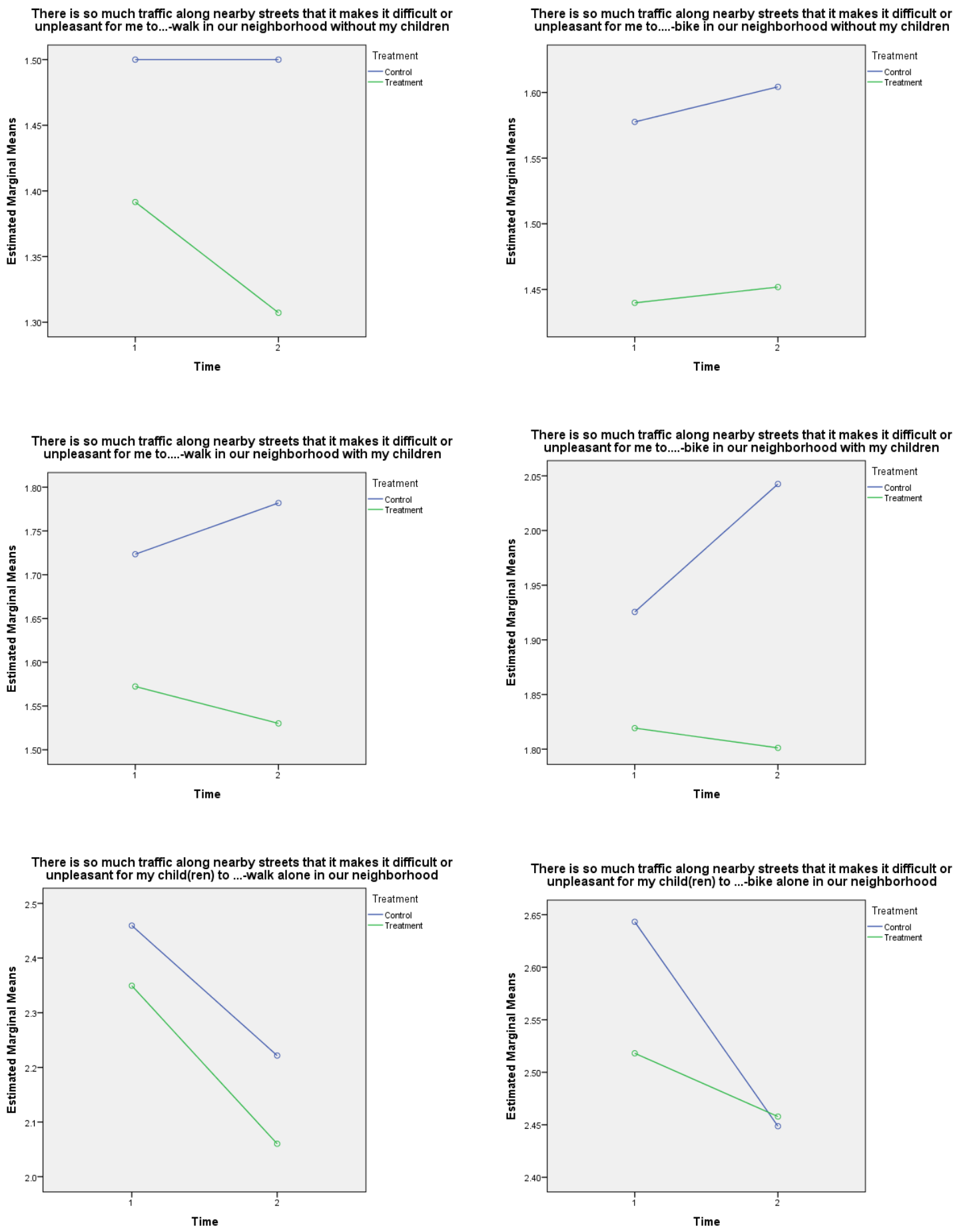
There is so much traffic along nearby streets that it makes it difficult or unpleasant for my child(ren) to ...-walk with other children in our neighborhood
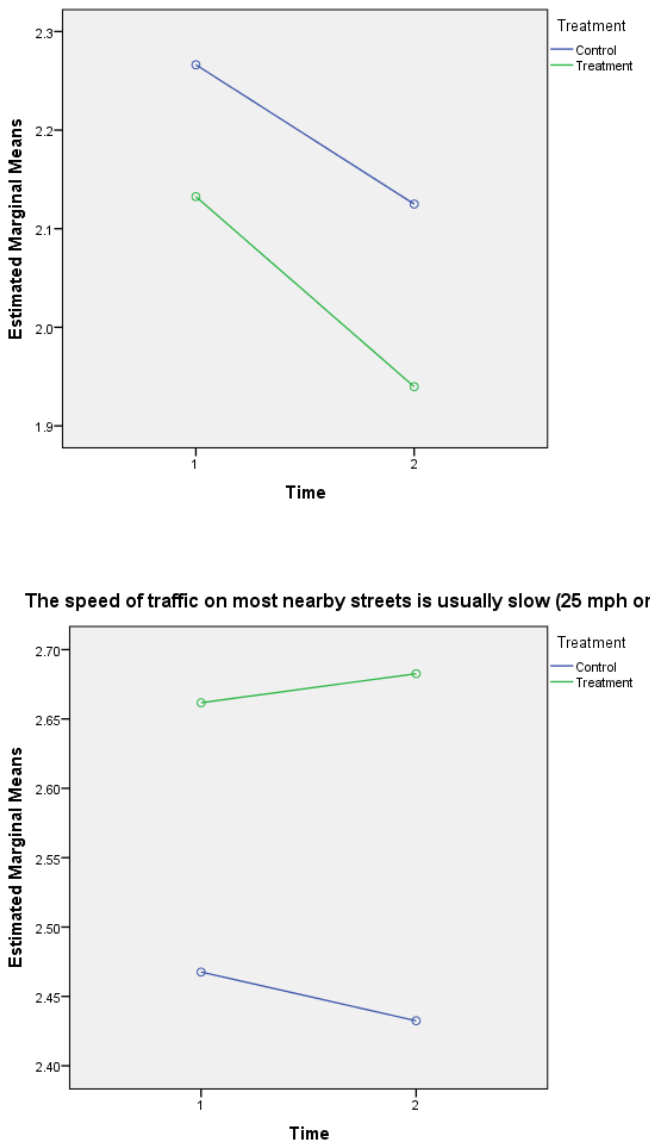

Walkers/bicyclists can easily be seen by people in their homes

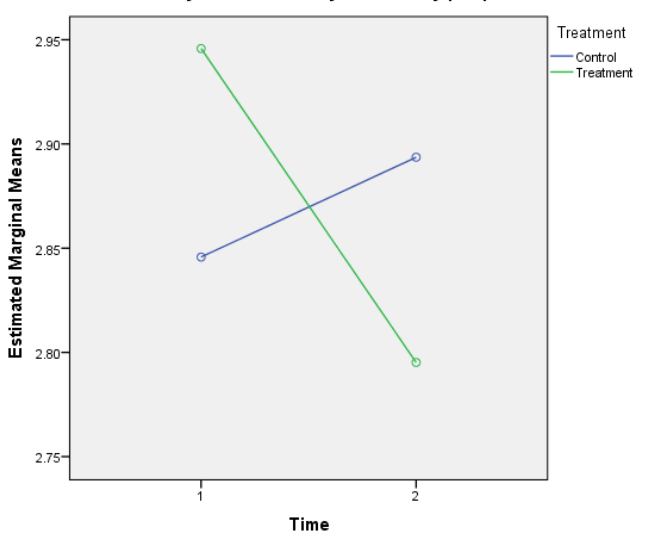

There is so much traffic along nearby streets that it makes it difficult or unpleasant for my child(ren) to ...-bike with other children in our neighborhood
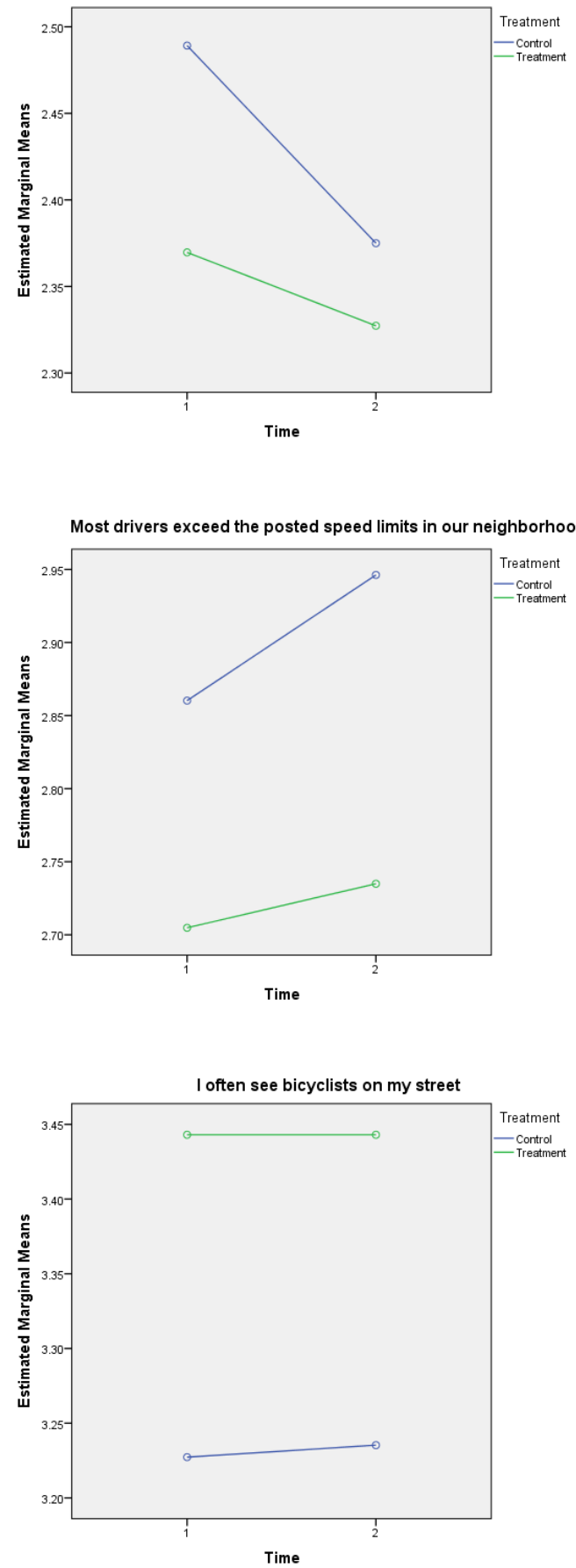
There are crosswalks and signals to help walkers cross busy streets in our neighborhood

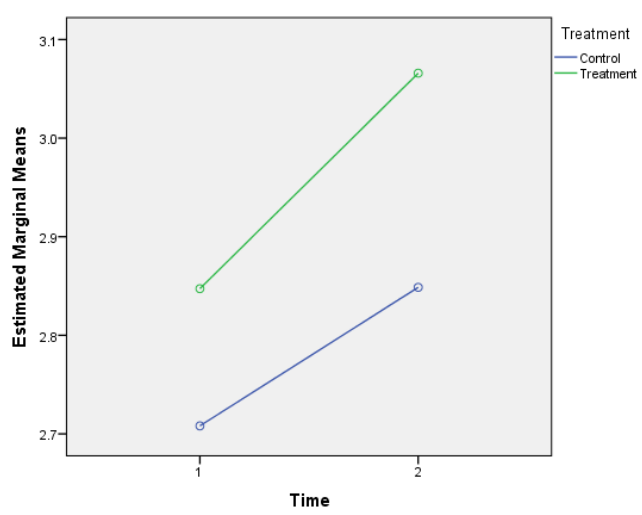

The crime rate in our neighborhood makes it unsafe for me to go on walks alone during the day

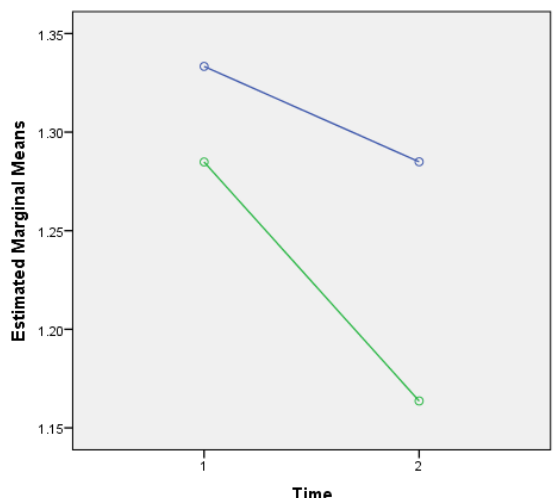

The crime rate in our neighborhood makes it unsafe for my child(ren) to go on walks alone during the day

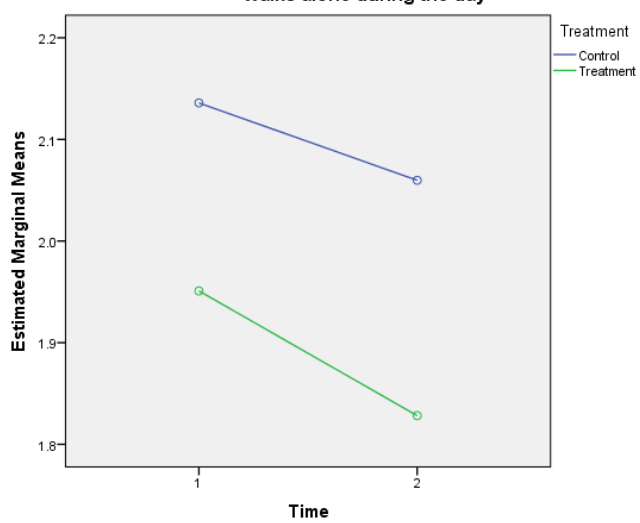

There is a high crime rate in our neighborhood

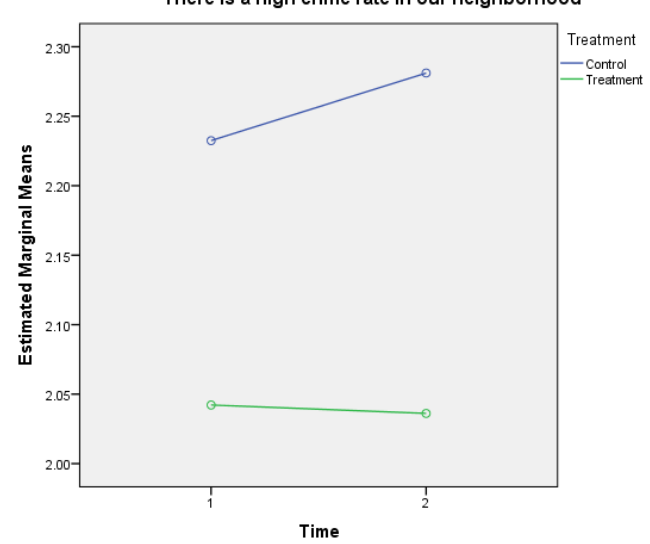

The crime rate in our neighborhood makes it unsafe for me to go on walks alone

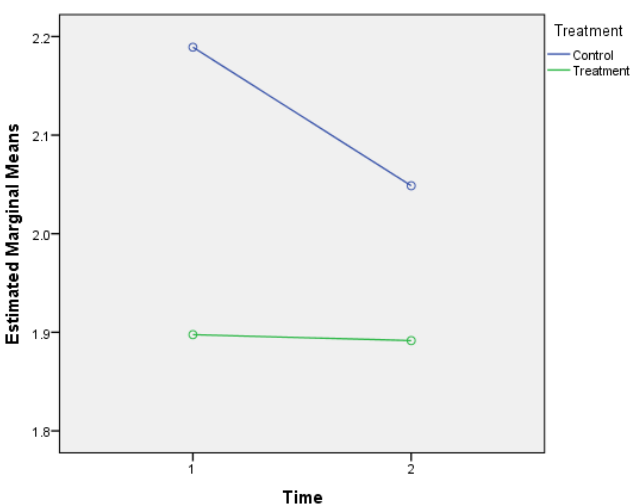

The crime rate in our neighborhood makes it unsafe for my child(ren) to go on

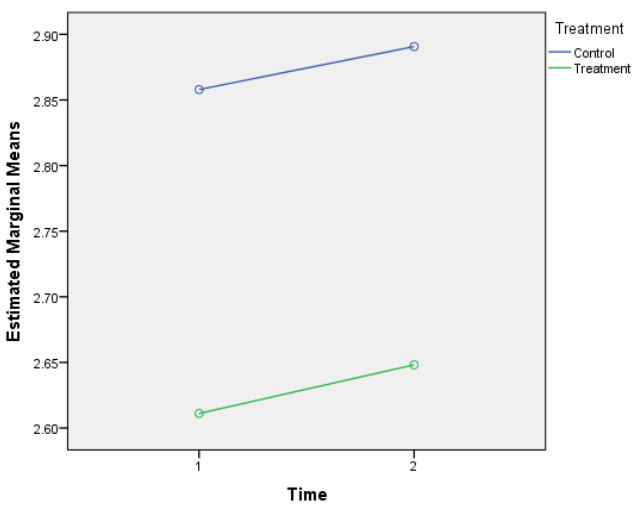



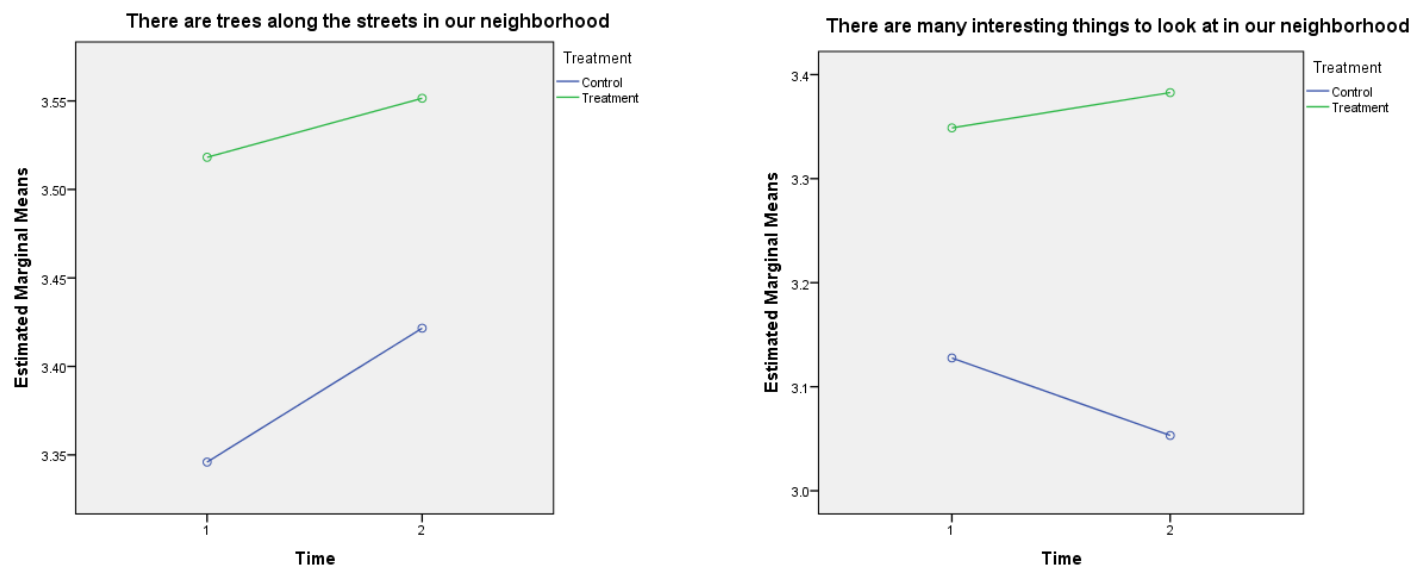

There are many attractive sights in our neighborhood (such as landscaping, views)
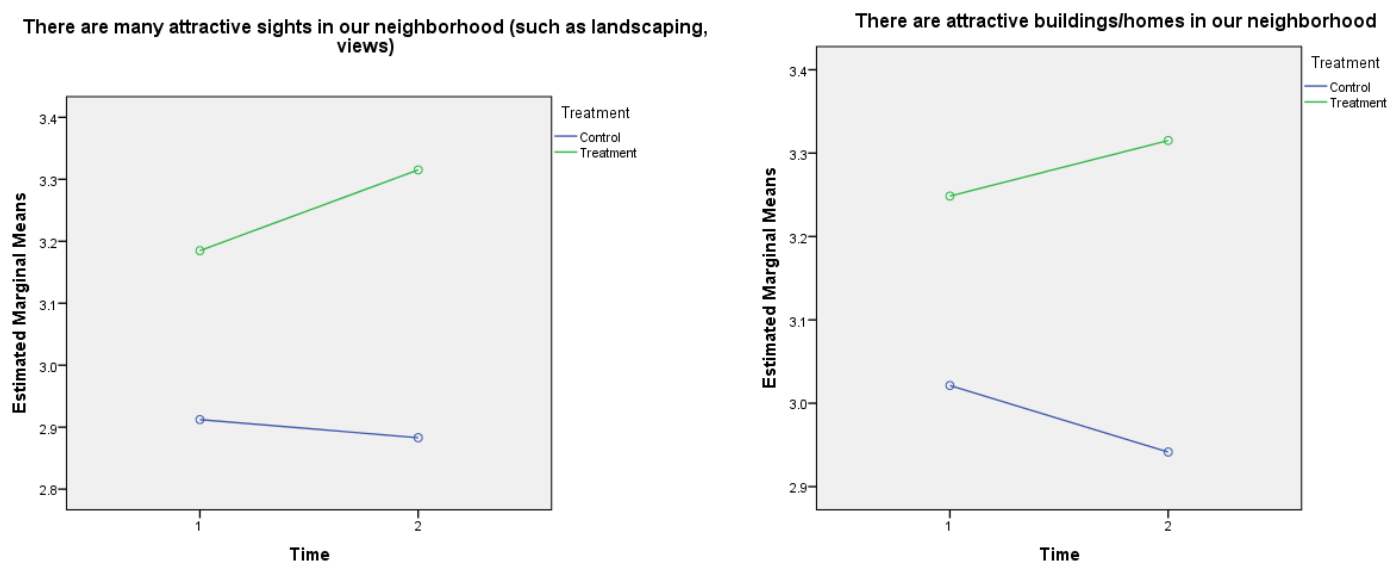

The following are within easy walking distance of home for me without kids along: Park
along distance

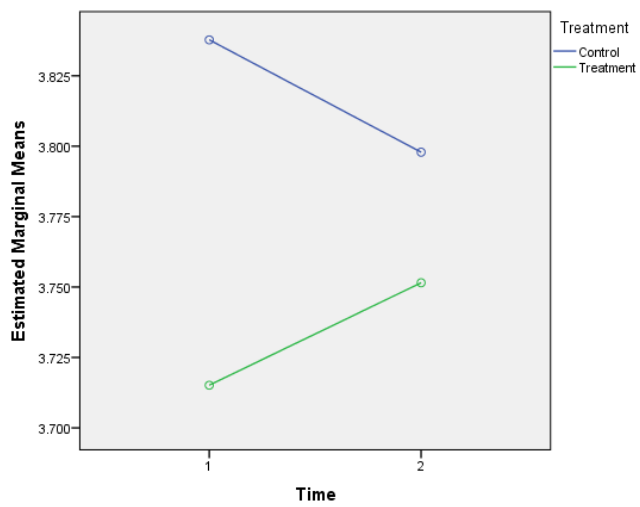

The following are within easy walking distance of home for me without kids

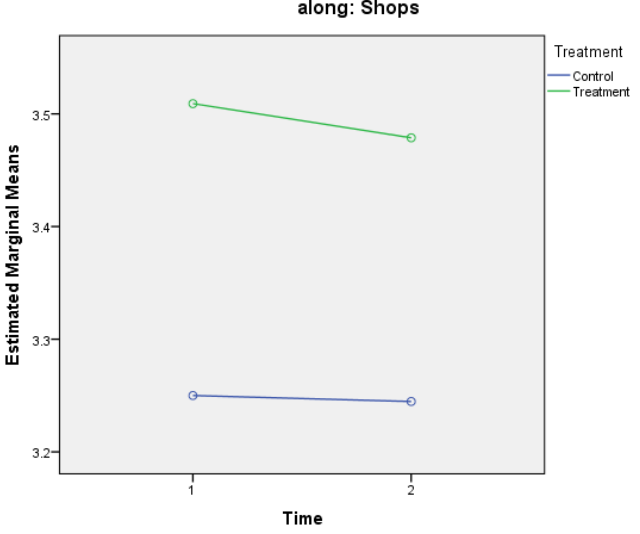


The following are within easy walking distance of home for me without kids along: Transit (Bus or MAX) stop

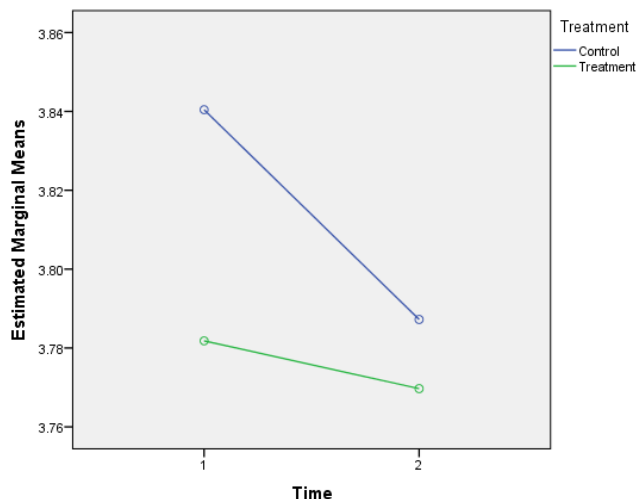

The following are within easy walking distance of home for me with kids along: Park

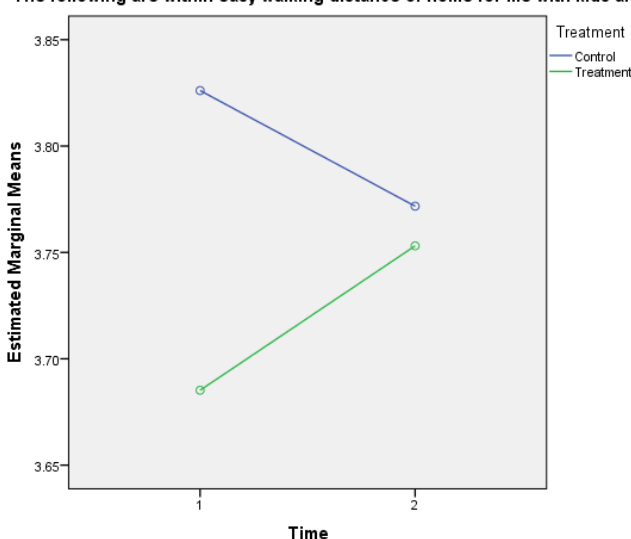

The following are within easy walking distance of home for me with kids along:

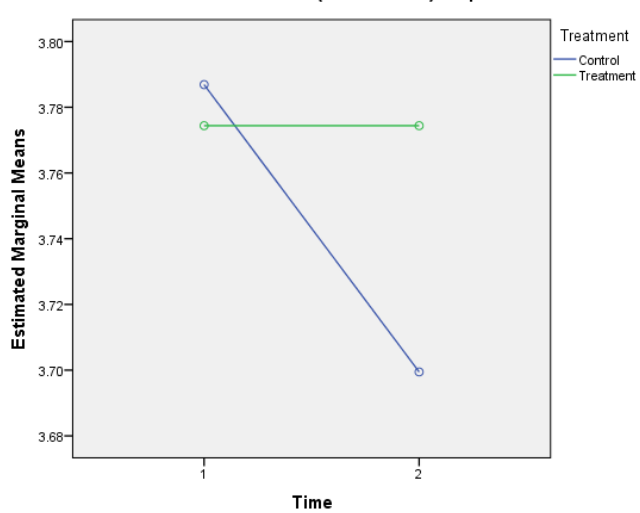

The following are within easy walking distance of home for me without kids along: Many places to go

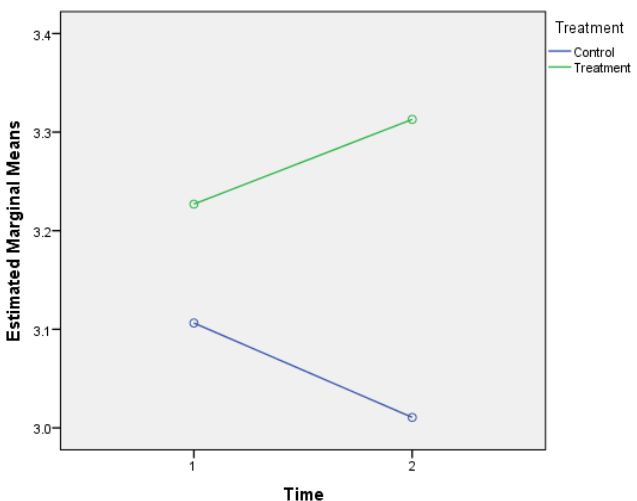

The following are within easy walking distance of home for me with kids along

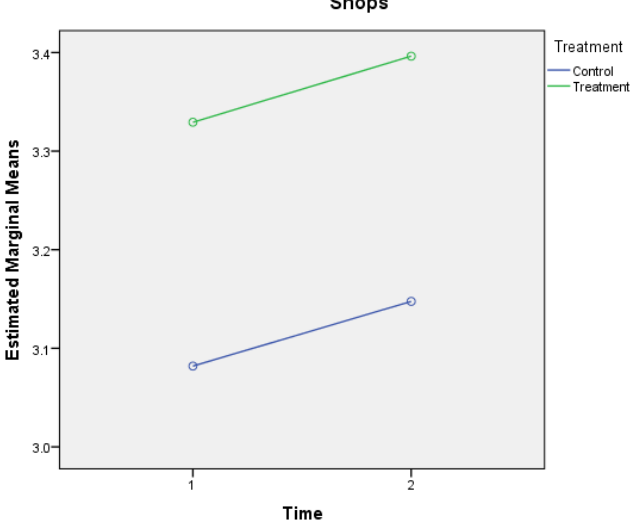

The following are within easy walking distance of home for me with kids along:
Many places to go

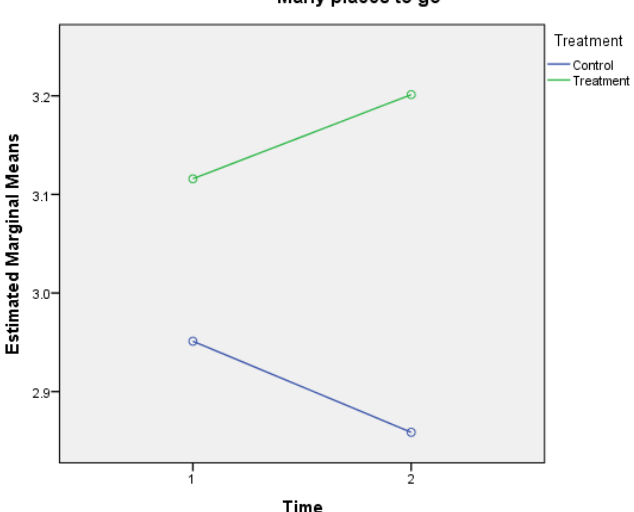


The following are within easy biking distance of home for me without kids along:

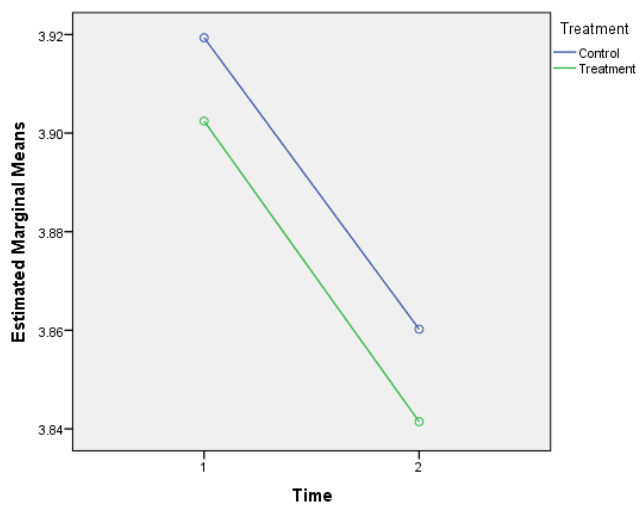

The following are within easy biking distance of home for me without kids along:
Transit (Bus or MAX) stop

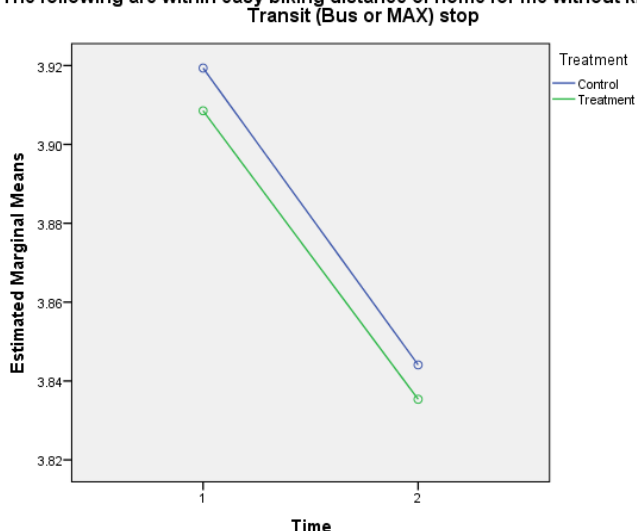

The following are within easy biking distance of home for me with kids along:
Park

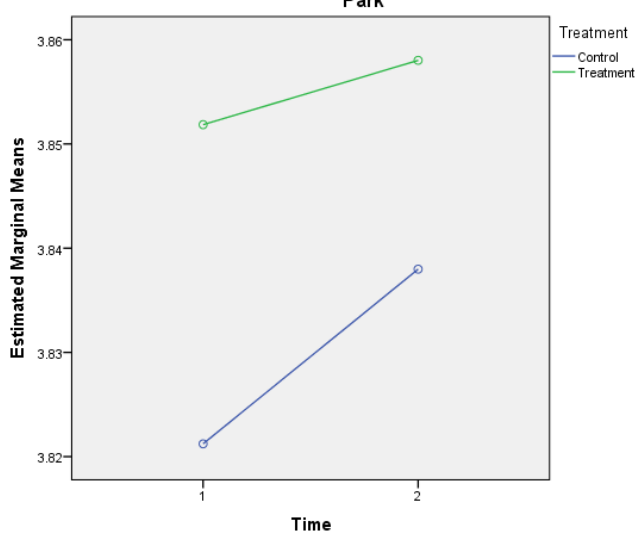

The following are within easy biking distance of home for me without kids along:

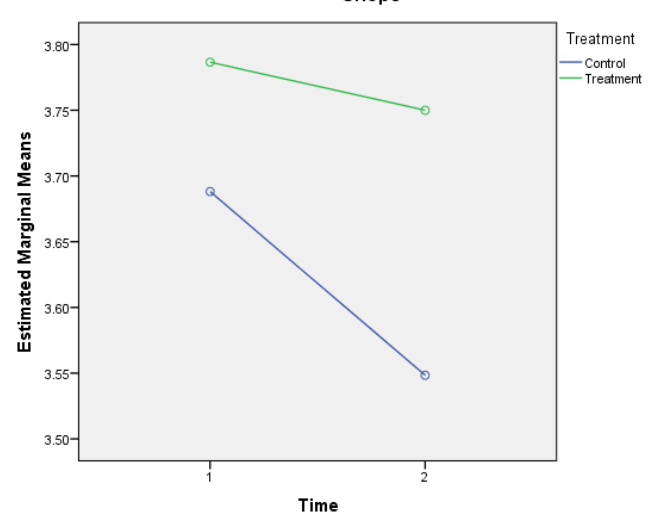

The following are within easy biking distance of home for me without kids along : Many places to go

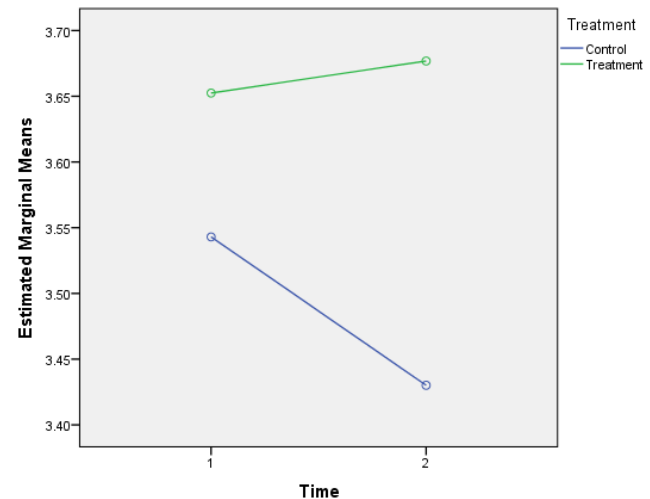

The following are within easy biking distance of home for me with kids along:

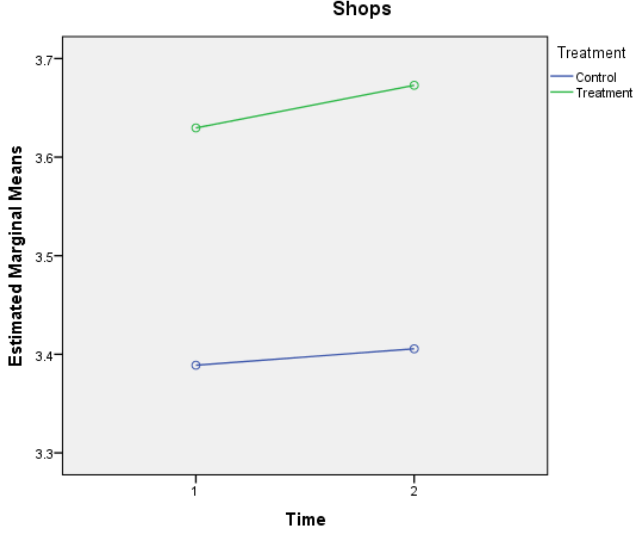




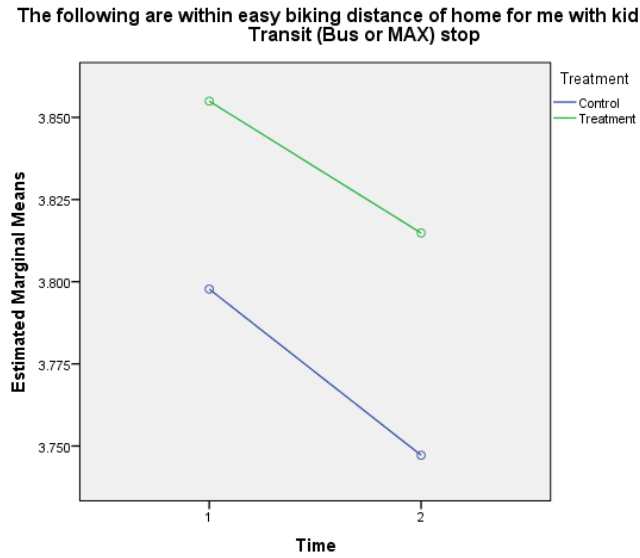

The following are within easy biking distance of home for me with kids along :

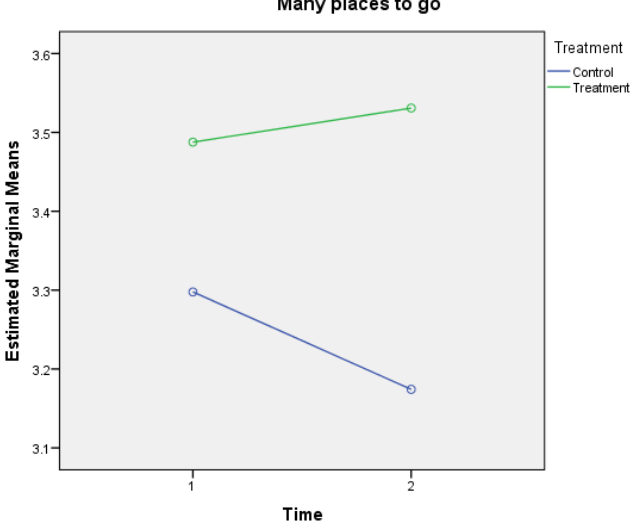

It would be easy for me to walk from home to places without my children along
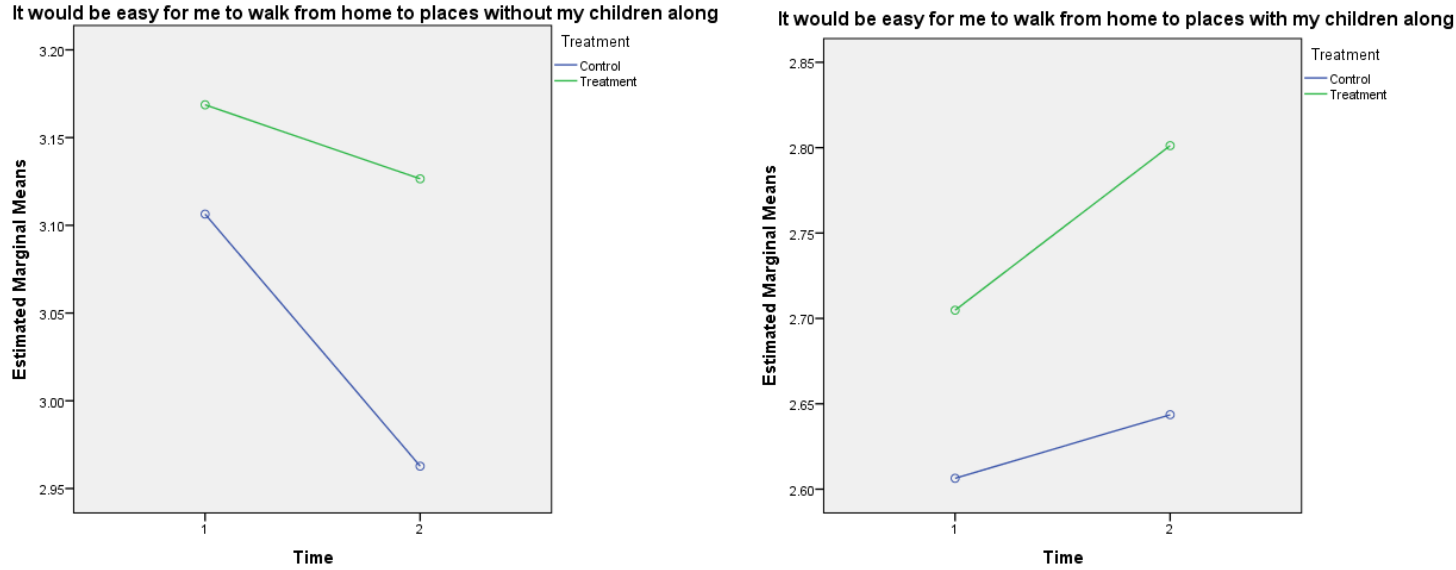

It would be easy for me to bike from home to places without my children along

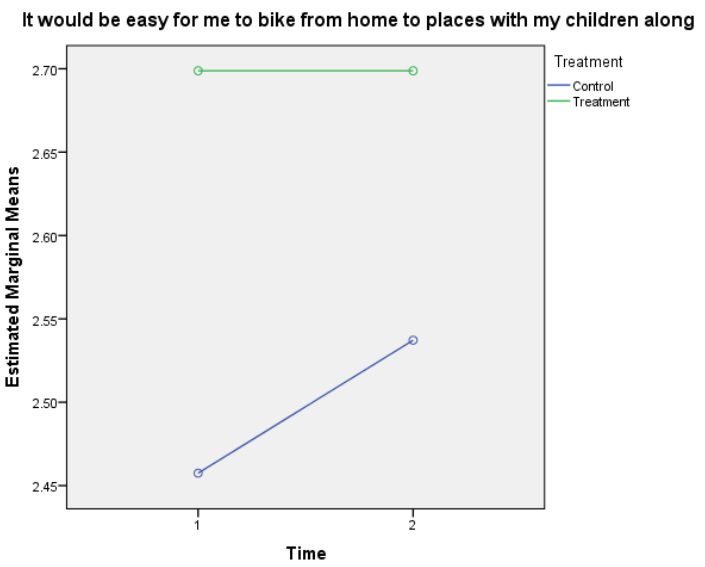


I know where I can walk safely to get places in my neighborhood without my children along

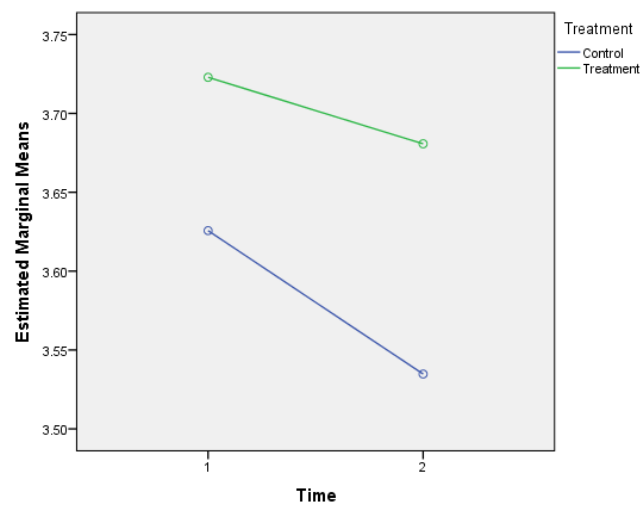

I know where I can bike safely to get places in my neighborhood without my
children along
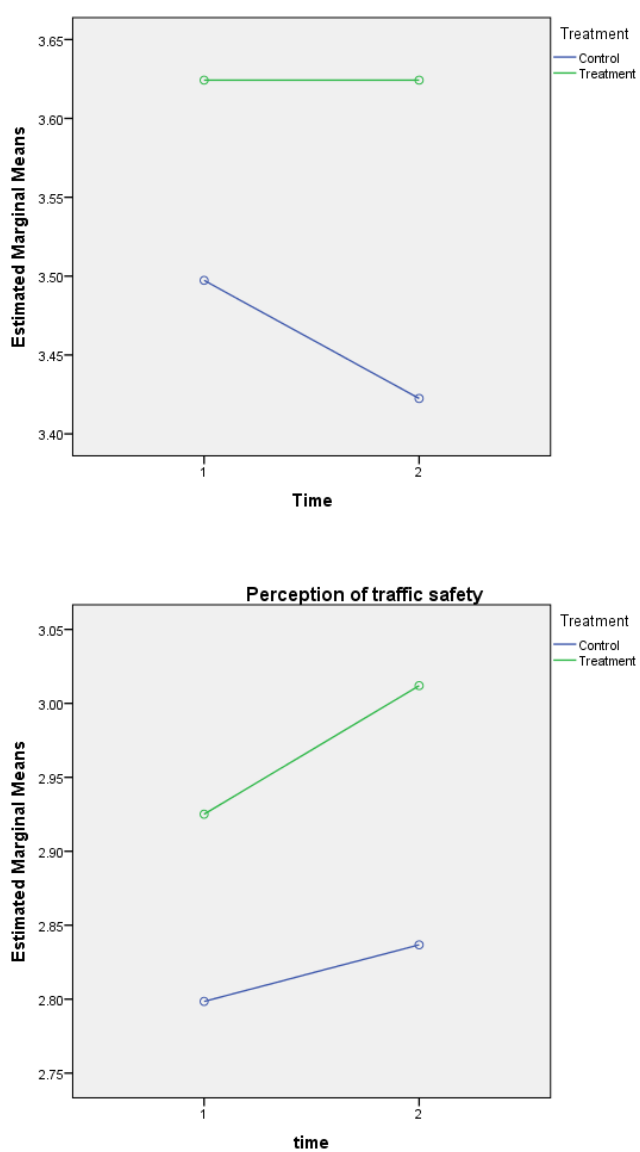

I know where I can walk safely to get places in my neighborhood with my

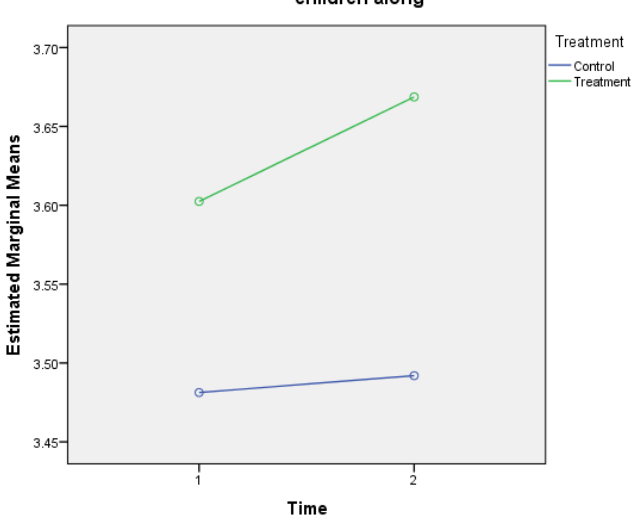

I know where I can bike safely to get places in my neighborhood with my children
along
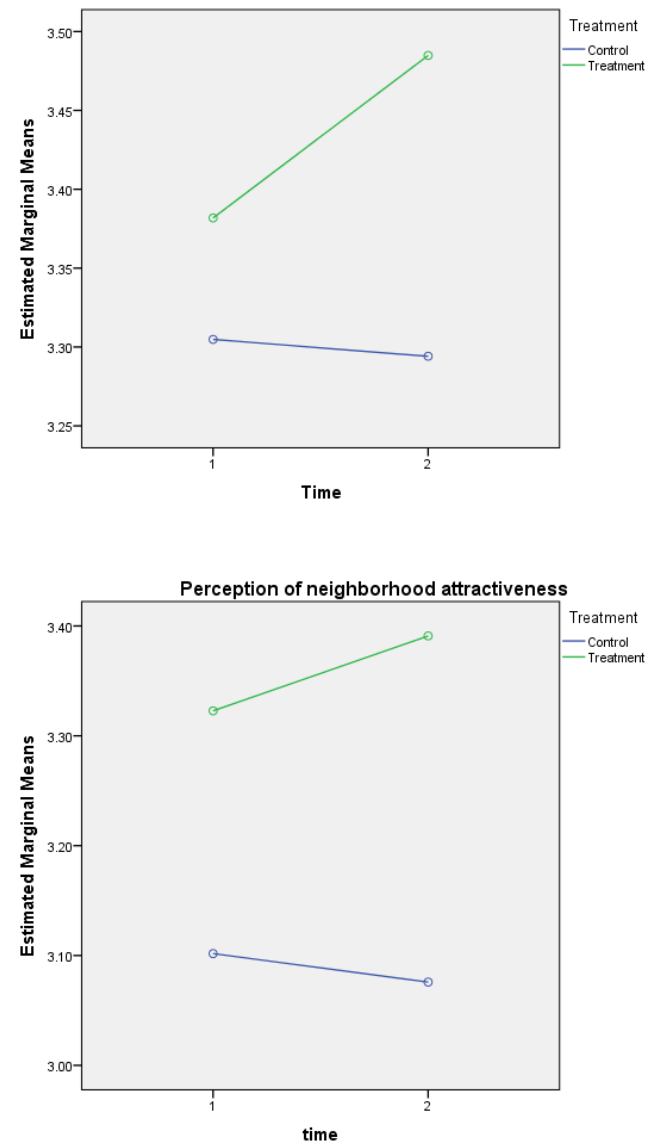

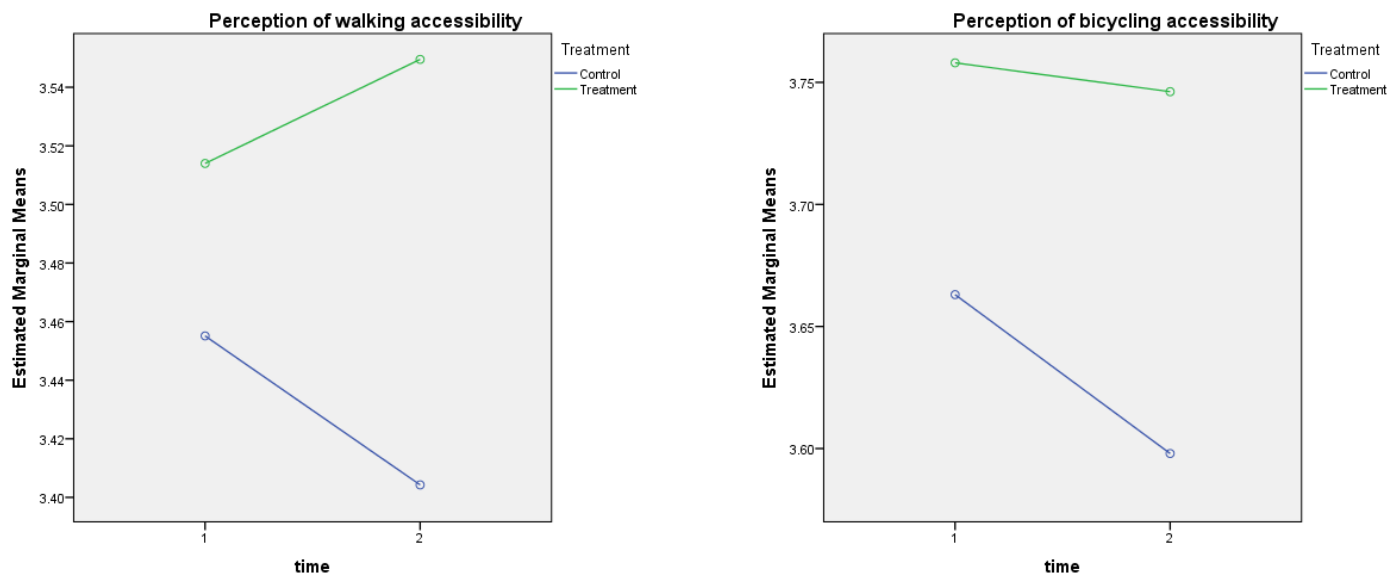